Cahiers Charlevoix

Études franco-ontariennes
Cahiers Charlevoix Études franco-ontariennes

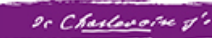

\title{
L’Ontario français et les « États généraux du Canada français » (1966-1969)
}

\section{Gaétan Gervais}

Volume 3, 1998

URI : https://id.erudit.org/iderudit/1039397ar

DOI : https://doi.org/10.7202/1039397ar

Aller au sommaire du numéro

\section{Éditeur(s)}

Société Charlevoix

Presses de l’Université d'Ottawa

\section{ISSN}

1203-4371 (imprimé)

2371-6878 (numérique)

Découvrir la revue

Citer cet article

Gervais, G. (1998). L’Ontario français et les « États généraux du Canada

français » (1966-1969). Cahiers Charlevoix, 3, 231-364.

https://doi.org/10.7202/1039397ar
Résumé de l'article

Gaétan Gervais analyse ce qu'il nomme « le dernier acte » de l'histoire du nationalisme canadien-français : les États généraux du Canada français qui eurent lieu à Montréal entre les années 1966 et 1969. Considérant le point de vue de la délégation franco-ontarienne, organisée par l'ACFÉo dont il a minutieusement dépouillé les archives, il montre le faible intérêt de l’Ontario français pour les débats qui s’y tinrent. Puis, scrutant le déroulement de ces assises, Gervais expose l'ambiguïté fondamentale du projet et rend apparent le noyautage des délégués " représentatifs » du Québec en vue du détournement de ce congrès au profit des idées indépendantistes. Compte tenu de ces faits, le refus de l'ACFÉo de coordonner la délégation franco-ontarienne en 1969, après avoir participé aux séances de 1966 et de 1967, et l'abstention quasi générale des minorités participantes furent sages, car, déduit l'auteur, « de la chrysalide des États généraux » ne pouvait sortir que « le papillon de l’indépendance ». Les décisions prises à Montréal, notamment le repli culturel et économique sur le seul Québec, conduisaient à la fin du Canada français, une politique inacceptable pour l'Ontario français. 


\section{L'ONTARIO FRANÇAIS ET LES «ÉtATS GÉNÉRAUX DU CANADA FRANÇAIS» (1966-1969)}

Gaétan Gervais

Département d'histoire

Université Laurentienne, Sudbury

Cahiers Charlevoix 3, 1998, pp. 231-364. 


\section{SOMMAIRE}

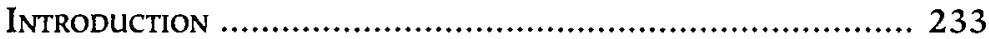

I - LeS ÉTAPES PRÉPARATOIRES (1961-1966) ..................... 237

L’origine des États généraux

du Canada français (1961-1966)

L'Ontario français et l'ACFÉO (1965-1970)

L'invitation aux minorités

Le choix des délégués

Le Mémoire de l'ACFÉO (1966)

La rencontre des minorités (26 novembre 1966)

Les assises préliminaires

Bilan des assises préliminaires

II - LES ASSISES DE 1967 ................................................. 275

Le «Mémoire des Canadiens français» (1967)

La délégation ontarienne

Les rencontres préliminaires des délégués

Les assises générales de novembre 1967

Les premières réactions

La déclaration de l'ACFÉO (27 novembre 1967)

III - AfFrontements ET RUPTURE (1968-1969)

Les tiraillements de l'ACFÉO

La «Commission de la participation

nationale aux États généraux"

La rencontre du $1^{\text {er }}$ juin 1968

L'ACFÉO récalcitrante

Une délégation raccourcie

La rencontre préliminaire

des minorités françaises (5 mars 1969)

Le déroulement des États généraux

du 5 au 9 mars 1969

Bilan des assises de 1969

Conclusion 


\section{L'ONTARIO FRANÇAIS ET LES «ÉTATS GÉNÉRAUX DU CANADA FRANÇAIS» (1966-1969)}

\section{INTRODUCTION}

La réunion à Montréal des États généraux du Canada français, entre 1966 et 1969, constitua un épisode, en fait le dernier acte, de l'histoire du nationalisme canadien-français.

Projet social et religieux élaboré au milieu du XIX ${ }^{\mathrm{e}}$ siècle, l'idée de "Canada français» excita pendant un siècle les efforts des chefs de file canadiens-français pour la sauvegarde, au Canada, d'une société catholique et française. Mobilisées par une idéologie nationaliste, conservatrice, agriculturiste et catholique, ces élites favorisèrent partout la colonisation, mais surtout elles travaillèrent à la mise en place d'un dense réseau d'institutions sociales à caractère confessionnel, notamment les écoles et les paroisses.

Avec le temps, les nationalistes canadiens-français finirent par proposer, pour définir leurs relations avec la majorité anglaise du pays, la thèse des deux peuples cofondateurs de la Confédération, le Canada français 
et le Canada anglais. Mais le faible respect accordé aux droits scolaires et religieux des CanadiensFrançais, durant le premier siècle de la Confédération, exacerba le ressentiment des nationalistes canadiens-français, outrés que, malgré son statut de peuple fondateur, le Canada français subît la constante violation de ses droits culturels et religieux. La persécution des minorités françaises, un peu partout au pays, sembla d'autant plus injuste que la minorité anglo-québécoise, barricadée derrière ses fortes institutions financières, jouissait, elle, de toutes les protections.

Pour scruter l'état des relations anglo-françaises au pays, le gouvernement canadien créa en 1963 la Commission royale d'enquête sur le bilinguisme et le biculturalisme (la commission LaurendeauDunton). La réponse du Canada anglais sembla bien en-deçà des attentes, même si, lentement, combien lentement, la majorité anglaise faisait droit à certaines revendications historiques des nationalistes canadiens-français: l'indépendance du Canada, l'égalité des deux peuples fondateurs, le statut officiel du français, le respect des droits minoritaires. C'est une évolution attestée par l'adoption, en 1965, d'un drapeau authentiquement canadien, portant une feuille d'érable et non le «Union Jack», et, en 1969, de la Loi sur les langues officielles. Pour certains, ces gestes étaient trop peu, pour d'autres, beaucoup trop.

Depuis la Deuxième Guerre mondiale, la société canadienne-française, sous les pressions grandissantes de l'urbanisation, de l'industrialisation et de la sécularisation, se modernisait rapidement. Aux traditionnelles revendications autonomistes s'ajouta une détermination nouvelle à maîtriser l'économie; 
dans la mouvance nationaliste, il sembla que l'affranchissement économique devait passer par la suprématie politique. Ainsi, au cours des années soixante, les nationalistes se tournèrent résolument vers le seul gouvernement provincial dominé par une majorité canadienne-française, c'est-à-dire le Québec, pour la mise en cuvre d'un important train de mesures économiques et sociales qui, sous le gouvernement libéral de Jean Lesage, prirent le nom de «Révolution tranquille» (1960-1966).

Le rejet du fédéralisme canadien par une partie grandissante du mouvement nationaliste étouffa le nationalisme canadien-français et assura le passage d'un nationalisme catholique, basé sur l'idée du Canada français, à un nationalisme québécois, défini par une appartenance territoriale.

Nouveau paradigme, nouvel univers mental. Restait-il une place, dans cette nouvelle vision du monde, pour les minorités françaises? Non. Pour se disculper d'avoir largué le Canada français, les néonationalistes québécois se convainquirent qu'ils n'avaient abandonné que des morts (les «dead ducks", les "cadavres encore chauds ${ }^{1}$ "). Ainsi, dans les milieux séparatistes, on éleva au rang d'axiome l'affirmation que les minorités françaises du pays étaient soit mortes, soit moribondes, en tout cas sans avenir. Certains pensaient que les minorités "dépendaient» de la province de Québec, d'autres qu'elles en "profitaient». Un article de L'Action

\footnotetext{
' La première expression a été prononcée par René Lévesque, premier ministre de la province de Québec, dans l'Ouest, la seconde par l'auteur Yves Beauchemin, devant la Commission Bélanger-Campeau. Eux aussi, ils contrastaient, d'une part, les nouvelles terres promises de l'indépendance en fleurs et, d'autre part, les mornes cimetières où vivaient les minorités françaises.
} 
nationale, en 1962, rendit par une image saisissante cette conviction: "Ou bien nous leur [les groupes minoritaires] donnons le coup de pied au ventre qui va les obliger à lâcher prise, ou bien nous coulons avec eux ${ }^{2} . »$ Tout au long des États généraux, certains délégués québécois répétèrent que les minorités étaient «mortes», «finies», "perdues» ou, ultime outrage, "assimilées", en tout cas promises à une disparition certaine et imminente. Certains prirent acte de cette disparition avec regret, d'autres avec soulagement. Les groupes minoritaires, eux, se sentirent trahis.

La plus éclatante preuve de la rupture se produisit au sein de l'Ordre de Jacques-Cartier (OJC), une société secrète fondée à Ottawa en 1926 et qui, depuis longtemps, veillait au grain de la nation canadienne-française. Par sa dissolution en sections régionales (Acadie, Québec, Ontario, Ouest), en février 1965, l'Ordre révéla la fissure profonde qui éloignait désormais les néonationalistes québécois des minorités. Mais les liens du sang sont forts et certains se résolvaient mal au repli dans la forteresse Québec. Une preuve de leur embarras se trouve dans l'hésitation sur le nom à donner au rassemblement de Montréal: en 1961, on parla des «États généraux du Canada français», puis, en 1965, des «États généraux du Québec ${ }^{3}$ », avant de revenir, en 1966, aux «États généraux du Canada français».

2 "Les minorités et le séparatisme», dans L'Action nationale 51(8), avril 1962 , p. 649.

${ }^{3}$ L'organigramme présenté en novembre 1965 était chapeauté du titre «États généraux du Québec". Voir: «États généraux du Québec», publié dans "L'ordre politique - Les états généraux", dans L'Action nationale 55(3), novembre 1965, p. 383. 


\section{I - Les ETAPES PRÉPARATOIRES (1961-1966)}

Le nationalisme canadien-français se manifesta rarement avec plus d'éclats qu'aux moments des grands congrès patriotiques. On peut considérer les États généraux du Canada français comme le dernier de ces rassemblements ${ }^{4}$. Ainsi, la convocation en 1966 de «tous les Canadiens-Français», invitation adressée à la "nation canadienne-française», accrédita, chez certains, l'idée que le rassemblement de Montréal s'inscrivait en continuité, non seulement des congrès patriotiques organisés un peu partout, depuis un siècle, par les Sociétés Saint-Jean-Baptiste, mais encore des fastueux «Congrès de la langue française" qui, à trois reprises (en 1912, en 1937 et en 1952), balisèrent avec magnificence la «vie nationale" du Canada français. Les minorités françaises du Canada étaient donc loin de s'imaginer qu'on allait bientôt introduire une distinction entre les «délégués du Québec» et les «délégués hors Québec».

L'ORIGINE DES ÉtTATS gÉNÉRAuX du CANADA FRANÇAIS (1961-1966)

En juin 1961, se déroula à Ottawa un premier "congrès conjoint» des deux fédérations, ontarienne et québécoise, des Sociétés Saint-Jean-Baptiste. Les mille délégués, réunis pour étudier les «relations françaises interprovinciales», entendirent une conférence d'Edgar Tissot, vice-président de la Fédération ontarienne et membre influent de l'Ordre de Jacques-Cartier, qui parla des besoins des groupes

${ }^{4}$ Sur les grands congrès patriotiques qui ont précédé les États généraux, voir Gaétan Gervais, «L'Ontario français et les grands congrès patriotiques canadiens-français", dans Cahiers Charlevoix 2, 1997, pp. 9-155. 
français vivant hors du Québec. Dans son discours, le président de la fédération québécoise, Albert Leblanc, confirma l'intention de son organisme d'aider les minorités: "Ce que nous avons fait jusqu'ici n'était qu'un début ${ }^{5} . »$ Parmi les nombreux projets proposés pour favoriser «l'avancement des Canadiens-Français dans les dix provinces canadiennes", figuraient les États généraux du Canada français ${ }^{6}$. Au banquet de clôture, le 3 juin 1961, le premier ministre québécois, Jean Lesage, prononça un discours où il donna ce que Le Droit appela des «gages de la coopération du Québec ${ }^{7}$ ».

Le projet de réunir des États généraux fut officiellement lancé à Québec, le 19 août 1962, au pied du monument de Champlain. Après dix ans, cette rencontre s'annonçait comme le relais du «Troisième Congrès de la langue française au Canada», tenu à Québec en juin 1952. De fait, la rencontre semblait si imminente, en 1962, que le secrétaire général de l'ACFÉO, Roger Charbonneau, afin de prévenir les

\footnotetext{
${ }^{5}$ Cité dans «Les SSIB du Québec ont toujours fait leur part», dans Le Droit, 5 juin 1961, p. 17.

${ }^{6}$ En 1965, L'Action nationale publia une chronologie des étapes préparatoires, où l'on note: "Juin 1961 - Annonce de la tenue des états généraux: Congrès des Fédérations des Sociétés Saint-Jean-Baptiste du Québec et de l'Ontario». Voir «L'ordre politique - Les états généraux», dans L'Action nationale 55(2), octobre 1965, pp. 255-256.

${ }^{7}$ Entre autres choses, Lesage déclara, en présence de l'ambassadeur de la France et de plusieurs dignitaires, que «le Québec doit en quelque sorte se considérer comme la mère-patrie [sic] de tous ceux qui en Amérique du Nord parlent notre langue. Notre province est donc presque moralement obligée d'accorder son concours à ces groupes de nos compatriotes quil, par leur situation, sont en plus grand danger d'être assimilés ou de perdre contact avec la culture française. Par son intérêt à leur égard, elle aidera ces groupes à sauvegarder leur entité propre et [à] se protéger elle-même grâce à l'appui que ces groupes éloignés de Canadiens français pourront lui donner»; texte cité dans Le Droit, 5 juin 1961, p. 15.
} 
conflits de calendrier, informa le président de la Fédération des Sociétés Saint-Jean-Baptiste du Québec que l'ACFÉO tenait son congrès général les 4-5-6 octobre $1962^{8}$.

En septembre 1962, la Fédération des Sociétés Saint-Jean-Baptiste constitua un Comité provisoire qui tint plusieurs réunions, de décembre 1962 à mars 1963, pendant qu'un «comité d'étude» se penchait sur la logistique d'une réunion des États généraux. Après de nombreuses consultations, le Comité provisoire produisit, en octobre 1963 , un document intitulé «Résumé des objectifs et élaboration des structures». Le mois suivant, on nommait un «coordonnateur provisoire» et, en décembre, le Comité provisoire remettait son rapport final. Le groupe eut pour successeur la Commission générale provisoire.

Entre-temps, le député unioniste provincial de Missisquoi (et futur premier ministre de la province), Jean-Jacques Bertrand, demandait au gouvernement de Jean Lesage la convocation d'un comité parlementaire «concernant la convocation des étatsgénéraux de la nation canadienne-française». Bertrand informa même le président de l'ACFÉO, Aimé Arvisais, de son projet ${ }^{9}$. Le gouvernement libéral accepta de réunir son comité parlementaire constitutionnel, alors que Daniel Johnson, chef de l'Union

\footnotetext{
${ }^{8}$ Roger Charbonneau à Marcel Daigneault (président de la Fédération des Sociétés Saint-Jean-Baptiste du Québec), Ottawa, 10 septembre 1962, copie dans le Centre de recherche en civilisation canadienne-française de l'Université d'Ottawa [désormais: CRCCF], Fonds de l'Association canadienne-française de l'Ontario [désormais: Fonds ACFO], C2/356/2.

${ }^{9}$ Le secrétaire général de l'ACFÉO, Roger Charbonneau, répondit au nom du président, Aimé Arvisais, que «Toute cette question est actuellement à l'étude par les organismes nationaux de langue française et d'ici quelques mois, une déclaration sera publiée à cet effet». Voir:
} 
nationale, et lui aussi futur premier ministre provincial, "commençait sa campagne pour qu'on réunisse une Constituante ${ }^{10}$ ». Ce sont les signes avant-coureurs de la mutation de l'Union nationale en Parti québécois.

La Commission générale provisoire, dont le secrétariat se trouvait à Québec, comptait vingt-cinq membres, recrutés dans les grandes associations qui parrainaient le projet, et un exécutif de sept personnes. Deux "commissions d'organisation" étudièrent le fonctionnement des États généraux, une dite technique (procédure, relations extérieures, publicité, locaux et programmes), l'autre dite administrative (secrétariat, finances, souscriptions), tandis que deux autres "commissions d'étude et de recherche" s'occupaient, l'une de "constitution et politique», l'autre des «relations avec les groupes francophones». Les participants aux États généraux devaient provenir de «toutes les associations canadiennes-françaises du Québec», mais on pensa adresser une invitation "aux associations des groupes français établis hors du Québec ${ }^{11} »$. En 1964, plusieurs associations et corps intermédiaires de la province de Québec (commissions scolaires, collèges classiques, fédérations de travailleurs, associations du monde de l'enseignement) endossèrent le projet d'États généraux. Tous ces groupes firent partie de l'Assemblée générale des associations, qui fonctionna jusqu'en novembre 1966 ,

\footnotetext{
Jean-Jacques Bertrand (député de Missisquoi) à Aimé Arvisais (président général de l'ACFÉO), Québec, 14 mars 1963 et Roger Charbonneau à Jean-Jacques Bertrand, Ottawa, 22 mars 1963, copies, CRCCF, Fonds ACFO, C2/356/2.

${ }^{10}$ Jacques Guay, «Les États généraux sont-ils viables?», Magazine Maclean 6(11), novembre 1966.

"Sur l'organisation des États généraux en novembre 1965, voir "L'ordre politique - Les états généraux", dans L'Action nationale 55(3), novembre 1965, pp. 383-386.
} 
quand elle fut remplacée par l'Assemblée générale des délégués.

L'objectif des États généraux fut double: d'abord étudier "notre" devenir constitutionnel et politique, puis définir "les relations et la solidarité entre les groupes francophones». Selon un article paru dans L'Action nationale en novembre 1965, deux idées essentielles conditionnaient le reste, à savoir qu'il fallait «aller au fondamental», mais aussi que «l'ordre juridique conditionne l'épanouissement de la Nation". L'article se terminait en énonçant trois postulats, à savoir que la "Nation canadienne-française existe», que le "Québec est l'État national des Canadiens français», que la «Nation canadienne[-]française a droit à l'autodétermination». Voilà, parfaitement résumées, et à l'avance, les futures décisions des États généraux, y compris l'ultime résolution demandant la convocation d'une Assemblée constituante, projet discuté en Commission générale provisoire dès février 1964.

Des difficultés, surtout financières, retardèrent la réalisation du projet. Les États généraux se trouvèrent donc un peu plus à la merci des subventions du gouvernement provincial. Quant à la Société Saint-Jean-Baptiste, débordée par des mouvements nationalistes plus radicaux, elle paraissait affaiblie, comme aussi le Conseil de la vie française à Québec. En fait, le néonationalisme québécois était de plus en plus travaillé par des courants radicaux d'inspiration révolutionnaire, décolonisatrice ou marxiste, autant de courants qui s'exprimèrent dans une variété d'organismes et de mouvements. En mars 1966, lors d'une réunion des organismes parrains, le projet fut confié à une nouvelle équipe, établie à Montréal, recrutée dans la mouvance de l'ancien Ordre de 
Jacques-Cartier et gravitant autour de la revue de L'Action nationale et de la Société Saint-Jean-Baptiste locale, un terreau plus radical que celui de la ville de Québec, encore attachée, à cette époque, à l'idée du Canada français. On en profita aussi pour donner un nouveau mandat à la Commission générale provisoire.

Après l'éclatement de l'Ordre de Jacques-Cartier, en février 1965, les biens, les fonds et les archives furent répartis entre les quatre organismes successeurs. La section québécoise de l'Ordre, appelée l'Ordre de Jean-Talon, sous la présidence de Rosaire Morin, décida dès avril 1965 de faire des États généraux une priorité. Ainsi, dans les mois suivants, L'Action nationale publia divers documents sur les États généraux $^{12}$. En mai 1966, Rosaire Morin prit la direction de l'organisation des États généraux, invitant le juriste Jacques-Yvan Morin à en assurer la présidence. Ce dernier, un professeur de droit, venait de se faire remarquer pour sa lutte contre la «formule Fulton-Favreau" d'amendement constitutionnel. Rosaire Morin, avec Léo Gagné, se réserva toutefois «le recrutement, l'organisation des élections régionales, la représentation des centaines de corps intermédiaires ${ }^{13} »$. C'était, selon G.-Raymond

\footnotetext{
12 L'Action nationale publia plusieurs articles: «L'ordre politique L'origine des états généraux en France», «L'ordre politique - Les états généraux en France de Charles V à la révolution», «L'ordre politique Les états généraux sous la révolution en France» et «L'ordre politique - Les différentes expériences constitutionnelles de la France après la Révolution", "L'ordre politique - Les états généraux - Pourquoi remonter si loin". Cette série d'études parut dans L'Action nationale en décembre 1965, pp. 506-510, janvier 1966, pp. 635-639, février 1966, pp. 755-758, mars 1966, pp. 879-882 et avril 1966, pp. 995-998. La revue de L'Action nationale continua jusqu'en mars 1967 à publier des textes, sous la rubrique «L'ordre politique», pour expliquer la démarche entreprise par les Etats généraux.

${ }^{13}$ G.-Raymond Laliberté, Une société secrète: l'Ordre de Jacques[-]
} 
Laliberté, «la dernière grande manifestation nationaliste de l'Ordre".

L'Assemblée générale des Associations identifia trois secteurs prioritaires: la question politique et constitutionnelle, les relations entre les Canadiens-Français du Québec et d'ailleurs, enfin les relations entre le Québec et la francophonie mondiale. Outre les trois commissions instituées pour examiner ces questions, l'Assemblée créa deux commissions d'organisation (technique et administrative). Ces cinq commissions dépendaient de la Commission générale, composée d'une vingtaine de membres provenant des associations fondatrices ${ }^{14}$. Aucun représentant des minorités ne siégeait à la Commission générale. Outre les cinq commissions, il y avait dix-sept comités d'organisation. Le chanoine Lionel Groulx, avant sa mort en 1967, fut président d'honneur des États généraux. Mais, en pratique, le sort des États généraux dépendait de quelques hommes, notamment du président général, Jacques-Yvan Morin, mais peut-être surtout du directeur général, Rosaire Morin, et de son adjoint, Michel Pelletier. Vice-président et directeur général, Rosaire Morin fut responsable de l'organisation technique. C'est avec lui, surtout, que traitèrent les porte-parole de l'Ontario.

En septembre 1966, L'Action nationale publia, sur les États généraux, une manière de "petit catéchisme», comportant questions et réponses. En quatre pages, on expliquait ce qu'étaient les États généraux ( «des éléments représentatifs de la nation"), qui y serait

Cartier, [Montréal], Hurtubise HMH, "L'homme dans la sociétê", [c1983], p. 243.

14 Le «comité exécutif» de la Commission générale se composait de F.A. Angers, Albert Boulet, Georges-Henri Fortin, Léo Gagné, Jean Lemay, Jean-Marc Léger, Jacques-Yvan Morin et Rosaire Morin. 
invité ( «Tous les groupements appartenant à la communauté francophone du Canada français"), définissant ses objectifs («le point de rencontre de toutes les forces vives de la nation»), sa raison d'être ( $\mathrm{Au}$ Québec, la nation canadienne-française recherche des structures et des institutions qui lui permettront de façon certaine et permanente de réaliser son plein épanouissement»). Selon ce document, la Confédération canadienne était périmée ( $« \mathrm{La}$ constitution canadienne prive l'État québécois, État national des Canadiens français, de revenus et de pouvoirs essentiels au bon fonctionnement d'un gouvernement moderne»), mais plusieurs solutions de rechange s'offraient («fédéralisme coopératif, statut particulier, États associés ou indépendance totale»).

Ce petit catéchisme enseignait encore que le choix d'avenir revenait au peuple (un "droit sacré»), et non au Parlement: «Le gouvernement et même le Parlement ne sont pas habilités à prendre des décisions [sur le choix d'avenir]. Le gouvernement, en effet, a pour rôle d'administrer le pays, alors que la question discutée porte sur la validité même de ces institutions.» Poussé par cette délirante doctrine constitutionnelle, l'article de L'Action nationale prétendait mettre les États généraux par-dessus les lois, par-dessus les parlements d'Ottawa et de Québec, par-dessus les tribunaux et par-dessus la constitution canadienne. Tant de témérité constitutionnelle annonçait déjà le geste final des États généraux, c'est-à-dire le projet de se transformer en Assemblée constituante, habilitée à écrire et à proclamer, en dehors de tout cadre juridique existant, une nouvelle constitution pour le Québec. 
À l'occasion de l'élection des délégués territoriaux de la province de Québec, en septembre 1966, le chanoine Lionel Groulx apporta un vibrant appui. Le vieux chef nationaliste plaida pour que «cessent nos criminelles dissidences» et que finisse la partisanerie politique. Dans une envolée patriotique, Groulx décrivit ainsi la réunion qui approchait:

Elle nous dira à tous, même à nos frères lointains, que nous sommes les fils du même passé, des mêmes traditions, d'un même pays : l'État du Québec.

À cet État, elle nous dira qu'il faut la souveraineté politique, poussée aussi loin que l'imposent nos exigences de vie, notre droit de rester nous-mêmes, de nous épanouir librement et pleinement.

Elle vous dira qu'il nous faut, dans toute la mesure possible, la libération économique, base essentielle de toute notre vie collective.

Elle vous dira qu'il nous faut, par conséquent, la récupération progressive de toutes nos ressources naturelles, de notre pouvoir d'achat, sous peine de rester perpétuellement un peuple de serfs et de mendiants.

Elle vous dira qu'il nous faut un ordre social fondé sur la justice et la charité, ordre organique qui s'appelle l'ordre chrétien.

Elle vous dira qu'il nous faut sauvegarder, à quelque prix que ce soit, notre langue, notre culture, et que cette culture doit rester celle d'un peuple jeune, sain, digne de la grande culture française à laquelle nous prétendons appartenir ${ }^{15}$.

Comment s'étonner que plusieurs aient vu, dans cet élan, un soutien au mouvement indépendantiste?

\footnotetext{
15 "La tâche des «états généraux" comme le voit le chan. Groulx», dans Le Devoir, 9 septembre 1966, p. 5. Le texte sera plus tard publié au début du procès-verbal des assises préliminaires: Les États généraux du Canada français. Assises préliminaires tenues à l'Université de Montréal, du 25 au 27 novembre 1966, [Préface de Jacques-Yvan Morin], s.l., s.n., s.d., pp. 9-12.
} 
L'ONTARIO FRANÇAIS ET L'ACFÉO (1965-1970)

L'Association canadienne-française d'éducation de l'Ontario (ACFÉO) dominait depuis sa fondation, en 1910, la vie scolaire et culturelle de l'Ontario français. Fortement pénétrée par l'Ordre de Jacques-Cartier, elle fut de tous les combats pour fonder des écoles ou des paroisses françaises, ou pour faire nommer des évêques canadiens-français. Sa principale mission touchait l'éducation, ce qui l'avait amenée, depuis les années 1930, à s'intéresser au financement des écoles séparées et à l'enseignement en français, mais aussi à favoriser la création d'organismes provinciaux en éducation (pour les enseignants, les commissaires d'écoles, les inspecteurs, les groupes de parents-instituteurs, les jeunes). L'ACFÉO s'intéressa même aux questions économiques, appuyant l'Union des cultivateurs franco-ontariens (UCFO), depuis longtemps affiliée à l'ACFÉO, mais aussi les caisses populaires, dont la plupart furent fondées dans les années quarante, à l'instigation de l'Ordre de Jacques-Cartier.

Peu de gens, à cette époque, auraient contesté que l'ACFÉO représentât la communauté canadienne-française de l'Ontario. Mais la multiplication des autres associations provinciales causa, entre l'ACFÉO et ses affiliées, un malaise qui fut à l'origine d'un «symposium» organisé en février 1965. Plusieurs déploraient le manque de communication, ce que Gaston Carbonneau appelait «le grand mal du temps ${ }^{16}{ }^{\text {}}$. Le "symposium» proposa deux remèdes: un "Comité des relations extérieures», chargé de faire circuler les informations, et la publication d'un «bulletin».

${ }^{16}$ Gaston Carbonneau, "Unité de pensée et unité d'action», dans $L a$ Vie franco-ontarienne 2 , septembre 1965 , p. 1 . 
Quelques mois plus tard, paraissait La Vie francoontarienne ${ }^{17}$. Cette publication s'avère utile pour connaître les problèmes qui préoccupaient les chefs de l'ACFÉO durant ces années agitées. Le bulletin se donnait trois objectifs: rejoindre les Franco-Ontariens dispersés sur un immense territoire, "faire connaître dans le Québec les efforts que nous faisons ici en terre ontarienne pour assurer une présence française ${ }^{18}$ ", enfin accroître le courant de sympathie qui s'intensifiait au Canada anglais, à l'heure de la commission Laurendeau-Dunton.

La Vie franco-ontarienne permet de constater que durant cette période (1965-1970), l'ACFÉO se soucia surtout des dossiers scolaires: la réorganisation du ministère de l'Éducation en 1965 , la commission Hall établie la même année, l'Association des écoles secondaires privées franco-ontariennes fondée au début de 1966, l'évolution de la politique provinciale en éducation, la naissance des collèges communautaires, la gestation des écoles secondaires françaises, les manuels. L'Association se préoccupait aussi des activités culturelles (la radio et la télévision françaises, la nouvelle Assemblée provinciale des mouvements de jeunes, fondée en mars 1967, le Comité d'enquête culturelle établi en 1967 et présidé par Roger Saint-Denis), en plus de divers autres dossiers régionaux ou provinciaux.

\footnotetext{
${ }_{17}$ Au début, La Vie française. Bulletin de l'Association canadiennefrançaise d'éducation d'Ontario était rédigé par l'oblat Robert Barsalou. Le bulletin "mensuel» fut lancé en juin 1965, continué en septembre, puis parut durant les années scolaires. Entre juin 1965 et janvier 1970 , vingt-six numéros, au total, furent publiés.

18 Le bulletin précisait, en passant: «Nous croyons que, sans ses minorités, le Canada français serait considérablement appauvri et se réduirait en fait à ce que l'on désigne parfois avec mépris la "réserve" du Québec.»
} 
L'ACFÉO, en fait, s'engageait à ce moment dans un processus qui la conduisit, en 1969 , à se donner un mandat élargi. C'est une transformation que traduit bien le changement de nom de l'association, qui laissa tomber le mot «éducation", pour mieux montrer que l'ACFO (Association canadienne-française de l'Ontario) s'intéressait désormais à tous les dossiers de l'Ontario français, non seulement à ceux de l'éducation.

En 1966, le dossier des écoles secondaires semblait prioritaire. Au XVIII ${ }^{\mathrm{e}}$ Congrès de l'ACFÉO, les 13-14 avril 1966, l'assemblée se prononça en faveur de l'école secondaire française et catholique. On décida de soumettre la proposition au ministre de l'Éducation (William Davis) et, en cas de refus, de discuter de nouveau de la question. Les évêques catholiques rencontrèrent le ministre de l'Éducation le 29 septembre 1966 puis, le 13 octobre 1966, les exécutifs de l'ACFÉO et de ses associations. À la fin de 1966 , on attendait aussi le rapport de l'Association des écoles secondaires privées franco-ontariennes (AÉSPFO) ${ }^{19}$. Pour piloter ce dossier, l'ACFÉO avait mis sur pied un "comité spécial» chargé de trouver une solution acceptable. Dès le 22 octobre 1966, l'Association décida de tenir un congrès spécial pour débattre de la question ${ }^{20}$. Le XIX ${ }^{\mathrm{e}}$ Congrès spécial de l'ACFÉO eut lieu le 18 février 1967. Les délégués adoptèrent alors le texte d'un mémoire qui demandait des écoles secondaires françaises (et non plus

\footnotetext{
${ }^{19}$ Les écoles secondaires privées franco-ontariennes. Situation actuelle. Perspectives d'avenir. Mémoire de la Commission d'étude de l'Association des écoles secondaires privées franco-ontariennes, Ottawa, 1966, vii-151 pages, plus appendices.

${ }^{20}$ "Un grave problème", dans La Vie franco-ontarienne 2(2), décembre 1966, p. 1.
} 
«françaises et catholiques ${ }^{21}$ »). Jusqu'alors inconcevable, cette dissociation des termes "français et catholique" constitua une autre rupture avec le passé.

Le gouvernement ontarien avait habitué l'ACFÉO à s'armer de patience. Mais cette fois, et contrairement aux attentes, les événements se précipitèrent. Le mémoire de l'ACFÉO fut remis au ministre de l'Éducation, William Davis, le 20 mars 1967, puis celui-ci l'achemina au cabinet ontarien. Le ministre demanda aussitôt à l'ACFÉO de proposer le nom de personnes aptes à siéger dans un comité consultatif qui serait appelé à préciser les modalités du régime scolaire préconisé par l'ACFÉO ${ }^{22}$. Ainsi, le 24 août 1967, dans le cadre du congrès de l'Association canadienne des éducateurs de langue française (ACÉLF), le premier ministre John Robarts annonça la création des écoles secondaires françaises en Ontario ${ }^{23}$. Un comité ministériel, sous la présidence de Roland Bériault, fut nommé le 24 novembre 1967, alors que l'ACFÉO créait un vaste comité consultatif de quarante membres (trois sous-comités: religieux, culturel,

\footnotetext{
${ }^{21}$ Voir Omer Deslauriers, «L'école secondaire bilingue publique confessionnelle: l'école qui répond à nos besoins...", dans La Vie francoontarienne 5, janvier 1966, p. 5. Le 19 janvier 1966, l'exécutif de l'ACFÉO "recevait» le rapport de son comité pédagogique sur la confessionnalité des écoles secondaires. Suivant l'énoncé du document adopté à ce moment, l'ACFÉO réclama des «écoles secondaires françaises et catholiques». Voir "Écoles françaises et catholiques», dans La Vie franco-ontarienne 1(6), février 1966, p. 1.

${ }^{22}$ L'ACFÉO proposa les noms du frère Omer Deslauriers (pour représenter l'épiscopat), de Lionel Desjarlais et Vincent Gauthier (pour les sociétés affiliées) et de Jacques Leduc (pour l'ACFÉO).

${ }^{23}$ Robarts énonça trois principes: que la survivance du Canada est une question dépassant les différents partis politiques; que le gouvernement de l'Ontario a pris l'engagement de «perpétuer l'existence de cultures et de langues diverses au Canada»; enfin que «Les Canadiens d'origine française doivent avoir la garantie de droits fondamentaux". Dans ce discours, Robarts y alla encore d'une analyse historique:
} 
administratif) avec des représentants des régions et des sociétés affiliées. Dans ce contexte, le déroulement des États généraux a pu paraître, à certains Franco-Ontariens, comme une activité plutôt périphérique.

Il est donc facile de voir qu'à l'automne de 1966, quand se tinrent les assises préliminaires des États généraux, l'ACFÉO avait d'autres préoccupations.

Prenons, à témoin de ce désintéressement de l'ACFÉO à l'endroit des États généraux, $L a$ Vie franco-ontarienne, dont les années de publication (1965 à 1970) encadrent parfaitement la durée des États généraux. En six années, seulement deux articles traitèrent des assises de Montréal. Le premier, en décembre 1966, expliquait ce que devaient être les États généraux du Canada français. À la fin de l'article, un nota bene précisait: «En dernière heure, il a été décidé que l'Ontario français serait présent aux assises [préliminaires] des États généraux du Canada français ${ }^{24}$.» Il fut une deuxième fois question des États généraux, le mois suivant, quand La Vie franco-ontarienne publia, «à titre documentaire», le texte complet du «mémoire préparé par les dirigeants du groupe franco-ontarien à l'endroit des États

\footnotetext{
"Pendant plus de trois siècles, les hommes et les femmes d'origine française ont joué un rôle important dans le développement de l'Ontario, à commencer par les explorateurs et les négociants en fourrure de la Nouvelle-France. Ce rôle, la communauté franco-ontarienne continue à le jouer aujourd'hui. Cette communauté représente près de 10 pour cent de la population de l'Ontario. Sa force, sa vitalité, ses réalisations et son potentiel sont immenses, l'Ontario, et en fait tout le Canada, est plus riche et plus fort grâce à la présence de ces citoyens de langue française.» Voir, pour ces extraits: «Une décision historique», dans $L a$ Vie franco-ontarienne 3(1), septembre 1967, p. 2.

24 "Les États généraux du Canada français», dans $\mathrm{La}$ Vie francoontarienne 2(2), décembre 1966, p. 5.
} 
généraux», document de novembre $1966^{25}$. Après janvier 1967, La Vie franco-ontarienne ne parla plus jamais des États généraux, ce qui constitue un silence révélateur.

À cette époque, le principal porte-parole de l'ACFÉO, et done de l'Ontario français, fut Roger-N. Séguin qui, après le départ d'Aimé Arvisais en 1963, devint "président général" de l'Association, poste qu'il occupa de 1963 à $1971^{26}$. Séguin avait été, entre 1960 et 1963, Grand Chancelier de l'Ordre de Jacques-Cartier. Il connaissait donc bien les techniques de noyautage pratiquées par cette société secrète depuis un tiers de siècle et pouvait donc mieux apprécier comment l'Ordre de Jean-Talon, successeur au Québec de l'Ordre de Jacques-Cartier, pouvait noyauter les États généraux.

\section{L'INVITATION AUX MINORITÉS}

Trois catégories de délégués eurent droit de participer aux États généraux: d'abord les délégués territoriaux du Québec (à raison de dix par comté), ensuite les délégués des corps intermédiaires (à raison d'un délégué par 10000 membres), enfin les "représentants des Canadiens français établis hors du Québec ${ }^{27}$ ». Ce mode de réprésentation, adopté en juin 1966,

\footnotetext{
${ }^{25}$ "Les États généraux du Canada français", dans $L a$ Vie francoontarienne 2(3), janvier 1967, p. 5.

${ }^{26}$ Séguin était un avocat en vue de la ville d'Ottawa, un membre influent de l'Ordre de Jacques-Cartier. Voici la liste des présidents de l'ACFÉO à cette époque: Ernest Desormeaux (1944-1953), Gaston Vincent (1953-1959), Aimé Arvisais (1959-1963), Roger N. Séguin (1963-1971), Ryan Paquette (1971-1972). Quelques-uns de ces noms seront mêlés aux États généraux (Desormeaux, Séguin, Paquette). ${ }^{27}$ Voir les actes: Les États généraux du Canada français. Assises nationales tenues da la Place des Arts de Montréal du 23 au 26 novembre 1967 , p. 5.
} 
remplaçait l'ancien projet, très "corporatiste", qui prévoyait la désignation des délégués par les «corps intermédiaires».

Pour recruter les délégués de la troisième catégorie (les «représentants des Canadiens français établis hors du Québec»), ceux que Lionel Groulx appelait les «frères lointains", les organisateurs des États généraux s'adressèrent aux organismes provinciaux des autres provinces, généralement les associations d'éducation. Ainsi, au début d'août 1966, Rosaire Morin invitait les minorités françaises du Canada à participer aux États généraux ${ }^{28}$. Cette lettre d'invitation mentionnait un manifeste, mais ce document n'accompagnait pas la lettre de Morin ${ }^{29}$.

À la lecture du Manifeste (il s'agit de la brochure Un peuple parle), les dirigeants de l'ACFÉO apprirent avec étonnement que les délégués n'auraient pas tous le même statut. Selon l'ACFÉO, la brochure contenait deux affirmations contradictoires. D'une part, on y lisait que «Tous les groupements appartenant à la communauté francophone du Canada français sont conviés à déléguer des représentants

$\overline{28}$ «Dans cette recherche d'un dénominateur commun dans cette précision de leur avenir constitutionnel, les Canadiens-français du Québec désirent inviter leurs compatriotes établis hors des frontières du Québec», dans la lettre de Rosaire Morin à Roger-N. Séguin, Montréal, 9 août 1966, au CRCCF, Fonds ACFO, C2/356/1. Cette lettre n'était que la première d'une longue liste. En effet, Rosaire Morin (secrétaire général) devint l'intermédiaire entre les dirigeants des États généraux et les délégués de l'Ontario, où l'interlocuteur fut, forcément, l'Association canadienne-française d'éducation de l'Ontario (ACFÉO). Une abondante correspondance s'échangea entre Morin, d'une part, et Roger Charbonneau, secrétaire général de l'ACFÉO, d'autre part.

${ }^{29}$ Charbonneau en demanda copie, que Morin lui fit parvenir peu après, avec une liste des associations. Voir: Roger Charbonneau à Rosaire Morin, Ottawa, 12 août 1966; Rosaire Morin à Roger Charbonneau, Montréal, 19 août 1966, copies dans CRCCF, Fonds ACFO, C2/356/1. 
aux États généraux», et, d'autre part, le document précisait que «Les Canadiens français établis hors du Québec sont invités à participer à l'assemblée générale préliminaire avec droit de vote sur les questions relevant des rapports entre le Québec et les minorités canadiennes-françaises, ainsi qu'entre le Québec et les autres gouvernements du pays».

Pour mieux s'expliquer, Rosaire Morin écrivait, le 30 août 1966, qu'après cinq années de vaines discussions sur le nom du grand rassemblement prévu depuis 1961, on avait décidé, en mars 1966, de convoquer les assises nationales sous le vocable de «États généraux du Canada français»:

Cette appellation [canadienne-française] englobe nos compatriotes établis en dehors du Québec. Une autre désignation les exclurait. Nous ne pouvons pas rejeter $1,000,000$ de compatriotes de culture française.

La convocation des États généraux du Québec nous obligeait à convoquer les Anglophones du Québec.

Si nous considérons les opinions de ceux qui préconisaient les États généraux du Québec français, nous constatons qu'ils appartiennent au groupe des séparatistes. Les tenants des États généraux du Québec étaient représentés par des chefs de file qui ne croient pas à la nation canadienne-française et qui veulent créer une nouvelle nation québécoise où la culture et la langue de demain nous seraient étrangers.

Il est opportun de souligner que la restriction dans le droit de vote des minorités me semble plutôt artificielle que réelle $[. .$.$] je ne crois pas en pratique qu'il y$ ait des divisions profondes ${ }^{30}$.

Perspicace, Morin avait mis le doigt sur les deux questions critiques pour les minorités: leur droit de

${ }^{30}$ Rosaire Morin à Roger Charbonneau, Montréal, 30 août 1966, CRCCF, Fonds ACFO, C2/355/3. 
vote et la définition de la «nation». Dans la brochure lancée en 1966, Un peuple parle ${ }^{31}$, la préface de Jacques-Yvan Morin affirmait bien qu'on entendait, par "États généraux», des "assemblées des éléments représentatifs de la nation", mais de quelle nation s'agissait-il? Les documents des États généraux ont cultivé une constante ambiguïté autour de ce sujet.

Lors d'une «rencontre spéciale», le 30 août 1966 , le Comité de régie de l'ACFÉO (Roger Séguin, Robert Barsalou, Jacques Leduc, Ernest-C. Desormeaux, Roger Charbonneau) examina la lettre d'invitation aux États généraux. L'Association, qui hésitait déjà, posa des conditions, notamment quant aux modalités de financement du déplacement des délégués. L'ACFÉO voulait aussi qu'on la rassurât sur le droit des minorités à faire valoir leur point de vue lors des assises. Mais puisque "organiser une délégation», ce n'était pas forcément y "participer», l'ACFÉO accepta de s'occuper de l'organisation de la délégation ontarienne ${ }^{32}$. Le reste serait décidé plus tard.

Le Comité exécutif de l'Association, pour préciser les conditions énoncées par le "comité de régie",

\footnotetext{
${ }^{31}$ Un peuple parle, [Montréal], États généraux du Canada français, [1966], non paginé [14 pages]. Un exemplaire de cette brochure se trouve au CRCCF, Fonds ACFO, C2/355/3.

${ }^{32}$ Résolution adoptée: "Que l'Association canadienne-française d'éducation d'Ontario organiserait la délégation de l'Ontario au congrès des Etats généraux du Canada français. - Adopté». Voir: "Procès-verbal d'une réunion spéciale du Comité de régie de l'ACFÉO», Ottawa, 30 août 1966, dans CRCCF, Fonds ACFO, C2/355/3. Sur le plan financier, on avait d'abord appris que les 150 délégués de l'Ontario disposeraient d'une moyenne de 120 \$ chacun (ce qui donnerait un total de $18000 \$$ ). À la fin du mois, il s'avéra que, au fait, la délégation ontarienne disposerait de $12000 \$$ (sur les $30000 \$$ prévus pour l'ensemble des minorités). Voir: Rosaire Morin à Roger-N. Séguin, Montréal, 9 août 1966 et Rosaire Morin à Roger Charbonneau, Montréal, 19 août 1966, copies dans CRCCF, Fonds ACFO, C2/356/1.
} 
développa un plan en cinq étapes: (1) désigner un "comité préliminaire" d'une vingtaine de personnes, (2) tenir une rencontre entre ce "comité préliminaire» et une délégation des États généraux, (3) charger un comité de six personnes de rédiger un document, (4) désigner quelques personnes qui pourraient ensuite soumettre ce travail aux différentes associations et, enfin, (5) chercher à «faire l'union avec les autres minorités du pays ${ }^{33}$ ». Le "comité spécial» (ou "préliminaire»), institué le 30 août, se réunit une semaine plus tard, le 7 septembre $1966^{34}$. Après discussion des sujets que le document en préparation devrait aborder, on décida de demander à cinq personnes de préparer chacune un exposé (de deux pages) sur différents sujets ${ }^{35}$.

À sa réunion du 21 septembre 1966, le Comité exécutif de l'ACFÉO ratifia le rapport de l'assemblée spéciale du 30 août. Aussi, selon le procès-verbal, le Comité

${ }^{33}$ "Procès-verbal d'une réunion spéciale du Comité de régie de l'ACFÉO", Ottawa, 30 août 1966, dans CRCCF, Fonds ACFO, C2/355/3.

${ }^{34}$ Étaient présents: Roger-N. Séguin, E.C. Desormeaux, Séraphin Marion, M. Boulay, Jacques Leduc, Roger Charbonneau, Robert Barsalou, Rémy Beauregard, A. Lalonde, $\mathbf{M}^{\text {lle }}$ G. Levasseur, G. Boutet, B. Parent, H. Dubois et D. Bélanger. Voir «Réunion du Comité spécial de l'ACFÉO relativement à la réunion des États généraux du Canada français», 7 septembre 1966, dans CRCCF, Fonds ACFO, C2/355/3.

${ }^{35}$ Voici les sujets prévus: Séraphin Marion, «La survie du Québec et le commun dénominateur du Canada français», Roger Charbonneau, «Les délégués venant de l'extérieur du Québec devraient avoir le droit de voter sur toutes les questions qui seront étudiées aux États généraux", Jacques Leduc, "La reconnaissance de la nation canadienne-française», Gaétan Legault, «Les amendements que l'Ontario français aimerait voir apporter à la constitution canadienne", Louis Sabourin et ses collaborateurs, "Économiquement le Québec ne peut pas, à l'heure actuelle, se séparer du Canada". L'énumération de ces sujets se trouve dans le «Procès-verbal du comité exécutif de l'ACFÉO», Ottawa, 30 août 1966, dans CRCCF, Fonds ACFO, C2/355/3. 
accepte en principe de participer aux États généraux, même s'il y a réticence de la part de quelques directeurs.

Nous voulons être en mesure d'exposer les besoins de notre groupe dès le début de l'assemblée. Si nous constatons que les minorités n'ont pas leur place dans ce congrès, il sera toujours temps de se retirer ${ }^{36}$.

Cette décision «en principe» montrait bien que les réticences persistaient et qu'on évoquait déjà l'idée d'un éventuel retrait.

Roger Charbonneau, le secrétaire général de l'ACFÉO, convoqua peu après une réunion comprenant le Comité exécutif (les vingt directeurs de l'ACFEO), des représentants des sept sociétés affiliées, un membre de l'Association des fonctionnaires et deux des rédacteurs de schémas ${ }^{37}$. Cette assemblée du 7 octobre 1966, en plus de permettre une discussion du mémoire que préparait l'ACFÉO, fut l'occasion de rencontrer des représentants des États généraux. La délégation de Montréal se composait de Jacques-Yvan Morin, de Rosaire Morin, de Solange Chaput-Rolland et de Michel Pelletier. Selon le rapport de la réunion, Jacques-Yvan Morin déclara: «Si les minorités n'assistaient pas aux États généraux, leurs opinions ne seraient pas émises et les décisions prises sans eux [elles]». En outre, les membres de la délégation des États généraux rappelèrent que la rencontre de novembre 1966 n'était que préliminaire, ajoutant, pour rassurer l'ACFÉO, qu'on avait demandé une subvention pour les frais de déplacement et de logement des minorités ${ }^{38}$.

36 "Procès-verbal du Comité exécutif de l'ACFÉO", 21 septembre 1966, CRCCF, Fonds ACFO, C2/355/3.

${ }^{37}$ Roger Charbonneau à "Chers collègues", Ottawa, 28 septembre 1966, CRCCF, Fonds ACFO, C2/355/3.

38 «Rapport d'une rencontre des représentants des États généraux du Canada français, l'exécutif de l'ACFÉ et des représentants des sociétés 
Au cours de cette rencontre du 7 octobre 1966, le débat porta sur la question du vote des minorités, puisqu'on prétendait leur refuser le droit de s'exprimer sur les «questions internes» du Québec, alors que les délégués québécois, eux, pourraient se prononcer sur toutes les questions. La délégation de Montréal reconnut que les minorités avaient peu participé à la préparation des États généraux, mais expliqua qu'on avait manqué de temps pour faire autrement. D'autre part, on prévoyait une «rencontre régionale" à Ottawa, le 5 novembre 1966 (elle n'eut pas lieu). À la fin de la rencontre, l'ACFÉO décida de participer aux assises de novembre, mais en promettant de faire valoir le point de vue de l'Ontario français.

Dans une réunion du Conseil d'administration de l'ACFÉO, le 22 octobre 1966, on fit rapport. Le procès-verbal confirme les doutes que plusieurs continuaient d'entretenir:

À la suite de la rencontre du 7 octobre 1966 avec les représentants des États généraux, les membres de l'exécutif et les représentants des sociétés affiliées qui étaient présents continuent à avoir des doutes sur la façon dont cette réunion sera organisée et sur les discussions qui s'y tiendront. Aucune décision finale n'a été prise quant à la participation de l'Ontario français ${ }^{39}$.

En attendant une décision finale, on jugea utile de participer pleinement aux assises préliminaires de novembre 1966.

affiliées", Ottawa, 7 octobre 1966, CRCCF, Fonds ACFO, C2/355/3. Dans une lettre du 4 octobre 1966, Rosaire Morin avait prévenu Charbonneau de la composition de la délégation de Montréal. Voir: Rosaire Morin à Roger Charbonneau, Montréal, 4 octobre 1966, CRCCF, Fonds ACFO, C2/356/2.

${ }^{39}$ "Procès-verbal du Conseil d'administration de l'ACFÉO», 22 octobre 1966, CRCCF, Fonds ACFO, C2/355/3. 


\section{GaÉtan Gervais}

Pourquoi les dirigeants des États généraux tenaient-ils à la présence des minorités? Jacques-Yvan Morin voulait empêcher le gouvernement fédéral de s'appuyer sur les minorités pour contrarier les revendications du Québec; aussi, Morin espérait empêcher les minorités françaises de se prononcer à l'encontre du Québec qui réclamait plus de pouvoirs ${ }^{40}$. Le muselage des minorités semble donc avoir fait partie, dès le départ, d'une stratégie de la part des dirigeants. Ce plan les amena à restreindre le droit de vote des délégués minoritaires, à les empêcher de voter sur les questions fondamentales, à restreindre leurs discussions à des questions banales.

\section{LE CHOIX DES DÉLÉGUÉS}

Le 12 octobre 1966, le Comité de régie de l'ACFÉO tint une réunion où l'on décida de confier à Jacques Leduc, Ernest-C. Desormeaux et Séraphin Marion le soin «de faire le choix des délégués de l'Ontario qui ne sont pas désignés par les associations ${ }^{41}$ \%. Des listes, amendées plusieurs fois pour tenir compte des désistements et des nouvelles désignations, furent compilées en septembre, en octobre et en novembre $1966^{42}$. En fait, le maître d'œuvre de ce travail d'organisation de la délégation ontarienne semble avoir été Roger Charbonneau, le secrétaire de l'ACFÉO: c'est à lui en tous les cas qu'en est attribué le mérite lors des assises préliminaires tenues à l'Université de Montréal, les 26 et 27 novembre 1966, où l'on nota que la délégation de quelque 150 délégués ontariens

${ }^{40}$ Laliberté, Une société secrète..., p. 244.

41 "Procès-verbal du Comité de régie de l'ACFÉO", Ottawa, 12 octobre 1966, CRCCF, Fonds ACFO, C2/355/3.

${ }^{42}$ Plusieurs de ces listes se trouvent dans les archives de l'ACFÉO. Voir : CRCCF, Fonds ACFO, C2/356/1. 
avait été «mise sur pied par le secrétaire de l'Association canadienne-française d'éducation d'Ontario". Dans cette délégation, comprenant très peu de femmes, environ 90 venaient de l'Est, une quarantaine du Nord et une vingtaine du Sud ${ }^{43}$. Ces nominations faisaient une large place aux "corps constitués».

Entre-temps, la question du droit de vote continuait d'inquiéter les dirigeants franco-ontariens. Roger Charbonneau, le secrétaire général de l'ACFÉO, prépara en octobre 1966 une note sur la question. Puisque les groupes à l'extérieur du Québec faisaient partie de la nation canadienne-française, écrivait le secrétaire général de l'ACFÉO,

on ne peut en toute justice leur refuser un droit de vote absolu aux assises des États généraux. Ce serait de la discrimination et c'est précisément ce que nous reprochons à nos confrères de langue anglaise. La nation canadienne-française ne s'arrête pas aux frontières québecquoises [sic].

[...] À notre avis, toute décision qui sera prise aux États généraux affectera et le Québec et les autres groupes d'expression française. C'est la raison pour laquelle nous devons réclamer le droit de vote sur toute proposition qui sera faite. Autrement, il faudra que les États généraux du Canada français deviennent les États généraux du Québec ${ }^{44}$.

C'était un peu reprendre la question de savoir s'il s'agissait des Etats généraux du Canada français ou du Québec.

Le président de la commission technique des Etats généraux, Rosaire Morin, cherchant un terrain d'entente, proposa le «compromis» suivant: d'une part,

\footnotetext{
${ }^{43}$ Hubert Potvin, "150 délégués de l'Ontario français au congrès des États généraux», dans Le Droit, 12 novembre 1966, p. 4.

${ }^{44}$ Roger Charbonneau, "Droit de vote aux États généraux", octobre 1966, CRCCF, Fonds ACFO, C2/355/3.
} 
seuls les délégués du Québec pourraient voter sur les questions touchant le Québec et, d'autre part, les délégués de "l'extérieur» n'auraient droit de vote que sur les «questions externes» au Québec. Morin faisait valoir auprès des minorités que, sans ce compromis, les délégués québécois pourraient se concerter et imposer une décision que les délégués des autres provinces ne voudraient pas: "Vous auriez peut-être à vous retirer des États généraux et à les [délégués québécois] dénoncer publiquement ${ }^{45}$.» La question fut débattue en assemblée, lors des assises préliminaires, en novembre, avec de nombreux débats de procédure. Finalement l'assemblée de Montréal adopta une résolution donnant un droit de vote égal à tous les délégués.

La deuxième question qui préoccupait l'ACFÉO, c'était de savoir qui forme la «nation canadiennefrançaise». Le manifeste intitulé Un peuple parle, paru à l'été, puis le texte de Groulx en septembre 1966, apportaient déjà un début de réponse. En octobre 1966, Rosaire Morin s'était en outre adressé aux «associations canadiennes-françaises en dehors du Québec», pour leur envoyer le manifeste ${ }^{46}$. Après avoir dit que tous les éléments de la nation canadienne-française participaient (les comtés, les corps intermédiaires du Québec, enfin les «Canadiens français établis hors du Québec»), la brochure ne traitait en fait que du Québec. À la première section, intitulée «Au Québec, une nation veut vivre pleinement", succédait une deuxième traitant de "La constitution canadienne: une formule périmée». Puis la

\footnotetext{
$\overline{45}$ Texte cité dans «Les délégués des minorités n'ont pas fait grand tapage", dans Le Droit, 28 novembre 1966, p. 1.

${ }^{46}$ Rosaire Morin aux Associations canadiennes-françaises en dehors du Québec, Montréal, octobre 1966, CRCCF, Fonds ACFO, C2/355/3.
} 
brochure consacrait une section à «Une question vitale pour les Canadiens français» et une autre au «Long silence d'un peuple opprimé», victime depuis la Conquête de 1760, le tout axé sur le seul Québec.

\section{LE Mémoire de L'ACFÉO (1966)}

Un comité de rédaction de cinq personnes se mit à l'œuvre dès le 30 août 1966. Divers textes préparatoires au Mémoire furent rédigés. Selon Séraphin Marion, l'idée qui devait rallier tout le monde, c'était «la question de la survie d'un Québec français», menacée par la situation démographique de Montréal, où les Anglais formeraient bientôt 52\% de la population, et qui pourrait alors réclamer le statut de onzième province canadienne. Cette situation condamnerait le Québec au statut de «seconde Louisiane française en Amérique du Nord, une Nouvelle France ratatinée, flétrie, meurtrie, rendez-vous tout désigné des amateurs de folklore et de vieilles lunes ${ }^{47}$ ».

Le texte de Jacques Leduc demandait, étant reconnu le principe "des deux nations fondatrices", s'il fallait chercher des solutions impliquant l'ensemble du Canada français ou s'il fallait abandonner les minorités. Selon l'auteur, les Franco-Ontariens rejetaient sans équivoque l'hypothèse d'une nation québécoise, «si les tenants de cette option veulent faire

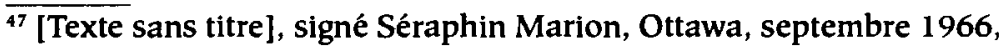
une page et demie, copies dans CRCCF, Fonds ACFO, C2/355/3 et Fonds Robert-Barsalou, P149/1/6. À la veille des assises de novembre 1967, Marion prononça (le mercredi 8 novembre 1967) un discours devant la Jeune Chambre de commerce d'Ottawa-Eastview, où il reprenait ses idées. Pour sa conférence de 1967, voir: "D'après l'historien Séraphin Marion "La nation canadienne-française est acculée à la décision suprême: être ou ne pas être"», dans Le Droit, 9 novembre 1967, p. 8. 
du Québec un État totalement dissocié du reste du Canada et indifférent aux problèmes des minorités». Leduc ajoutait: «Des Franco-Ontariens admettent cependant, et sans réserves, le principe de la nation canadienne-française et ils s'entendent pour reconnaître que son avenir repose sur un Québec fort ${ }^{48}$.»

L'Association de la jeunesse franco-ontarienne (AJFO) prépara aussi un document ${ }^{49}$. Il repoussait le fédéralisme coopératif et l'indépendance du Québec, mais préconisait soit un "statut particulier" pour le Québec, soit un régime d'États associés. Le document de la jeunesse précisait cependant que «la nation canadienne-française ne se limite pas au Québec». Le document décrivait le bilinguisme universel comme une utopie, tout en préconisant l'enseignement obligatoire des deux langues partout. Selon le document, «La nation canadienne-française s'épanouira dans la mesure où les minorités et le Québec feront un front commun dans un Canada fort et reconnaissant l'existence de notre nation et nos droits dans une nouvelle constitution».

Un autre texte, par Ernest-C. Desormeaux, traitait de la question scolaire en Ontario ${ }^{50}$. La loi constitutionnelle de 1867 avait placé les minorités françaises dans un état d'infériorité, ce qui continuait de susciter

\footnotetext{
${ }^{48}$ Jacques Leduc, «Rencontre des États généraux du Canada français - La nation canadienne-française ou québécoise? Prise de position des Franco-Ontariens», copies dans CRCCF, Fonds ACFO, C2/355/3 et Fonds Robert-Barsalou, P149/1/6.

49 "Schéma du mémoire à être présenté par la délégation ontarienne aux Ettats généraux du Canada français», préparé par l'Association de la jeunesse franco-ontarienne, Ottawa, 5 octobre 1966, copie dans CRCCF, Fonds Robert-Barsalou, P149/1/6.

${ }^{50}$ E.-C. Desormeaux, "Les problèmes scolaires de l'Ontario français et l'Acte de l'Amérique du Nord britannique», 3 p., octobre 1966, copie dans CRCCF, Fonds Robert-Barsalou, P149/1/6.
} 
des difficultés en Ontario français. Par conséquent, les progrès se sont heurtés à «l'incompréhension, pour ne pas dire le fanatisme, de nos coreligionnaires de langue anglaise». Beaucoup de FrancoOntariens étaient toujours privés d'écoles. Desormeaux analysait longuement la question des impôts et le traitement inique imposé aux contribuables canadiens-français, privés de la taxe commerciale et industrielle. L'auteur abordait ensuite la question des écoles secondaires. Desormeaux réclamait donc pour les minorités un traitement équitable et juste, comme celui que recevait la minorité anglaise du Québec.

La Fédération des Sociétés Saint-Jean-Baptiste de l'Ontario produisit aussi son analyse. Dès septembre 1966, le secrétaire général de la Fédération, Aurèle Chénier, écrivait qu'en préparation d'un mémoire, on devrait tenir compte des éléments suivants: l'existence d'un "dénominateur commun" entre tous les Canadiens-Français, la nécessité d'assurer l'égalité aux délégués hors Québec, la nature des amendements requis dans la constitution canadienne, l'affirmation que le Québec ne pouvait pas, économiquement, survivre seul. Enfin, Chénier demandait qu'on évitât «d'insulter les séparatistes». Selon la Fédération, les États généraux devaient regrouper tous les Canadiens d'expression française «en vue d'un effort décisif et final vers l'égalité et la reconnaissance de la NATION canadienne-française et vers la rédaction d'une constitution rénovée». La Fédération ne souhaitait pas devenir complice de la séparation du Québec «car il paraît indéniable que celle-ci n'améliorerait pas notre situation en tant que minorité». Elle était d'accord pour participer aux États généraux «si ces derniers se veulent vraiment représentatifs de 
la NATION canadienne-française. Nos délégués réclament toutefois le droit de vote sur toute question devant y être discutée et ce, sans la moindre discrimination entre les délégués des minorités et ceux du Québec». Le document était d'accord pour donner plus de pouvoirs au Québec («État national des Canadiens français $\left.{ }^{51} »\right)$.

Tous ces documents furent acheminés à l'ACFÉO qui en tint compte dans la rédaction de son Mémoire. Les archives de l'ACFÉO ne contiennent pas les documents demandés à Charbonneau, Legault et Sabourin. Dans un article du 12 novembre, Le Droit affirmait que les responsables de la délégation franco-ontarienne étaient «à mettre la dernière main à un mémoire qui sera soumis au congrès et qui pourrait devenir le document de base de tous les Canadiens français demeurant à l'extérieur du Québec ${ }^{52}$ ». Le document commun, rédigé par Roger Duhamel, reçut l'aval du Comité exécutif de l'ACFÉO, après quelques amendements. Le Mémoire ne fut donc prêt qu'au début des assises à Montréal ${ }^{53}$.

\section{LA RENCONTRE DES MINORITÉS (26 NOVEMBRE 1966)}

Roger Charbonneau, dans une lettre du 14 novembre 1966, informa les délégués ontariens d'une

${ }^{51}$ La Fédération des Sociétés S[ain]t-Jean-Batiste de l'Ontario, "Les États généraux du Canada français", [Ottawa], octobre 1966, copie dans CRCCF, Fonds Robert-Barsalou P149/1/6. Les délégués de la Fédération aux États généraux furent convoqués le 22 septembre 1966 pour discuter de son mémoire; la délégation, en fait, se composait de huit personnes: six d'Ottawa, une de Pembroke (Raymond Schryer) et une de Windsor (Rosaire Masse). Voir: Aurèle Chénier à Raymond Schryer, 12 septembre 1966, copie dans CRCCF, Fonds FSSIBO, C19/18/1.

${ }^{52}$ Hubert Potvin, "150 délégués de l'Ontario français au congrès des Etats généraux", dans Le Droit, 12 novembre 1966, p. 4.

53 "Procès-verbal du Comité exécutif de l'ACFÉO», Ottawa, 16 novembre 
rencontre qui aurait lieu le samedi 26 novembre 1966 , à $9 \mathrm{~h} 30^{54}$; puis, le 21 novembre, il faisait aussi parvenir, aux différents groupes minoritaires du Canada, un exemplaire du Mémoire et les invitait à la rencontre du samedi ${ }^{55}$. Les responsables de la délégation ontarienne espéraient que les délégués provenant des provinces anglaises adopteraient le Mémoire comme leur position commune, avec les deux éléments de base, à savoir le rejet du séparatisme et l'exigence d'un droit de vote égal sur toutes les questions.

Le samedi matin, 26 novembre 1966, les groupes provenant de l'extérieur du Québec tinrent leur réunion, à l'Université de Montréal ${ }^{56}$. Ernest-C. Desormeaux, à la fois secrétaire du Conseil de la Vie française et directeur de l'ACFÉO, souhaita la bienvenue à quelque 220 délégués, alors que $\mathrm{M}^{\mathrm{gr}}$ Paul-É. Gosselin, secrétaire du Conseil de la Vie française, agit comme secrétaire de la rencontre. Après une discussion sur la présence de la presse, les journalistes furent admis à la rencontre. L'assemblée entendit d'abord la présentation de Rosaire Morin, puis elle discuta du Mémoire préparé par l'ACFÉO.

Le président de la Commission technique des États généraux, Rosaire Morin, rappela l'urgence de tenir ces assises, parce que le Québec ne contrôlait pas son économie et qu'il fallait modifier la constitution pour arrêter l'assimilation. Selon le compte rendu:

1966, CRCCF, Fonds ACFO, C2/355/3. Le texte du Mémoire a été reproduit dans La Vie franco-ontarienne 2(3), janvier 1967, p. 5.

54 Roger Charbonneau, ["Directives aux 150 délégués de l'Ontario français qui assistent aux États généraux»], Ottawa, 14 novembre 1966, CRCCF, Fonds ACFO, C2/355/3.

${ }^{55}$ Roger Charbonneau [aux groupes minoritaires], Ottawa, 21 novembre 1966, copie dans CRCCF, Fonds ACFO, C2/355/4.

56 «Réunion des groupes hors du Québec aux États généraux - Montréal - 26 novembre 1966", 3 p., CRCCF, Fonds ACFO, C2/355/3. 
M. Morin souligne l'importance du Québec au sein de la nation canadienne-française, mais il souligne le mot nation canadienne-française. À ce sujet, il déclare que les dirigeants des Etats généraux ont tenu fermement à la participation de tous les Canadiens français à travers le Canada, en dépit des pressions exercées par les séparatistes, les partisans d'une nation québécoise et certaines centrales syndicales. Trois de ces dernières se sont retirées des États généraux pour cette raison ${ }^{57}$.

Morin souligna le caractère préliminaire des assises de 1966 et insista qu'il fallait «éviter les options globales et rechercher un dénominateur commun». Pour l'heure, on étudiait et on n'adoptait pas de solutions particulières. Mais Morin voulait traiter surtout de trois questions importantes: le financement, l'égalité du droit de vote, enfin la participation des minorités à la Commission générale.

Les États généraux avaient éprouvé des difficultés financières, mais le gouvernement du Québec venait de promettre une somme de 30000 \$ pour assurer la participation des groupes minoritaires. Rosaire Morin remit alors à $\mathrm{Mgr}^{\mathrm{gr}}$ Gosselin une lettre du sous-ministre Claude Morin promettant ce montant au Conseil de la Vie française, aux fins d' «indemniser les associations patriotiques hors du Québec pour les dépenses de leurs délégations aux États généraux ${ }^{58}$ ».

\footnotetext{
$\overline{57 \text { Ibid., p. } 1 .}$

${ }^{58}$ Le 11 novembre, Rosaire Morin avait confirmé par lettre à Roger Charbonneau que les États généraux recevraient les 30000 \$ demandés (dont $12000 \$$ étaient destinés à la délégation franco-ontarienne). Mais le paiement tarda à venir, ce qui aigrit un peu le climat. Ainsi, Roger Charbonneau s'en plaignit à $\mathrm{M}^{\mathrm{Br}} \mathrm{P}$.-E. Gosselin, du Conseil de la Vie française, en affirmant: "Mes gens sont dégoûtés du retard qu'apporte le gouvernement du Québec à vous remettre le subside pour les frais de déplacement aux États généraux", dans la lettre de Roger Charbonneau à P.-É. Gosselin, Ottawa, 7 décembre 1966, copie au CRCCF, Fonds ACFO, C2/355/5.
} 
Le deuxième problème présenté par Morin fut celui du droit de vote. Après la décision de limiter le droit des minorités, on s'était par la suite aperçu que ce vote limitatif était inacceptable parce qu'il créait des compatriotes de seconde zone. Il y aurait donc un vote pour tous sur les questions d'intérêt général, mais seuls les délégués québécois voteraient sur «les problèmes proprement québécois», tandis que les délégués de l'extérieur voteraient seuls «sur les problèmes qui les concernent proprement».

La troisième question soulevée par Morin fut celle de la représentation des minorités à la Commission générale des États généraux. Avant, la seule représentation des minorités avaient été les délégués, soit du Conseil de la Vie française, soit de l'Association canadienne des éducateurs de langue française (ACÉLF). Les dirigeants des États généraux venaient de porter de 20 à 37 le nombre de membres de la Commission générale, ce qui permettait d'attribuer quatre sièges à l'Ontario, deux à l'Acadie et un à l'Ouest. Morin termina sa présentation en rappelant "son attachement aux groupes hors du Québec». Selon le journaliste du Devoir, «À la suite de cette déclaration, il semble que la plupart des mécontents des autres provinces se soient ralliés ${ }^{59}$ ».

Après avoir entendu la présentation de Rosaire Morin, les délégués des groupes minoritaires passèrent à l'examen du Mémoire des minorités françaises aux États généraux du Canada français Montréal - 26 \& 27 novembre $1966^{60}$, document que l'ACFÉO leur avait envoyé quelques jours plus tôt et dont la presse

${ }_{59}$ "Aux États généraux les minorités ne pourront voter sur les questions qui concernent le Québec», dans Le Devoir, 28 novembre 1966, p. 11.

${ }^{60}$ Mémoire des minorités françaises aux États généraux du Canada 
avait déjà commencé à parler. Le document contenait deux propositions qui, dès le départ, furent au cœur des revendications de la délégation ontarienne: il y avait d'abord la condamnation du séparatisme, puis la question de procédure, à savoir l'égalité du droit de vote de tous les délégués.

Le Mémoire reconnaissait que les minorités profiteraient d'un Québec fort, mais il rejetait «sans la moindre équivoque cette notion qui ferait du Québec un État entièrement dissocié du reste du Canada et plus ou moins indifférent à l'existence des minorités françaises». On voulait que le Québec disposât d'une autorité suffisante, «sans jamais perdre de vue que la nation canadienne-française ne se limite pas au Québec».

Le compte rendu de la réunion, préparé par $\mathrm{M}^{\mathrm{gr}}$ Gosselin, parle d' «un intéressant mémoire exposant la situation des groupes hors du Québec à l'endroit des États généraux ${ }^{61} »$. Roger Duhamel donna lecture du Mémoire dont il était le rédacteur, et il proposa que le document fût soumis aux États généraux pour étude et considération. Il se produisit alors ce que le secrétaire Gosselin appela une "discussion assez confuse». Plusieurs jugèrent que le ton du Mémoire était trop sarcastique, qu'il manquait de compréhension des problèmes et qu'il ne reconnaissait pas assez les situations différentes de chaque minorité.

Le débat, finalement, se cristallisa autour de la question du droit de vote des groupes minoritaires. Certains appuyèrent le compromis que Rosaire Morin français - Montréal - 26 \& 27 novembre 1967, novembre 1966, des copies dans CRCCF, Fonds ACFO, C2/366/5, Fonds Robert-Barsalou, P149/1/6 et Fonds Institut-canadien-français-d'Ottawa, C36/47/2.

${ }^{61}$ «Réunion des groupes hors du Québec aux États généraux - Montréal

- 26 novembre 1966", p. 2, CRCCF, Fonds ACFO, C2/355/3. 
venait de proposer, mais d'autres réclamaient un droit de vote égal pour tous. Ces derniers craignaient que la majorité des questions ne soient tout simplement classées comme "québécoises", ce qui priverait les minorités de l'occasion de se prononcer sur elles. Selon le compte rendu, ces «durs» se demandaient «comment il peut $y$ avoir place pour des questions provinciales dans une réunion de la nation canadienne-française». On demanda «que le droit de vote soit égal pour tous les congressistes».

La discussion continua sur d'autres aspects du Mémoire. On convint d'en bannir le mot "minorité» et d'en rendre le ton "moins agressif». La proposition d'adopter le Mémoire fut alors retirée, puis l'assemblée demanda que le document fût envoyé à tous les groupes représentés dans la salle pour qu'ils eussent le temps d'acheminer leurs suggestions au Conseil de la Vie française, où un comité devait modifier le Mémoire selon les suggestions reçues, le faire approuver par les délégués des groupes minoritaires et l'envoyer aux dirigeants des États généraux.

Enfin, avant de se quitter, les délégués des minorités adoptèrent une résolution demandant que 12 des 41 places de la Commission générale soient occupées par les représentants des minorités.

\section{LES ASSISES PRÉLIMINAIRES}

Les actes des assises préliminaires, publiés par la revue L'Action nationale, commencent avec le texte de Lionel Groulx, suivi de l'allocution de bienvenue du maire Jean Drapeau. Le premier grand discours, sur les "Raisons d'être et buts des États généraux», fut prononcé par Jacques-Yvan Morin. 
Devant les quelque 1750 délégués réunis à l'Université de Montréal, le juriste Morin («sa silhouette se détachant sur un immense fleurdelysé déployé derrière lui ${ }^{62}$ »), souhaita la bienvenue "à tous, vous qui venez de tous les horizons du Canada français, délégués du Québec, de l'Acadie, de l'Ontario et de l'Ouest". Après avoir décrit, dans une première partie, l'état de la nation, le conférencier traita ensuite de "notre situation économique au Québec», de "notre vie sociale au Québec», de "notre vie culturelle». Dans la deuxième partie, consacrée à la nécessité du dialogue, il parla de l'arrivée de l'heure des choix. "Avouons que nous nous connaissons fort mal. Combien de Québécois se sont promenés dans Sudbury ou Welland, combien ont visité l'Université de Moncton ou de S[ain]t-Boniface?», demandait l'orateur. Par les États généraux, qui ne sont ni un parti politique, ni un gouvernement, on voulait établir un nouveau dialogue. Ainsi, les États généraux n'étaient au service "d'aucune option constitutionnelle global ${ }^{63}$ ».

Dans le discours qui suivit ${ }^{64}$, Rosaire Morin évoqua de nouveau les divisions de la nation, mais en rappelant bien que les véritables assises n'auraient lieu qu'en octobre 1967. Il parla longuement de la sélection des délégués, de leur rôle et aussi, forcément, du financement. Il manquait 300000 \$, et la campagne s'ouvrait le lendemain après-midi, sous le

\footnotetext{
${ }^{62}$ Hubert Potvin, «Jacques-Yvan Morin: Les États généraux ne sont au service d'aucune option constitutionnelle globale», dans Le Droit, 28 novembre 1966, p. 3.

${ }^{63}$ Le discours de Jacques-Yvan Morin, «Raison d'être et but des États généraux", prononcé le 26 novembre 1966, se trouve dans Les États généraux du Canada français. Assises préliminaires tenues à l'Université de Montréal, du 25 au 27 novembre 1966, pp. 17-32.

${ }^{64}$ Rosaire Morin, «L'avenir des États générauX», dans Ibid., pp. 33- 40.
} 
thème «Un peuple parle». Enfin, Michel Pelletier présenta un rapport d'activités.

Lors de ces assises préliminaires, les discussions se déroulèrent en "commissions", trente-six au total, qui traitèrent de vingt-quatre sujets différents (certains thèmes ont donc deux commissions). Les sujets se répartissaient sous quatre grandes rubriques: (1) les problèmes culturels, (2) les problèmes sociaux, (3) les aspects économiques et (4) les questions politiques et constitutionnelles. Chaque commission avait son président, son "aviseur", son secrétaire et son rapporteur. À une exception près (Fernand Gratton), tous les délégués ontariens qui ont occupé de telles fonctions (de président, aviseur, secrétaire ou rapporteur) provenaient d'Ottawa ${ }^{65}$. Cette liste, on le voit, ne comprend pas de femmes.

${ }^{65}$ Le nom de ces personnes se trouve dans un document des États généraux: «Assemblée préliminaire-Commissions», copie dans CRCCF, Fonds ACFO, C2/355/3. Voici les noms des personnes qui ont occupé une fonction dans l'une ou l'autre des commissions. Dans le secteur «national», Roger Saint-Denis fut président de la deuxième commission («Notre vie nationale»), Roger Guindon fut aviseur de la troisième («Relations entre Canadiens français»), Jacques de Courville Nicol, secrétaire de la quatrième ("Le Canada français et le monde francophone»), E.-C. Désormeaux, président de la sixième («Le statut de la langue"), Jacques Leduc, secrétaire de la septième ("Radio et télévision»), Marc-Yvain Giroux, secrétaire de la neuvième («Arts et sciences"). Dans le secteur économique, Florian Carrière fut secrétaire de la première commission («Domaine fiscal»), Cyrille Goulet, secrétaire de la sixième ( Pour une économie canadienne-française»). Dans le secteur social, on trouve les noms d'Hervé Cyr, président de la quatrième commission ("Famille canadienne-française»), de Lionel Desjarlais, secrétaire de la septième («Problèmes ouvriers») et de Benoît Parent, secrétaire de la neuvième («Plans conjoints»). Enfin, dans le domaine politique, Fernand Gratton fut secrétaire de la première commission ("Politique de population»), Donat Pharand, aviseur de la deuxième ("Méthode d'amendement constitutionnel»), Louis Charbonneau, président de la cinquième ( «Fonctions du lieutenantgouverneur et droit de désaveu») et Louis Beauchesne, secrétaire de la sixième («Ports québécois et navigation d'hiver»). 
L'opposition entre les partisans de la séparation du Québec et les minorités éclata dès le premier jour, alors que la délégation du comté d'Ahuntsic proposa trois résolutions «essentielles». Le secrétaire de la délégation d'Ahuntsic (qui signait «Jules Emery, Ph.D., S.M.D. de la Société de Jésus»), proposait premièrement que le mandat des délégués fût maintenu durant toute la durée des États généraux, que la langue française fût déclarée la langue officielle des États généraux («par analogie avec la constitution des États qui décrètent une langue officielle») et troisièmement «Que les États Généraux s'appellent les États Généraux de la Nation québécoise ${ }^{66}$.

Ces résolutions renvoyaient à un autre problème, celui de la représentativité des délégués territoriaux du Québec. Leur élection, en septembre, avait été entachée de nombreuses irrégularités et de tentatives de noyautage. Rosaire Morin souhaitait donc procéder à de nouvelles élections, geste qui déplut à «certains délégués susceptibles - des membres du R.I.N. en l'occurrence». On espérait élire des délégations tenant mieux compte des différents territoires, des différentes idéologies, des différentes classes sociales. Après la défaite de leurs résolutions, plusieurs groupes séparatistes quittèrent l'amphithéâtre. Le dimanche après-midi, les délégués présents (il ne restait plus que le cinquième des 1750 inscrits) adoptèrent une recommandation de la Commission générale provisoire de procéder à de nouvelles élections pour choisir des délégations plus diversifiées. Ces élections eurent lieu en avril 1967.

\footnotetext{
${ }^{66}$ Jules Emery, «Ph.D., S.M.D. de la Société de Jésus», [lettre] «À Monsieur le Président des États généraux, À tous les Délégués et Observateurs des États généraux», Montréal, 24 novembre 1966,
} 
Indignés, les groupes séparatistes dénoncèrent "la mainmise inadmissible des dirigeants des États généraux sur l'assemblée». Ils dénoncèrent surtout la "manœuvre qui semble devoir aboutir à un noyautage systématique des États généraux par une société occulte connue sous le nom de «LA PATENTE» dont le dirigeant est M. Rosaire Morin». Ce dernier riposta que c'était en fait le RIN (Rassemblement pour l'indépendance nationale) qui avait tenté de noyauter les États généraux, ajoutant pour bonne mesure qu'il ne connaissait rien de l'Ordre de Jean-Talon qui aurait succédé à l'Ordre de Jacques-Cartier. Pierre Gravel, de Montréal, déclara à la presse qu'il était lui-même un directeur de l'Ordre de Jean-Talon, dont il démissionna sur le champ, en plus de quitter les États généraux à cause de «l'importance trop grande accordée à la délégation des minorités des autres provinces $^{67}$ \%.

\section{BILAN DES ASSISES PRÉLIMINAIRES}

En éditorial, Claude Ryan écrivit au lendemain des assises préliminaires que les États généraux s'étaient terminés dans "une demi-confusion», à cause de "stériles débats de procédure». Il parlait d'un "malaise» et notait qu'on avait d'abord cru à un projet culturel, social et économique, mais qu'en fait, l'aspect politique domina. Dans le numéro de novembre du Magazine Maclean, déjà, le journaliste Jacques Guay se demandait si les États généraux parviendraient à franchir «le cap des assises

copie dans CRCCF, Fonds de la Fédération des Sociétés SaintJean-Baptiste, C19/18/1.

${ }^{67}$ Paul Cliche, "Éclatement aux États généraux — Les indépendantistes se retirent après que l'assemblée eut rejeté une de leurs résolutions», dans Le Devoir, 28 novembre 1966, p. 1. 
préliminaires», puisqu'il faudrait définir la nation en choisissant «entre le Canada français et le Québec». Selon Guay: «Le fait, par exemple, que le Conseil de la Vie française en Amérique ait été l'un des plus gros souscripteurs des États généraux est pour d'aucuns le signe que l'Ordre de Jacques Cartier, nouvelle formule, a déjà largement infiltré le mouvement ${ }^{68}$." Luc Racine, dans la revue Parti pris, de façon assez prévisible, y vit les agissements "d'une petite bourgeoisie", restée muette «sur la libération économique des travailleurs ${ }^{69} »$.

Dans Le Droit du 28 novembre 1966, une grande manchette à la une proclamait: «Aux États généraux du Canada français. Remise en question de la représentation». En éditorial, Marcel Gingras conclut que deux groupes seraient déçus: les «idéalistes» qui espéraient l'union parfaite et les indépendantistes désireux d'un «violent et irrémédiable désaccord entre francophones du Québec et ceux de la diaspora». Il citait Jacques-Yvan Morin, «que l'on dit indépendantiste», mais que l'on qualifiait de "pondéré, habile», malgré ses vues. Gingras décriait le fait que dans les commissions, les délégués québécois avaient traité la langue des minorités de «folklore» et accusé les minorités de «se conter des histoires", déclarant le français non viable à l'extérieur du Québec. Deux jours plus tard, Le Droit publiait un deuxième éditorial, pour mettre en cause, cette fois, la représentati-

\footnotetext{
${ }^{6 B}$ Jacques Guay, «Les États généraux sont-ils viables?", dans Magazine Maclean 6(11), novembre 1966.

${ }^{69}$ Editorial de Claude Ryan, «Les États généraux: voie difficile», dans Le Devoir, 29 novembre 1966, p. 4.; Jacques Guay, «Les États généraux sont-ils viables?", dans Magazine Maclean 6(11), novembre 1966; Luc Racine, «L'inévitable projet d'indépendance du Québec: pour qui et au profit de qui?», dans Parti pris 5(4), décembre (janvier) [1968], p. 10.
} 
vité des États généraux ${ }^{70}$. L'éditorialiste, toutefois, ne disait rien de la représentativité des délégations minoritaires, comme celle de l'Ontario.

Durant les assises, on avait peu entendu parler les minorités françaises, dont les représentants firent peu d'interventions. La presse rapporta que les délégués venant de l'extérieur du Québec «n'ont à vrai dire pas fait beaucoup de bruits ${ }^{71}$.

\section{II - LES ASSISES DE 1967}

En 1967, de nombreuses célébrations marquèrent le premier centenaire de la Confédération canadienne. $\mathrm{Au}$ Québec, toutefois, un climat politique survolté atteignit son paroxysme avec le cri du général de Gaulle à l'hôtel de ville de Montréal. Attisé par le gouvernement du Québec et son lourd contentieux avec le gouvernement fédéral, le mouvement nationaliste traversait une période agitée. Le nombre d'indépendantistes, recrutés dans les rangs des syndicats, d'une fonction publique provinciale agrandie et de la nouvelle bourgeoisie d'affaires franco-québécoise, ne cessait de croître. Certains chefs séparatistes prédisaient avec confiance que le Québec serait indépendant "avant cinq ans".

Toujours soucieux de maintenir «l'unité et la cohésion», les dirigeants des États généraux firent droit à certains griefs des minorités françaises, en cherchant à leur faire une place, tant à la Commission générale que dans les autres commissions. Les dirigeants des

7o Editorial de Marcel Gingras, «Les États généraux», dans Le Droit, 28 novembre 1966, p. 6; éditorial de Marcel Gingras, "Être représentatif", dans Le Droit, 30 novembre 1966, p. 6.

71 «Les délégués des minorités n'ont pas fait grand tapage», dans Le Droit, article daté de Montréal, 28 novembre 1966, p. 1. 
États généraux invitèrent l'ACFÉO «à nommer quatre [F]ranco-[O]ntariens venant des régions d'Ottawa, Toronto, Sudbury et Timmins, pour siéger à la Commission générale ${ }^{72}$ ». Le Comité exécutif confia cette tâche au président (Roger-N. Séguin) et au secrétaire (Roger Charbonneau), qui désignèrent Gaston Carbonneau (Ottawa), Ryan Paquette (Hamilton), Albert Aubé (Earlton) et F.H. Trudeau (North-Bay) ${ }^{73}$. À l'été de 1967, Roger Charbonneau proposa à Rosaire Morin le nom de certaines personnes (qu'il n'avait pas encore consultées), mais qu'il jugeait aptes à occuper diverses fonctions (conseiller, rapporteur) dans les différentes commissions d'étude ${ }^{74}$.

\footnotetext{
72 "Procès-verbal du Comité exécutif de l'ACFÉO», Ottawa, 18 janvier 1967, CRCCF, Fonds ACFO, C2/355/3.

73 "Procès-verbal du Comité exécutif de l'ACFÉO", Ottawa, 15 mars 1967, copie dans CRCCF, Fonds ACFO, C2/355/3. Pour l'informer des quatre noms que l'ACFÉO proposait, Roger Charbonneau écrivit à Rosaire Morin, Ottawa, 21 février 1967, CRCCF, Fonds ACFO, C2/356/2. ${ }^{74}$ Voici les noms proposés: J.M. Tessier (conseiller à la Commission sur le statut de la langue française), Roger Saint-Denis (rapporteur à la Commission d'études et subventions), Albert Regimbal (secrétaire à la Commission de la culture populaire, radio et télévision), Maurice Chagnon (conseiller à la Commission sur les relations entre les Canadiens français), Conrad Lavigne (conseiller à la Commission du développement économique), Cyrille Goulet et Jean-Louis Renaud (respectivement conseiller et secrétaire à la Commission de la théorie constitutionnelle) et Gérald Boutet (rapporteur à la Commission de la famille et de la politique familiale). Sauf Tessier (Toronto) et Régimbal (Sudbury), les noms proposés proviennent tous de la région d'Ottawa. Sur la copie de la note de service proposant ces noms, un texte manuscrit indique: «Morin a choisi pour l'aspect culturel $\mathbf{1}^{\text {er }}$ choix $\mathrm{R}$. Duhamel. $2^{c}$ R. Bériault, Père [Roger] Guindon, [Gaston] Carbonneau». Voir: Memo de Roger Charbonneau à Rosaire Morin, Ottawa, 18 août 1967, avec notations manuscrites sur la copie, CRCCF, Fonds ACFO, C2/355/3.
} 
LE «MÉmoire des CANAdiens fRANÇAIS» (1967)

Le Conseil de la Vie française ${ }^{75}$ devait consulter les différents groupes minoritaires et préparer un nouveau document qu'on appela généralement le Mémoire des Canadiens français. Le secrétaire du Conseil de la Vie française, $\mathbf{M}^{\mathrm{r}}$ Paul-Émile Gosselin, se chargea du délicat travail de concertation et de rédaction.

Le 15 mars 1967, le Comité exécutif de l'ACFÉO fit ses commentaires sur une première version du nouveau texte ${ }^{76}$. Plusieurs lettres s'échangèrent au cours du mois de mars à ce sujet. Le 4 avril 1967 , Charbonneau informa Gosselin que le Comité exécutif de l'ACFÉO endossait le texte du projet de Mémoire: "Vous avez bien démontré que la nation canadiennefrançaise ne se limite pas seulement au Québec et c'est à cette condition que nous acceptons de participer aux prochains États généraux ${ }^{77}$.» Le projet de Mémoire fut de nouveau discuté lors de la réunion du Comité exécutif de l'ACFÉO le 19 avril 1967, quand on constitua un petit comité (Bruno Comeau, Roger Duhamel, Lucien Côté) pour mieux étudier le document et réviser le «Mémoire des minorités ${ }^{78}$ ».

\footnotetext{
${ }^{75}$ Sur l'histoire du Conseil de la Vie française et son rôle auprès des minorités, voir: Marcel Martel, Le Deuil d'un pays imaginé. Rêves, luttes et déroute du Canada français. Les rapports entre le Québec et la francophonie canadienne (1867-1975), [Ottawa], Presses de l'Université d'Ottawa, «Amérique française» 5/Centre de recherche en civilisation canadienne-française, [c1997], $203 \mathrm{p}$.

${ }^{76}$ «Procès-verbal du Comité exécutif de l'ACFÉO», Ottawa, 15 mars 1967, copie dans CRCCF, Fonds ACFO, C2/355/3. Une copie du projet de Mémoire, tel qu'il est formulé en mars 1967 ( «Mémoire des groupes canadiens-français hors du Québec aux Etats généraux du Canada français») se trouve au CRCCF, Fonds Robert-Barsalou, P149/1/6.

${ }^{77}$ Roger Charbonneau a P.-E. Gosselin, Ottawa, 4 avril 1967, copie dans CRCCF, Fonds ACFO, C2/355/5.

78 "Procès-verbal du Comité exécutif de l'ACFÉO», Ottawa, 19 avril 1967, copie dans CRCCF, Fonds ACFO, C2/355/3. Pour une copie du
} 
L'ACFÉO demanda d'affirmer «avec vigueur l'unité de la nation canadienne-française et le rôle primordial des Canadiens français du Québec au sein de cette nation ${ }^{79}$ ".

À l'été de 1967, le Conseil put finalement soumettre le Mémoire des Canadiens français ${ }^{80}$ à la Commission générale des États généraux. Ce texte reprenait de grandes tranches du Mémoire de l'ACFÉO (novembre 1966) et, dans sa version de juillet 1967 , donnait en trois pages (simple interligne) la position des minorités. Huit «associations nationales» lui accordèrent leur l'appui officiel ${ }^{81}$.

Le Mémoire des Canadiens français affirmait que les minorités seraient heureuses de participer aux assises des États généraux, mais seulement sur la base d'une reconnaissance de «l'existence de la nation canadienne-française au Canada, principalement au Québec». Plusieurs options constitutionnelles se présentaient (statu quo, remaniement constitutionnel,

texte du Mémoire, tel qu'il existait en avril 1967, voir le document (portant les corrections de l'ACFÉO) accompagnant la lettre du Secrétaire du Conseil de la Vie française [ $M^{\sharp}$ P.-E. Gosselin] au Secrétaire de l'ACFÉO [Roger Charbonneau], CRCCF, Fonds Robert-Barsalou, P149/1/3.

79 «Procès-verbal du Comité exécutif de l'ACFÉO», Ottawa, 17 mai 1967, copie dans CRCCF, Fonds ACFO, C2/355/3. Deux jours plus tard, Charbonneau communiquait avec Gosselin, l'informant que le Comité exécutif avait étudié le texte du Mémoire et qu'il souhaitait faire deux suggestions: Roger Charbonneau à P.-É. Gosselin, Ottawa, 19 mai 1967, copie dans CRCCF, Fonds ACFO, C2/355/5.

${ }^{80}$ Mémoire des Canadiens français hors du Québec aux États généraux (version de juillet 1967), CRCCF, Fonds ACFO, C2/459/27.

${ }^{81}$ L'Association canadienne-française d'éducation d'Ontario, la Société nationale des Acadiens, l'Association d'éducation des CanadiensFrançais du Manitoba, l'Association culturelle franco-canadienne de la Saskatchewan, l'Association canadienne-française de l'Alberta, la Fédération canadienne-française de la Colombie, la Société Saint-Thomas-d'Aquin de l'Île-du-Prince-Édouard, la Société Saint-Pierre du Cap-Breton. 
fédéralisme coopératif, statut particulier, États associés, séparation) et les minorités étaient d'accord que le Québec obtînt plus de pouvoir, mais «sans jamais perdre de vue que la nation canadiennefrançaise ne se limite pas au Québec». Pour ellesmêmes, les minorités demandaient la reconnaissance de leurs droits fondamentaux, notamment en éducation et dans les services publics. À ce point, le Mémoire devient un peu romantique:

À nos frères de la province-mère, auxquels nous rattachent tant de liens, nous rappelons que si nous avons besoin du Québec, le Québec a également besoin de nous et devrait nous regarder comme le prolongement naturel de la nation canadienne-française à l'extérieur du Québec. La nation canadienne-française accomplira son destin temporel dans la mesure où nos groupes et le Québec offriront un front commun dans un Canada fort. Ce qui nous unit demeure incroyablement plus fort que ce qui nous divise ${ }^{82}$.

L'unité de la nation canadienne-française étant affirmée, c'est sur l'égalité de ses membres que le Mémoire portait ensuite son attention.

Selon le Mémoire des Canadiens français, les minorités ne sauraient participer aux États généraux autrement que sur la base d'une "égalité des droits et des devoirs". Le quart des membres de la nation canadienne-française vivant à l'extérieur du Québec, ils devraient compter pour 25 pour cent tant au comité central et aux commissions, que dans l'ensemble des délégués. Les minorités étaient cependant disposées à accepter le compromis proposé en novembre $1966^{83}$.

${ }^{82}$ Mémoire des Canadiens français hors du Québec aux États généraux (version de juillet 1967), CRCCF, Fonds ACFO, C2/459/27.

${ }^{83}$ On apprend, lors de la réunion du Comité exécutif de l'ACFÉO, le 17 mai 1967, que «Le bulletin de vote des délégués du Québec sera de couleur différente de celui des délégués des autres provinces». Voir le «Procès-verbal du Comité exécutif de l'ACFÉO», 17 mai 1967, copie 
Mais le Mémoire proposait qu'une Commission de six membres (trois du Québec, trois de l'extérieur) devînt «l'autorité suprême pour décider, avant et pendant l'assemblée de septembre, quelles questions devraient être l'objet du vote de tous les délégués et quelles questions devraient être soumises à un vote partiel».

Une troisième question soulevée par le Mémoire des Canadiens français traitait des schémas remis aux participants. Le Mémoire demandait que la plupart soient tout simplement refaits et "orientés dans un sens canadien-français, pas seulement québécois». Le document affirmait que douze des vingt schémas étaient d'intérêt général, cinq d'intérêt québécois et trois d'intérêt pour les groupes minoritaires. Le Mémoire disait explicitement que ses recommandations visaient à freiner le glissement des États généraux sur la pente du séparatisme. Il demandait enfin que «la publicité faite aux États généraux, notamment les déclarations des dirigeants», tînt compte «non seulement de son caractère québécois, mais du véritable caractère canadien-français et démocratique de cette entreprise». Le document fut soumis à la Commission générale, réunie le 10 juin 1967.

Quelques jours plus tard, Roger Charbonneau envoyait une lettre aux 210 délégués de l'Ontario, accompagnée d'une copie du procès-verbal de la réunion de la Commission générale (tenue le 10 juin 1967), pour expliquer à tous comment se déroulerait le vote, lors des assises générales de novembre 1967.

\footnotetext{
dans CRCCF, Fonds ACFO, C2/355/3. Le 10 juin 1967, la Commission générale apprit que la société Bell Canada devait enregistrer les votes automatiquement, un mode de scrutin qui permettrait à tous les délégués de voter sur toutes les questions. Le mécanisme permettrait en outre de «distinguer la provenance des votes», selon qu'ils venaient
} 
LA DÉLEGGATION ONTARIENNE

L'Ontario avait droit à 210 délégués. Comme en 1966, il revint à l'ACFÉO d'assurer, selon des directives très précises reçues de Montréal, une certaine "représentativité corporative». Selon les voux des organisateurs des États généraux, les délégations devaient représenter toutes les parties de la province, principe qui s'appliquait aussi aux délégués choisis par les sociétés affiliées de l'ACFÉO.

Lors de sa réunion du 19 avril 1967, le Comité exécutif de l'ACFÉO décida que la délégation ontarienne comprendrait les directeurs de l'ACFÉO, les membres de son secrétariat, des hauts fonctionnaires du ministère de l'Éducation, les inspecteurs du secondaire, des représentants des quatre régions géographiques, des représentants de sociétés affiliées (qui auront 82 des 210 places) et les délégués d'organismes non affiliés (tels l'Union du Canada, Le Droit, le secteur universitaire, l'Institut canadienfrançais d'Ottawa) ${ }^{84}$. Les 210 membres de la délégation ontarienne se répartissaient ainsi: 57 d'Ottawa, 30 de North-Bay, 36 de Sudbury, 42 de Toronto, 45 de Windsor (ou de leurs régions respectives). Le Droit écrivait: «Selon M. Rosaire Morin, président de la commission technique des États généraux du Canada français, jamais aucune association n'a atteint un tel degré de représentation de la nation ${ }^{85} \%$. Dans les actes des assises générales, on précisa plus tard que "Cette délégation [ontarienne] était organisée par l'Association d'Éducation d'Ontario en collaboration

des dix régions économiques du Québec, ou des neuf autres provinces canadiennes.

${ }^{84}$ "Procès-verbal du Comité exécutif de l'ACFÉO», Ottawa, 19 avril 1967, copie dans CRCCF, Fonds ACFO, C2/355/3.

${ }_{85}$ "Assemblée représentative", dans Le Droit, 18 novembre 1967, p. 3. 
et sous la direction de la Commission générale ${ }^{86}$ \%.

Le Comité exécutif de l'ACFÉO apprit, à sa réunion du 21 juin 1967, que la Commission technique des États généraux obligeait l'ACFÉO à réviser sa liste de délégués dans le dessein de diversifier la délégation, selon les normes prescrites par la Commission technique ${ }^{87}$. À partir de l'été 1967 , des listes commencèrent à se constituer, avec un certain nombre de changements en cours de route (additions, radiations). Dans les archives de l'ACFÉO, il subsiste deux listes de délégués, une première datée de septembre 1967 et la seconde de novembre 1967. Elles sont presque identiques, sauf que certains noms ne figurent que sur l'une ou l'autre ${ }^{88}$.

Parmi la délégation ontarienne, largement recrutée dans la mouvance de l'ACFÉO (et done de la "patente»), il y avait cependant un groupe de «jeunes turcs», apparemment plus sympathiques aux revendications des Québécois (on peut, par exemple, mentionner les noms des délégués Pierre Allard, Rémy Beauregard, Victor Lapalme, Jean-Louis Renaud) qui, par calcul politique, espéraient faire débloquer le dossier constitutionnel en appuyant les revendications, mêmes extrêmes, des néonationalistes québécois. Lors des délibérations, quelques membres de ce groupe

\footnotetext{
${ }^{86}$ Michel Pelletier, «Rapport d'activités», dans Les États généraux du Canada français. Assises nationales tenues d la Place des Arts de Montréal du 23 au 26 novembre 1967 ([Montréal, Éditions de L'Action nationale, s.d.]), p. 30.

${ }^{87}$ «Procès-verbal du Comité exécutif de l'ACFÉO», 21 juin 1967, copie dans CRCCF, Fonds ACFO, C2/355/3.

88 Voir les deux listes, préparées en septembre et novembre 1966: "Liste des délégués de l'Ontario aux Etats généraux - septembre 1966" et "Liste des délégués de l'Ontario aux Etats généraux», CRCCF, Fonds ACFO C2/459/27. Les modifications correspondaient à la radiation de vingt-quatre noms et a l'addition de vingt et un autres.
} 
(Renaud, Lapalme) prirent la parole pour défendre des positions nettement plus pro-québécoises que celles de leurs aînés de l'ACFÉO. Ce «groupe de jeunes», selon Le Droit, se composait d'environ vingt-cinq personnes.

\section{LES RENCONTRES PRÉLIMINAIRES DES DÉLÉGUES}

Conformément aux vœux de la Commission générale, l'ACFÉO organisa des «rencontres préliminaires» des délégués, auxquelles des représentants de la Commission devaient participer. On décida d'abord de tenir des rencontres dans cinq régions ${ }^{89}$. Roger Charbonneau informa les délégués qu'ils devaient participer aux sessions régionales et que celles-ci auraient lieu le $1^{\text {er }}$ octobre 1967. En préparation de ces rencontres, l'ACFÉO envoya deux documents: premièrement le texte du Mémoire des Canadiens français hors Québec, deuxièmement un extrait du procès-verbal de la réunion de la Commission générale ${ }^{90}$. Charbonneau envoyait aussi une liste des 210 délégués de l'Ontario, plus les noms des substituts qui pourraient éventuellement remplacer les délégués. Pour bien délimiter la nature des responsabilités individuelles, la note précisait que «Le représentant d'une association siège aux assemblées régionales et nationales à titre personnel ${ }^{91} »$.

\footnotetext{
${ }^{89}$ Pour la réunion du 8 octobre (elle eut lieu, de fait, le $1^{\text {er }}$ octobre), on avait désigné les responsables suivants: pour la rencontre de Sudbury, A.E. Charette, pour Ansonville, Emest C. Lapalme, pour Toronto, Ryan Paquette (remplacé par Jacques Dubois), pour Windsor, Joseph Goulet, et, pour Ottawa, Roger Charbonneau.

90 «Memo du Comité exécutif de l'ACFÉO aux 210 délégués», 9 août 1967, CRCCF, Fonds ACFO, C2/459/23.

91 "Memo du Comité exécutif de l'ACFÉo aux 210 délégués», 13 septembre 1967, CRCCF, Fonds ACFO, C2/459/23.
} 
Au total, 177 délégués participèrent à ces rencontres régionales. Le «Sommaire des rapports des réunions régionales" rapporta le résultat des votes, les présences et une description du déroulement. Les délégués qui participèrent à la rencontre de la région North-Bay/Sudbury/Sault-Sainte-Marie adoptèrent une résolution suggérant que «l'ACFÉO prenne l'initiative de convoquer une réunion des délégués d'Ontario au début des assises pour discuter des problèmes qui regardent particulièrement les [F]ranco-[O]ntariens ${ }^{92}$ ». En fait, il n'y eut pas de rencontre de l'ensemble de la délégation ontarienne.

En résumé, le travail préparatoire prit trois formes. D'abord, l'encouragement donné aux délégués de faire la lecture des documents qu'on leur remettait (les "Cahiers des États généraux»); ensuite l'incitation faite aux délégués ontariens de se répartir dans les diverses commissions (au lieu de se concentrer dans quelques commissions seulement); enfin, les réunions préliminaires régionales. La délégation ne se retrouva réunie qu'à Montréal, juste avant les assises.

Même si l'ACFÉO avait été le maître d'œuvre de la constitution de cette délégation franco-ontarienne, celle-ci ne fonctionnait pas en bloc. Ce n'est que la veille des assises générales, à Montréal, que la délégation tint à huis clos une séance «houleuse», où les deux principaux protagonistes furent Séraphin Marion (partisan d'un renforcement du Québec) et Roger Duhamel (partisan d'une grande fermeté contre les velléités séparatistes). À cette soirée participèrent

92 «Sommaire des rapports des réunions régionales aux États généraux", octobre 1967; "Rapport des rencontres régionales", avec une copie du procès-verbal du Conseil d'administration de l'ACFÉO, 28 octobre 1967, CRCCF, Fonds ACFO, C2/355/3. 
aussi le père Richard Arès et Rosaire Morin.

En arrivant à Montréal, en novembre 1967, les délégués reçurent vingt (20) documents de travail ${ }^{93}$. Selon l'analyste de l'ACFEO (Charbonneau?), ces documents «disparates et non numérotés», et couvrant un grand nombre de sujets, ne traitaient que du Québec. L'analyste parlait d'un «ensemble disparate de questions qui se recoupent en plusieurs endroits. Elle [la documentation] témoigne d'un manque de préparation intellectuelle assez explicable et d'une certaine ignorance du fait français hors du Québec au sein de l'équipe qui dirige les États généraux". Le document de l'ACFÉO réclamait un plan précis, une meilleure documentation et demandait de «ne pas se laisser hypnotiser par l'aspect politique des problèmes. L'État n'est pas seul en cause ${ }^{94}$." Quant aux dirigeants des États généraux, ils se réconfortaient à l'idée que les documents provenaient de «spécialistes» et qu'ils abordaient «deux pôles principaux: la recherche de pouvoirs essentiels au Québec et des droits naturels des Canadiens-Français établis à l'extérieur du Québec ${ }^{95} »$.

Les deux questions qui préoccupaient les minorités (l'égalité des délégués d'une part, la définition du terme «nation» d'autre part) n'étaient qu'à moitié réglées. Sur la question du droit de vote, la solution

${ }^{93}$ Les documents de travail ont été publiés: États généraux du Canada français. Exposés de base et documents de travail ([Préface de Jacques-Yvan Morin, Montréal, L'Action nationale], 1967), 277 p. Ces documents constituent, par ailleurs, les numéros de L'Action nationale 57(3-4), novembre-décembre 1967, pp. 213-485.

${ }^{94}$ [Document non daté et non identifié analysant la vingtaine d'instruments de travail distribués en novembre 1967], texte de trois pages se trouvant dans le CRCCF, Fonds ACFO, C2/355/4.

${ }^{95}$ Michel Pelletier, «Rapport d'activités», dans Les États généraux du Canada français. Assises nationales tenues d la Place des Arts de Montréal du 23 au 26 novembre 1967 ([Montréal, Éditions de L'Action nationale, s.d.]), p. 31 . 
avait été trouvée en décidant que tous les délégués voteraient sur toutes les questions, mais que les résultats seraient "compartimentalisés" pour qu'on sache comment chaque région (Acadie, Québec, Ontario, Ouest) avait voté. Sur la deuxième question (qui forme la «nation»?), la réponse tardait. À la veille des assises de novembre 1967, l'éditorialiste du Devoir, Claude Ryan, avait nettement proposé une réponse: «Si la nation canadienne[-]française est "répandue dans tout le Canada" et y possède partout des droits certains, pourquoi son "territoire national", même si elle doit le partager avec d'autres, ne serait-il pas avant tout le territoire canadien? Si on ne veut parler que du Québec, pourquoi le territoire évoqué par ce mot n'appartiendrait-il pas à tous les habitants du Québec, sans aucune distinction d'origine, de groupe ethnique ou de religion ${ }^{96}{ }^{\text {" }}$

\section{LES ASSISES GÉNÉRALES DE NOVEMBRE 1967}

Les assises générales se déroulèrent à Montréal (à la Place des arts), du 23 au 26 novembre 1967. Plus de 2000 délégués s'inscrivirent: 1575 délégués des comtés du Québec, 167 représentants d'associations officielles, 364 délégués des Canadiens-Français venant des neuf autres provinces canadiennes, 436 observateurs $^{97}$. Tout commença, dès le jeudi matin, par une querelle de drapeaux; en fin de compte,

${ }^{96}$ Éditorial de Claude Ryan, "À la veille des États généraux», dans Le Devoir, 22 novembre 1967, p. 4.

${ }^{97}$ Les États généraux du Canada français. Assises nationales tenues da la Place des Arts de Montréal du 23 au 26 novembre 1967 ([Montréal, Éditions de L'Action nationale, s.d.]), p. 5. Ces actes furent aussi publiés comme numéro de L'Action nationale, volume 57, numéro 6, février $1968,383 \mathrm{p}$. Ces actes contiennent les débats en assemblée générale (mais non les débats des quatre ateliers, ni de leurs dix-sept sous-groupes d'études). 
après les huées et le reste, il resta sur scène onze drapeaux québécois et un drapeau acadien. Mais pas de drapeau canadien.

Les organisateurs regroupèrent les délégués en 255 équipes d'analyse, de huit membres chacune; la synthèse de leurs discussions prenait ensuite le chemin de dix-sept groupes d'études, où devait se dégager «le dénominateur commun recherché». Dans ces groupes d'études, l'accent devait être mis sur les opinions, mais "sans polémique ni critique». Ainsi devaient émerger les «avant-projets de résolution». Enfin, à un troisième niveau, les délégués (environ 500) se retrouvaient dans des ateliers de travail. Ici, on suivait la méthode de travail suivante: les délégués se répartissaient en cinq groupes, chargés qui de s'interroger sur les projets de résolution (le groupe d'interrogation), qui d'en amplifier la portée (le groupe d'amplification), qui d'y proposer des nuances (le groupe des nuances), qui de soulever des objections (le groupe d'opposition), qui de les appuyer (le groupe d'appui). Cette méthode, inspirée par «l'animation sociale», explique comment les documents de travail, préparés antérieurement, se transformèrent en propositions de plus en plus radicales. Il s'avéra que tous ces groupes orientèrent les résolutions dans un même sens, c'est-à-dire le séparatisme.

L'adoption des propositions ne dépendait pas d'une simple majorité. En fait, lors du comptage des votes, "la nation" était divisée en quatre régions: le Québec, l'Ontario, l'Acadie et l'Ouest canadien. Pour adopter une résolution, il fallait obtenir deux tiers des voix, mais seulement dans "la région concernée $e^{98}$ ». En

${ }_{98}$ Pour la description détaillée des procédures, voir le discours de Rosaire Morin, "La procédure des Assises", dans Les États généraux 
outre, l'Assemblée adopta une règle de procédure qui empêchait les amendements et qui limitait les débats à 40 minutes sur chaque proposition. Le choix des intervenants se décidait au sort.

La matière était divisée en quatre grands sujets (culturel, social, économique, politique), chacun étant divisé en quatre ou cinq sous-ateliers. Dans l'atelier culturel, il y avait quatre sous-ateliers (l'enseignement et la recherche, le statut de la langue française, la radio et la télévision, les relations entre CanadiensFrançais), de même que dans l'atelier social (législation du travail, peuplement et immigration, sécurité sociale et santé, famille et politique familiale). L'atelier économique se divisait en cinq parties (législation financière et commerciale, politique fiscale, développement économique par la planification, politique agricole, monnaie et banque), et l'atelier politique en quatre (arbitrage constitutionnel et organisation pénale, intégrité du territoire québécois, pouvoirs extensibles, relations internationales). Pour chaque sujet de sous-atelier, on avait préparé d'abord un "exposé de base" sur la question, mais aussi un "document de travail" soulevant les questions pertinentes et proposant des réponses éventuelles 99 . Partout, on écrivait que ces documents n'étaient destinés qu'à la discussion, qu'ils n'épuisaient pas la question. Mais «l'astuce», c'est qu'un biais informait tous les documents.

Le ton de la rencontre fut donné dès le vendredi matin (le 24 novembre 1967), quand un membre de

du Canada français. Assises nationales tenues a la Place des Arts de Montréal du 23 au 26 novembre 1967, pp. 17-20.

${ }^{99}$ États généraux du Canada français. Exposés de base et documents de travail, préface de Jacques-Yvan Morin, [Montréal, États généraux du Canada français], 1967, $277 \mathrm{p}$. 
la Commission générale soumit une résolution appelée la «Déclaration préliminaire sur le droit d'autodétermination». La proposition, émanant de la direction des États généraux, fut soumise à la fin d'un discours de François-Albert Angers ${ }^{100}$. Après avoir postulé une série d'attendus (que les Canadiens-Français forment un peuple, que ce peuple est concentré au Québec, qu'íls disposent d'un État de langue et de culture françaises, que la vie et l'épanouissement dépendent du rayonnement du Québec), et après avoir cité l'article premier (par. 2) de la Charte des Nations-Unies qui exige «le respect de l'égalité des droits des peuples et de leur droit à disposer d'eux-mêmes", l'assemblée a déclaré, en trois points, que "Les Canadiens-Français forment une nation", que le territoire national de cette nation est le Québec et que la nation canadienne-française a le droit de disposer d'elle-même et de choisir librement son régime politique $^{101}$. Cette résolution, exceptionnellement, n'eut pas à franchir les trois étapes normalement prévues (c'est-à-dire les "groupes d'études», les «ateliers de travail» et "l'assemblée générale»).

Les minorités, s'appuyant sur la série d'attendus du Mémoire des Canadiens français, tentèrent vainement de présenter une contre-proposition. Les minorités voulaient réaffirmer que «Les Canadiens français étaient citoyens d'un même pays et d'un même État», que les groupes français avaient conscience d'appartenir à la

${ }^{100}$ François-Albert Angers, «Déclaration préliminaire sur le droit d'autodétermination», dans Les États généraux du Canada français. Assises nationales tenues d la Place des Arts de Montréal du 23 au 26 novembre 1967, p. 41.

101 Projet de déclaration préliminaire [Montréal, 24 novembre 1967], CRCCF, Fonds ACFO, C2/355/3. Le texte officiel de cette résolution se trouve dans Les États généraux du Canada français. Assises nationales tenues d la Place des Arts de Montréal du 23 au 26 novembre 1967, p. 42. 
nation canadienne-française, que les États généraux devaient affirmer l'unité de la nation canadiennefrançaise, tout en réclamant un Québec fort avec des pouvoirs suffisants. Ces délégués se déclarèrent par conséquent «incapables de se rallier au projet de déclaration préliminaire soumis par la Commission générale à l'Assemblée du 24 novembre $1967^{102}$ ».

Lors des discussions, un délégué de la jeunesse franco-ontarienne, Jean-Louis Renaud, se présentant comme «le porte-parole d'un groupe de jeunes Franco-Ontariens», apporta son appui à la proposition, tout en soumettant deux amendements. Hervé Cyr, de Toronto, après avoir noté la générosité du Québec envers les minorités, notamment à l'époque du Règlement XVII (1912-1927), affirma que les Canadiens-Français des autres provinces étaient les "défenseurs sur la première ligne de défense». Enfin, Albert Régimbal, de Sudbury, se leva pour proposer trois amendements. La présidente de la séance rappela aux délégués que la procédure n'admettait pas les amendements ${ }^{103}$. Par la suite, un autre jeune délégué de l'Ontario, Victor Lapalme, se leva pour «se rallier à la position prise par la jeunesse franco-ontarienne», mais cet étudiant en sciences politiques affirma que les minorités n'agissaient qu'à "court terme», alors que le Québec «commençait» à penser à long terme ${ }^{104}$.

102 "Les Canadiens français hors du Québec et participant aux États généraux du Canada français...», [amendement proposé au "Projet de déclaration préliminaire, 24 novembre 1967], copie dans CRCCF, Fonds ACFO, C2/355/3.

${ }^{103}$ "Débats sur la déclaration préliminaire", interventions de JeanLouis Renaud, Hervé Cyr et Albert Regimbal [écrit "Régimbald" dans le procès-verbal], dans Les États généraux du Canada français. Assises nationales tenues à la Place des Arts de Montréal du 23 au 26 novembre 1967, pp. 43-44.

104 "Débats sur la déclaration préliminaire», intervention de Victor Lapalme, 
Cette résolution sur l'autodétermination fut le cour des assises générales en 1967. La résolution soumise par la Commission générale fut approuvée à $98 \%$ par les délégués québécois, à $52 \%$ par les Acadiens, mais ne recueillit que $35 \%$ des votes ontariens et $30 \%$ des délégués de l'Ouest.

Le groupe d'études (le deuxième niveau) qui se penchait sur les «relations entre Canadiens-Français» produisit un résultat assez banal, réitérant que «les Canadiens-Français à l'extérieur du Québec" se considéraient comme des membres de «la grande nation canadienne-française». Le groupe réclama plus d'aide des pouvoirs publics, surtout pour les institutions culturelles, et proposa d'accroître les échanges entre les parties de la communauté nationale. On souhaitait aussi que le gouvernement de Québec "prenne tous les moyens pour assumer pleinement son rôle vis-à-vis [de] la nation canadienne-française». Une foule de résolutions furent préparées. Comme dans les autres sous-ateliers, les propositions étaient identifiées selon qu'elles s'adressaient "au Québec" ou à «l'extérieur du Québec». Par exemple, dans l'atelier de travail culturel (troisième niveau), les résolutions des minorités demandaient une reconnaissance juridique du français, l'extension des services de radio et de télévision ${ }^{105}$.

À la séance du samedi matin (25 novembre 1967), l'assemblée étudia des résolutions "pour le Québec" et d'autres pour «l'extérieur du Québec». Le délégué

dans Les États généraux du Canada français. Assises nationales tenues da la Place des Arts de Montréal du 23 au 26 novembre 1967, p. 46.

105 «Les relations entre Canadiens-Français», section intitulée «Groupes établis hors du Québec", dans Les États généraux du Canada français. Assises nationales tenues da la Place des Arts de Montréal du 23 au 26 novembre 1967, p. 63. Pour «l'atelier culturel», voir ibid., pp. 90-94. 
Yvan Roy (Richmond, Qc), devant l'hostilité de certains gouvernements anglais dans le dossier scolaire, se demanda s'il ne faudrait pas créer un ministère fédéral des minorités et, ailleurs, un "collège canadien-français élu par les Canadiens-Français». Yves Laflamme (D'Arcy-McGee, Qc) proposa d'accorder à la minorité anglo-québécoise, "exactement" ce que les autres provinces accordaient à leur minorité française. M.-J. Mercier (Bourget, Qc), s'adressant aux délégués des provinces anglaises, affirma qu'ils n'obtiendraient jamais le même traitement que les Anglo-Québécois. Il indiqua que dans un Québec indépendant, tous apprendraient «la langue de ce pays".

De nombreuses résolutions demandaient, à l'avantage exclusif de la province de Québec, la suprématie en toutes sortes de questions, telles que le syndicalisme, la législation ouvrière, le transport, les communications. Les délégués approuvèrent très largement (selon les régions, l'accord variait entre $\mathbf{7 2} \%$ et $94 \%$ ); l'Ontario n'appuya qu'à $26 \%$. L'atelier des questions financières et commerciales proposa que le Québec détienne en exclusivité tous les pouvoirs touchant l'activité financière. Cet atelier rapporta aussi, "pour les délégués de l'extérieur du Québec», des recommandations d'établir des missions commerciales canadiennes-françaises pour visiter les minorités et de créer des entreprises pour prendre possession des fonds canadiens-français. L'Ontario français n'appuya ces propositions qu'à $47 \%$ ( $22 \%$ d'abstentions). L'atelier sur le «statut de la langue française au Québec" soumit à l'assemblée douze résolutions pour le Québec, et trois «hors Québec» (faire reconnaître le statut juridique du français, établir un réseau de radio et télévision, faire du français une langue 
officielle au Nouveau-Brunswick). La délégation ontarienne appuya ces résolutions à $51 \%$ seulement (22\% d'abstention).

L'atelier social traita de peuplement et d'immigration. Au cours des discussions sur les recommandations de cet atelier, Laurent Isabelle, d'Ottawa, se leva pour souligner qu'en demandant pour les Franco-Ontariens le même droit que les Anglo-Québécois, et qu'en demandant par ailleurs que les Anglo-Québécois n'étudient en anglais qu'au secondaire, on demandait en fait que les FrancoOntariens aussi n'étudient en français qu'à partir du secondaire. Or ils étudiaient déjà en français au primaire. Dans cette même logique, les résolutions demandaient donc à l'Ontario de maintenir l'unilinguisme anglais et d'empêcher les conseils municipaux et les conseils scolaires de fonctionner en français en Ontario:

Cela veut dire, je pense, monsieur le Président, qu'au profit de cinq millions, c'est le génocide d'un million. La fin ne justifie pas tous les moyens et quant à cesser, il est peu probable que ce million veuille émigrer en bloc au Québec, parce que Franco-Ontarien pour ma part, le territoire national pour moi, c'est l'Ontario, c'est le Canada, le Québec y compris ${ }^{106}$.

L'Ontario français vota à $53 \%$ seulement en faveur de cette proposition touchant le peuplement et l'immigration, l'intégration des immigrants et des dizaines de sujets, tous englobés dans la même résolution émanant de «l'atelier social»; chez les délégués du Québec, selon les zones, le vote varia entre $89 \%$ et $100 \%$ en faveur.

106 Section «Le peuplement et l'immigration», intervention de Laurent Isabelle, dans Les États généraux du Canada français. Assises nationales tenues d la Place des Arts de Montréal du 23 au 26 novembre 1967, p. 136. 
L'atelier de "la politique fiscale» accoucha d'une souris: il demanda que le Québec «détienne les ressources nécessaires à son expansion économique». Le premier intervenant, de l'Ontario, fut Michel Perrault, professeur à l'université Laurentienne. Il rappela aux délégués québécois qu'ils avaient adopté la veille une résolution disant que «La nation canadienne-française avait le droit de disposer d'elle-même». L'atelier sur «l'intégrité du territoire», non content de réclamer le contrôle exclusif de tout le territoire provincial du Québec, demandait aussi l'éventuelle annexion de la Terre de Baffin, la reprise du Labrador, l'expropriation des terres fédérales au Québec, le contrôle de l'espace aérien, etc. Le premier intervenant fut un Ontarien, Bernard Benoît, qui loua le contenu audacieux de cette résolution, dont la clarté devrait servir d'exemple. Jacques de Courville Nicol [le procès-verbal écrit "Nichols"] déclara qu'il y avait unanimité sur la résolution, sauf pour la question du Labrador, où il faudrait tenir compte «du petit peuple qui vit sur le territoire du Labrador", pour respecter son droit à l'autodétermination, lui aussi. Le délégué rappela que l'annexion de la Terre de Baffin ne faisait pas partie des documents préliminaires, et il suggéra d'enlever cette partie. Sur ces résolutions, la délégation ontarienne vota oui à $58 \%$ (avec $16 \%$ d'abstentions), alors que les dix zones québécoises approuvaient avec des majorités entre $94 \%$ et $100 \%$.

L'atelier de «la radio et la radiodiffusion» réclama que la province de Québec prît la responsabilité exclusive, sur son territoire, de tout ce secteur en établissant un "organisme souverain de régie», une société d'exploitation (Radio-Québec), de même qu'un contrôle sur «tous les autres modes de 
LES «ÉTATS GENÉRAUX DU CANADA FRANÇAIS»

communication et "mass media", outils de culture populaire». Pour les minorités, on demandait un «organisme paritaire» où elles seraient représentées également aux Anglo-Canadiens. Marc-Yvain Giroux, de Welland, se prononça contre ces propositions. Il défendit le rôle de Radio-Canada, un des rares organismes où les Canadiens-Français avaient reçu un traitement plus équitable. Si le Québec obtenait un «droit exclusif», les autres provinces en réclameraient autant, ce qui serait nuisible aux groupes minoritaires. Qui financerait alors les services en français? Seulement $26 \%$ de la délégation ontarienne appuya ces résolutions (au Québec, l'approbation variait entre $81 \%$ et $97 \%$ ).

Au cours des discussions autour des résolutions de l'atelier sur "la sécurité sociale», certains délégués notèrent que les minorités ne s'opposaient pas au retrait du Québec des programmes conjoints fédéraux. La moitié de la délégation ontarienne approuva (à $51 \%$, soit 38 voix) les résolutions. L'atelier du «développement économique» abonda dans le sens des autres ateliers, demandant que le gouvernement de Québec détienne seul la responsabilité exclusive en matière de planification. Au cours de cette discussion, le délégué ontarien Bernard Benoît intervint (sur la question de la radiodiffusion, donc hors contexte) pour dire que les minorités réclamaient trois choses, l'éducation en français, la radiodiffusion en français et la garantie de leurs droits religieux: la première s'adresse au gouvernement provincial, la deuxième au fédéral et la troisième à l'Église. Il évoqua même l'hypothèse que Radio-Québec établisse «un satellite qui rayonne sur tout le Canada». Lors des discussions sur la résolution financière, Laurent Isabelle intervint pour déplorer la «tendance générale 
vers l'exclusivité que revêt cette résolution comme plusieurs résolutions précédentes d'ailleurs». Il proposa une route plus mitoyenne: "c'est évident que c'est l'optique d'un minoritaire. Ne nous oubliez pas!» Cette résolution n'obtint que $44 \%$ (soit 17 voix) de la délégation ontarienne.

Lors des discussions, en assemblée générale, des résolutions sur "les relations entre CanadiensFrançais», Albert Regimbal [écrit «Regimbald» dans le procès-verbal] appuya "le plus vigoureusement» possible la résolution demandant plus d'échanges et rappelant que les minorités faisaient partie de la nation canadienne-française. Cette question était pour lui «le cœur du problème des États généraux». Mais Regimbal s'en prenait au radicalisme triomphant partout aux États généraux. Le Canada français a besoin d'un Québec fort, certes, mais

le radicalisme québécois dont nous sommes témoins, ici, aux États généraux, inquiète profondément les CanadiensFrançais non-Québécois [sic] ou, comme on dit déjà assez désobligeamment, d'outre-frontières. Ce radicalisme explique en grande partie plusieurs abstentions et même le départ de plusieurs des nôtres. Les Anglo-Canadiens, les plus fermés à la réalité française au Canada, n'ont jamais, à aucun moment de notre vie collective d'outre frontières, posé de geste aussi cruel que celui que se prépare à poser le séparatisme québécois à l'endroit des minorités françaises [...] Le séparatisme québécois est en train d'étouffer nos demiers espoirs, à mon sens; un séparatiste québécois ne peut pas sincèrement voter "oui» à la présente résolution sans être en contradiction avec lui-même. J'invite donc tous les délégués à voter à $100 \%$ en faveur de cette résolution ${ }^{107}$.

${ }^{107}$ «Les relations entre Canadiens-Français», intervention d'Albert Regimbal, dans Les États généraux du Canada français. Assises nationales tenues d la Place des Arts de Montréal du 23 au 26 novembre 1967, p. 170. 
Marc-Yvain Giroux intervint aussi pour appuyer la résolution, lui aussi «à cent pour cent». Il faisait partie de «ces cent soixante fidèles de l'extérieur ou des Franco-Ontariens qui demeurent présents, puisque je présume qu'une présence vaut mieux qu'une absence». Lors du vote, la délégation ontarienne appuya à $93 \%$ (soit 28 voix), sans abstention et deux voix contre. Quant aux dix zones du Québec, elles appuyèrent à $96 \%$ (856 voix), l'Acadie à $91 \%$ (38 voix) et l'Ouest à $74 \%$ seulement (52 voix). Au total, lors de ce vote, seulement 1035 délégués votèrent, dont 30 seulement pour l'Ontario.

L'atelier de "la famille et la politique familiale» réclama à son tour des compétences exclusives pour le Québec. Seulement 25 délégués ontariens votèrent. En "politique agricole», on réclama d'autres "compétences exclusives» et, lors du vote (dimanche matin), il n'y avait plus que 23 délégués ontariens qui votaient. Dans les "relations internationales", on demanda que le Québec dirigeât ses propres relations internationales et qu'il adhérât aux organismes internationaux. Lors de ce vote, seulement 22 voix ontariennes s'exprimèrent (il y en avait 865 du Québec, 22 de l'Acadie et 64 de l'Ouest). L'atelier «monnaie et banque» proposa de créer la "Banque du Québec» et que celle-ci participât avec la Banque du Canada à la politique monétaire. Seulement 20 Ontariens participèrent à ce vote (dont $30 \%$ seulement appuyaient la proposition).

Dans un tableau récapitulatif des votes sur les dix-sept résolutions, on peut voir qu'en moyenne, seulement 63 des 188 délégués ontariens ont voté sur les résolutions. Sur le vote touchant l'autodétermination, 166 Ontariens votèrent, puis 110 sur la 
résolution suivante, puis le chiffre baissa à chaque vote, pour n'être plus que 22 votants sur la dernière résolution ${ }^{108}$.

À la séance de clôture, le dimanche 26 novembre 1967, Rosaire Morin et Jacques-Yvan Morin firent chacun un discours.

\section{LES PREMIĖRES RÉACTIONS}

En demandant, dans tous les domaines, une «juridiction exclusive" pour le Québec, les délégués confortèrent l'idée que les États généraux avaient un parti pris en faveur de la séparation. À preuve, l'accueil très enthousiaste réservé à René Lévesque ${ }^{109}$, récemment séparé du parti libéral et promoteur de la souveraineté-association, disait assez les sympathies politiques des délégués. Pourtant, les dirigeants ne cessaient de répéter qu'ils ne privilégiaient aucune

$\overline{108}$ Pour le détail de tous ces votes, voir Les États généraux du Canada français. Assises nationales tenues a la Place des Arts de Montréal du 23 au 26 novembre 1967 et voir le compte rendu des interventions et le tableau de résultats des votes, chapitre V, "Débats de l'Assemblée", pp. 107-187; dans le chapitre VI, contenant les résolutions et les votes, la section «Résultats des votes de l'Ontario» dresse le bilan des votes sur les 17 résolutions adoptées, p. 213.

${ }^{109}$ Lors de son passage aux États généraux, René Lévesque reçut ce que le journaliste Gilles Lesage appela "une réception extrêmement chaleureuse de la très grande majorité des délégués», l'ovation la plus importante de toute la fin de semaine. Dans une déclaration subséquente à la presse, Lévesque déclara que les États généraux lui semblaient «fort importants parce qu'ils réunissaient une bonne partie de la population "influente" du Québec; dans son sens le plus riche, des gens qui, en dehors des partis politiques, expriment de façon authentique ce que pensent les Québécois d'aujourd'hui; stratégiques, d'une part, les Etats généraux expriment une volonté de plus en plus nombreuse et déterminante qui s'en va vers un Québec libre». Lévesque se félicitait aussi de l'ortentation des résolutions qui se rapprochent de celles de son groupe de souveraineté-association. Voir Gilles Lesage, "M. Lévesque est reçu avec enthousiasme aux États généraux», dans Le Devoir, 27 novembre 1967, p. 5. 
option et qu'il n'y avait pas de scission entre les délégués québécois et les groupes provenant des minorités françaises du Canada.

La presse fut un peu surprise par le radicalisme des propositions. L'éditorialiste du Devoir, Claude Ryan, écrivit que le rassemblement avait pris, dès le premier jour, «l'allure d'une réunion indépendantiste", une tendance confirmée "avec le choix des nouveaux membres de la Commission générale et l'adoption des dernières résolutions ${ }^{110}$ ". Le 25 novembre, l'éditorial de Marcel Gingras, dans Le Droit, titrait: «Pas de panique, s.v.p.». Selon l'éditorialiste, il ne fallait pas trop s'émouvoir, «encore qu'il faille condamner l'incommensurable bêtise de ceux qui ont hué le délégué qui réclamait la présence sur la scène du drapeau canadien à côté du drapeau québécois». Gingras notait toutefois que "plus grave toutefois [était] l'hostilité manifestée en ateliers de travail envers les francophones des provinces anglaises, ces héros des avant-postes de résistance qui, au prix de très lourds sacrifices, gardent vivante la flamme française hors des frontières du Québec. Le respect qu'on doit aux gens dans l'épreuve commande qu'on les écoute avec plus d'attention que d'autres; c'est là simple civilité ${ }^{111}$." Cependant, concluait Gingras, il faudrait s'alarmer si le même climat se répandait en assemblée générale.

Deux jours plus tard, le lundi 27 novembre, Le Droit accordait beaucoup de place aux Etats généraux en première page. L'envoyé spécial Jules Labelle résumait ainsi les résultats: «Moyennant la mise en

${ }^{110}$ Claude Ryan, dans Le Devoir, 27 novembre 1967.

11 Éditorial de Marcel Gingras, «Pas de panique, s.v.p.», dans Le Droit, 25 novembre 1967, p. 6. 
vigueur des mesures demandées dans les résolutions qu'ont adoptées les États généraux du Canada français, la province de Québec deviendrait un État souverain et autonome, avec peu de vestiges de la Confédération canadienne ${ }^{112}$.»

Dans un nouvel éditorial, Marcel Gingras accusait les délégués québécois d'avoir traité les minorités "exactement comme nos compatriotes de langue anglaise se sont toujours comportés à l'endroit de tous les Canadiens de langue française». L'accueil réservé aux minorités avait offusqué l'éditorialiste:

Hostilité ouverte ou mal dissimulée, indifférence et froideur ou, pis encore, condescendance couverte d'un sourire en coin, tout y passait à mesure que se déroulaient les travaux. Chaque fois qu'un délégué de l'extérieur du Québec prenait la parole, sarcasmes et huées saluaient ses propos, sauf s'il louait ou approuvait un point quelconque des résolutions à l'étude. [...] la seule mention des mots Ottawa ou Confédération et même du mot Canada suscitait une volée de huées aux séances plénières [...] il n'y avait d'égalité et de liberté que pour les délégués du Québec, tout comme aux réunions pancanadiennes, il n'y a égalité réelle que pour nos compatriotes anglophones qui eux, cependant, ont la décence de nous laisser parler, même s'ils ne tiennent ensuite aucun cas de nos propos et observations.

Gingras s'interrogeait sur l'avantage que le Québec tirerait à la disparition des minorités:

Que perd le Québec à la présence et à l'épanouissement des minorités? Les minorités sont-elles un obstacle à la marche du Québec sur la voie du progrès? Pour plusieurs délégués québécois aux États généraux, il est évident qu'elles le sont. En cela encore, ils ressemblent à s'y méprendre aux anglophones qui nous refusent le droit à notre culture, ne comprenant pas que construire une école

$\overline{112}$ Jules Labelle, «Les pleins pouvoirs pour le Québec», dans Le Droit, 27 novembre 1967 , p. 1 . 
française ne coûte pas plus cher que construire une école anglaise.

Enfin, l'éditorialiste du Droit loua les appels de Jacques-Yvan Morin et de Rosaire Morin pour le respect des opinions, mais blâma les fédéralistes qui n'avaient pas assez participé aux États généraux, de même que les hommes d'affaires. Le gouvernement de la province de Québec, les autres gouvernements provinciaux, le gouvernement fédéral, tous devaient agir rapidement ${ }^{113}$.

Au Canada anglais, les États généraux firent peu de bruit, sauf au moment même des assises, quand les journaux en traitèrent comme d'une nouvelle. Avec un peu plus de recul, la Canadian Annual Review 1967 dressa un bilan des assises de novembre 1967 et nota surtout le radicalisme révolutionnaire des résolutions (texte de Paul Stevens et John Saywell) ${ }^{114}$. Dans les deux années suivantes (1968 et 1969), la Canadian Annual Review ne reviendra plus jamais sur les États généraux, peut-être parce qu'on ne les considérait plus comme un porte-parole de l'ensemble de la population. Le Canadian News Facts aussi notait le caractère ultra-nationaliste des résolutions adoptées à Montréal. On notait en plus que les séparatistes agressifs avaient dominé les débats, que l'assemblée chahutait tous ceux qui défendaient la Confédération. Mais la presse parla peu des États généraux.

Le ministre des postes, Jean-Pierre Côté, qui était le seul ministre fédéral présent aux États généraux, mais avec le statut d'observateur seulement, déclara

${ }^{113}$ Éditorial de Marcel Gingras, «Des États généraux à l'anglo-saxonne», dans Le Droit, 27 novembre 1967, p. 6.

${ }^{114}$ John Saywell (dir.), Canadian Annual Review for 1967 [Toronto], University of Toronto Press, [c1968], p. 72. 
que les États généraux n'étaient pas représentatifs de l'ensemble de la population, ajoutant même que l'assemblée avait été menée de manière fasciste parce que personne ne pouvait s'opposer aux résolutions présentées ${ }^{115}$. Le président du parti progressiste-conservateur du Québec et maire de Granby, Paul-O. Trépanier, fut le seul délégué du Québec à s'opposer publiquement à la résolution sur l'autodétermination ${ }^{116}$.

\section{LA DÉCLARATION DE L'ACFÉO (27 NOVEMBRE 1967)}

Dès le samedi (25 novembre), les délégations du Manitoba (30 membres) et de l'Alberta ( 24 membres) avaient déploré, dans un communiqué, les positions séparatistes adoptées par les États généraux. La délégation manitobaine avait même menacé de faire claquer la porte, mais elle resta, comme les autres minorités, malgré son impuissance à changer l'orientation déjà contenue dans les documents de travail. Comment a réagi la délégation ontarienne? Le secrétaire général de l'Association, Roger Charbonneau, écrivit au président Roger Séguin: «Les quarante délégués qui sont venus à ma chambre samedi ont décidé que l'ACFÉO devait publier un communiqué au sujet des États généraux ${ }^{117}$." Ainsi, les représentants de l'ACFÉO préparèrent une déclaration qui fut envoyée à la presse pour diffusion à compter de midi, le lundi 27 novembre.

Cette «Déclaration de l'Association canadienne-

115 Canadian News Facts 1(23), 4 décembre 1967, p. 178-179.

${ }^{116}$ "Selon M. Paul-O. Trépanier - Les États généraux ne sont pas la voix du peuple», dans Le Devoir, 25 novembre 1967, p. 5.

117 «Memo à M. Roger Séguin, président général de l'ACFÉO, de Roger Charbonneau", 27 novembre 1967, CRCCF, Fonds ACFO, C2/459/27. 
française d'éducation d'Ontario en marge des États généraux du Canada français ${ }^{118}$ " déplorait "la difficulté qu'elle a[vait] rencontrée de s'exprimer d'une façon efficace et valable à cause de l'orientation donnée aux États généraux par la majorité de la délégation québécoise», avec laquelle il y avait «impossibilité de dialogue». Le communiqué affirmait que la délégation québécoise «ne représentait pas adéquatement la pensée de la population canadienne-française du Québec» et que toutes les discussions étaient orientées "vers une option pré-déterminée». En outre, l'ACFÉO déplorait «la nature du texte soumis au début des États généraux par la Commission générale», une preuve du parti pris en faveur d'une seule option. Enfin, «l'absence de l'unifolié [...] démontre que la majorité des membres présents avaient déjà pris leur option». L'ACFÉO acceptait le principe de l'autodétermination de la nation canadienne-française, mais elle regrettait «que la délégation du Québec ait confondu le principe du droit de choisir avec le choix lui-même».

La délégation ontarienne sortait très déçue des assises des États généraux, où elle n'a pas trouvé les solutions qu'elle espérait aux problèmes des minorités. En fait, l'ACFÉO, dans sa déclaration du 27 novembre 1967, disait qu'elle espérait davantage de la Conférence de demain qui s'ouvrait alors à Toronto le jour même ( 27 novembre) et qui serait «en mesure d'apporter une solution plus acceptable». Les griefs des délégués ontariens touchaient deux points: les délégués aux États généraux n'étaient pas représentatifs, d'une part, et ces délégués empêchèrent les groupes minoritaires de s'exprimer, d'autre part.

118 Copie de cette déclaration dans CRCCF, Fonds ACFO, C2/459/27. 
Le 28 novembre 1967, Le Droit titrait un article: "Les États généraux ne représentent pas tous les Québécois». Le journal reprenait les plaintes de l'ACFÉO: les "délégués territoriaux» du Québec ne représentaient pas l'ensemble du Québec, les délégués franco-ontariens n'eurent pas la possibilité de faire entendre leur point de vue, l'absence de l'unifolié "après l'avoir réclamé à maintes reprises", la confusion entre le droit de choisir et l'adoption d'un choix en particulier (l'indépendance). Dans le même numéro du Droit, un autre article, provenant cette fois de la Presse canadienne sous la signature de Gérard Alarie, était coiffé du titre suivant: "Le ministre Côté dit avoir été frappé par le caractère fasciste des États généraux», accusation portant sur le refus de l'assemblée plénière d'écouter des points de vue contraires à celui des résolutions, notant que toutes les résolutions favorables au fédéralisme canadien avaient été éliminées à l'étape des ateliers, et que les résolutions soumises à l'assemblée devaient être adoptées sans amendements. Une note, signée R.B. [Robert Barsalou?], dans les archives de l'ACFÉO parle de «Démocratie simulée, où l'on ne peut amender une résolution... ${ }^{119}$ ».

Même les jeunes délégués, au départ plutôt sympathiques aux revendications néonationalistes, sortirent déçus de ces assises. Les quelque vingt-cinq jeunes se réunirent, à Montréal, pour en faire l'évaluation. Quelques-uns de ces jeunes (un groupe de sept) fit

\footnotetext{
119 "Les Êtats généraux ne représentent pas tous les Québécois", dans Le Droit, 28 novembre 1967, p. 1, suite p. 4; Gérard Alarie (de la Presse canadienne), «Le ministre [Jean-Pierre] Côté dit avoir été frappé par le caractère fasciste des Etats généraux", dans Le Droit, 28 novembre 1967, p. 3. Enfin, voir un texte signé R.B. [Robert Barsalou?], CRCCF, Fonds ACFO, C2/356/2.
} 
une déclaration le jeudi 30 novembre 1967 où ils affirmaient que les États généraux n'avaient pas permis aux délégués hors Québec de s'exprimer, ajoutant que la délégation du Québec n'était pas représentative de la masse de sa population. La déclaration, qui "représente l'opinion générale des jeunes Franco-Ontariens qui ont participé aux États généraux», était signée par Jean-Louis Renaud, Pierre Allard, Rémy-M. Beauregard, Gilles Valiquette, Paul Sylvestre et Jean-Robert Gauthier.

Les jeunes s'en prirent aussi «à l'émotivité et à la canalisation des débats lors des assises et à certaines irrégularités de procédure». Les délégués des minorités furent noyés dans «le cheminement vers le consensus». La procédure permettait l'expression des opinions, certes, mais «ceux qui ne partageaient pas l'opinion majoritaire se voyaient presque réduits au silence par les huées et le manque de civisme d'un certain groupe de délégués québécois». Les jeunes notaient encore que les votes inscrits pour les quelque dix-sept résolutions étaient en deçà des 1123 voix exigées pour obtenir le quorum. Les jeunes constataient encore l'illogisme de demander pour les minorités françaises un traitement semblable à celui de la minorité anglaise du Québec et, du même souffle, de vouloir réduire celle-ci à l'assimilation, à la diminution de ses droits et à l'unilinguisme provincial. Aussi, les jeunes tenaient à préciser que leur vote en faveur de "l'auto-détermination de la nation canadienne-française» n' affirmait que le droit de faire un choix, mais sans faire ce choix ${ }^{120}$.

\footnotetext{
${ }^{120}$ Jules Labelle, «Les jeunes Franco-Ontariens et les États généraux Les délégations d'outre-Québec n'ont pu s'exprimer librement», dans Le Droit, 30 novembre 1967, p. 1, suite p. 3.
} 
Beaucoup de délégués reprirent cette idée que les résolutions adoptées par les États généraux étaient cuites d'avance. Ainsi, le président de l'Association des commissaires d'écoles bilingues d'Ontario (ACÉBO), Gaétan Rochon, de Sturgeon-Falls, déclara le mercredi 29 novembre 1967 que les États généraux n'avaient pas été le lieu d'un dialogue et avaient seulement adopté "des résolutions cuisinées d'avance». Lui non plus ne croyait pas que les délégués québécois représentaient l'ensemble de leur province. Les minorités avaient appris l'anglais, savaient mieux dialoguer et possédaient par conséquent plus de "maturité» que les Québécois ${ }^{121}$.

Pendant que les minorités, les unes après les autres (sauf les Acadiens), dénonçaient le parti pris des États généraux en faveur de l'option séparatiste, Jacques-Yvan Morin, à Montréal, colmatait la brèche ouverte dans le front de l'unité en déclarant qu'il n'y avait pas de "scission", mais que les minorités avaient "appris ce qu'est le Québec et ce qu'il veut, tandis que le Québec commence à prendre conscience de la réalité totale du Canada français ${ }^{122}$ ». Jacques-Yvan Morin, devant toutes ces contestations sur la représentativité, possédait l'assurance du juste: «Faute de pouvoir s'en prendre à la qualité de nos débats, ceux qui ne partagent pas les opinions majoritaires de l'assemblée mettent souvent en cause notre représentativité. Nous ne craignons pas ce genre d'attaque et nos dossiers sont grands ouverts ${ }^{123}$."

121 Presse canadienne, «Des résolutions cuisinées à l'avance», dans $L e$ Droit, 30 novembre 1967, p. 1.

122 "Morin: il n'est pas question de "scission" entre Québécois et minorités francophones», dans Le Devoir, 27 novembre 1967, p. 5.

${ }^{123}$ «M. Robichaud et les radiodiffuseurs estiment que les États généraux ne sont pas représentatifs", dans Le Devoir, 28 novembre 1967, p. 2. 
Rosaire Morin s'adressa aux délégués, à la fin de l'année, pour «dégager certaines conclusions»: premièrement, que «la démocratie a[vait] permis à chacun de s'exprimer»; deuxièmement, qu'il y avait eu une remarquable cohérence, "voire même une certaine unité»; troisièmement, que les quinze résolutions adoptées «ne constitu[ai]ent pas une option constitutionnelle, quoi qu'en ont pu dire les média d'information"; quatrièmement, que les États généraux n'étaient "pas un parti politique en gestation", mais devaient devenir un mouvement d'animation et d'information; cinquièmement, que les délégués de l'extérieur du Québec avaient connu «de grands moments d'hésitation et d'incertitude» devant «l'unité des délégués du Québec ${ }^{124}$ ».

Cette obstination à nier la politisation des États généraux s'expliquait en partie par le souci de ne pas mécontenter l'important bailleur de fonds qu'était le gouvernement provincial. Le premier ministre Daniel Johnson, qui craignait la transformation des États généraux en parti politique, servit un avertisssement: «Si les États généraux deviennent un parti politique, je les traiterai comme un parti politique." Johnson menaçait de couper les subventions «dans l'hypothèse où ils continueraient leur travail dont l'orientation serait contraire à la doctrine du gouvernement en matière constitutionnelle». Les dirigeants des États généraux rencontrèrent Johnson le 19 décembre 1967 pour réaffirmer officiellement le statut non partisan des États généraux, répétant que les États généraux n'avaient adopté aucune option constitutionnelle. Johnson qui, à l'époque, réclamait le contrôle de Radio-Canada, pouvait profiter des revendications

$\overline{124}$ [Lettre] «Rosaire Morin à chaque délégué», Montréal, 27 décembre 1967, copie dans CRCCF, Fonds ACFO, C2/355/3. 
des États généraux ${ }^{125}$. Le 4 juin 1968, Johnson annonça que le gouvernement continuerait d'appuyer financièrement les État généraux, mais de manière moins généreuse que l'année précédente ${ }^{126}$.

Des questions surgirent, éventuellement, sur la représentativité des délégations des groupes minoritaires. Le Magazine Maclean, en janvier 1968, donnait, parmi les futures tâches de la Commission générale de trente-sept membres issue des assises de 1967, celle de "démocratiser les délégations venant d'en dehors du Québec ${ }^{127}$ ». L'article citait Rosaire Morin: "À l'heure actuelle, il s'agit de quelques citoyens qui se choisissent entre eux; il faudra établir des normes plus démocratiques». La vérité, c'est qu'une bien faible partie de la population francoontarienne était au courant de ces débats de Montréal. En éditorial, Claude Ryan soulevait lui aussi la question de la représentativité: «En ce qui touche le Québec, l'unanimité fut impressionnante. Nous doutons qu'elle soit représentative du Québec que nous connaissons et fréquentons, auquel nous appartenons depuis toujours ${ }^{128}$."

L'Association canadienne de la radio et de la télévision françaises (ACRTF) publia aussi un communiqué affirmant qu'il était «impossible de considérer les États généraux comme un porte-parole valable de la "population canadienne d'expression française" 129 ".

125 Voir I'article de Jean-Charles Bonenfant, "Québec», dans John Saywell (dir.), Canadian Annual Review 1967, [Toronto], University of Toronto Press, [c 1968], pp. 129-130.

${ }^{126}$ Canadian News Facts 2(11), 19 juin 1968, p. 84

127 "État généraux: 1,819 paroisses à représenter», dans Magazine Maclean 8(1), janvier 1968.

${ }^{128}$ Éditorial de Claude Ryan, "Etats généraux... ou Etats particuliers?", dans Le Devoir, 27 novembre 1967, p. 4.

${ }^{129}$ «M. Robichaud et les radiodiffuseurs estiment que les Etats généraux 
Le premier ministre du Nouveau-Brunswick, Louis Robichaud, abonda aussi dans le sens de la non-représentativité, précisant que les États généraux, «c'était trop exclusif pour être représentatif ${ }^{130}$ ». Le ministre fédéral des Affaires extérieures, Paul Martin, déclara à la presse que le Canada français était une communauté distincte dans ce pays ${ }^{131}$.

Un mois après les assises de 1967, dans son «Bloc Notes» de la page éditoriale, le chroniqueur V[incent] P[rince] donnait une interprétation nettement plus favorable de la réaction des minorités dont il louait la présence aux États généraux et la volonté de continuer d'y participer. Habituées aux luttes contre les majorités anglaises, les minorités devraient désormais se battre aussi contre la majorité française au Québec, «ce qui fait tout le tragique de la situation». Mais les «liens du sang» sont forts, et certains parlaient soit de protéger les minorités, soit de les rapatrier au Québec. "Cette politique de présence, nous le répétons, était et reste toujours la bonne. Elle témoigne d'une confiance qu'il faut non seulement souligner mais approuver sans réticence ${ }^{132} . "$

À l'ACFÉO, cependant, on se demandait s'il fallait continuer de participer aux États généraux. Mais on ne voulait pas agir seul. C'est l'idée qu'exprime une lettre que Roger Charbonneau adressait à un délégué de North-Bay: «Inutile de dire que presque tous les délégués n'ont pas encore digéré la tournure des dernières assises. On croit, cependant, que l'Ontario

ne sont pas représentatifs», dans Le Devoir, 28 novembre 1967, p. 2.

${ }^{130}$ Loc. cit.

${ }^{131}$ "M. Paul Martin: le Canada français est, dans ce pays, une "communauté distincte" ", dans Le Devoir, 28 novembre 1967, p. 2.

${ }^{132}$ V[incent] P[rince], "Bloc Notes - La réaction des minorités aux "états généraux du Québec"”, dans Le Devoir, 27 décembre 1967, p. 4. 
ne devrait pas être la seule minorité à décider si on doit continuer ou non notre participation aux États généraux ${ }^{133}$.»

\section{III - Affrontements et rupture (1968-1969)}

Deux jours après les assises de novembre 1967, l'Institut canadien-français d'Ottawa se retirait des États généraux. Fondé en 1852, cet organisme regroupait des gens d'affaires et avait délégué son président (Albert Brisson) et son secrétaire (Michel Pelletier). Les deux se dirent «surpris que la discussion n'était pas permise», puisqu'il fallait approuver en bloc des résolutions préparées d'avance, une méthode "peu démocratique» à leurs yeux. En arrivant à Montréal, les délégués avaient en effet découvert "que le tout avait une saveur de séparatisme ou d'indépendantisme». Sur réception de leur rapport, l'Institut décida incontinent de se retirer des Etats généraux ${ }^{134}$. L'exemple serait-il suivi?

\section{LES TIRAILLEMENTS DE L'ACFÉO}

Échaudée par les assises de novembre 1967 , l'ACFÉO prit des distances encore plus grandes à l'égard des États généraux. Lors d'une réunion du Comité exécutif de l'ACFÉO, le 17 janvier 1968, on se demanda quelle politique adopter. Déjà, certains délégués avaient commencé à faire connaître leur opinion sur l'éventuel retrait de l'Ontario français ${ }^{135}$.

\footnotetext{
133 Roger Charbonneau a Jean-Louis Duchesneau, Ottawa, 24 janvier 1968, copie dans CRCCF, Fonds ACFO, C2/356/2.

${ }^{134}$ "L'Institut canadien-français se retire des États généraux», dans Le Droit, 29 novembre 1967, p. 1, suite p. 2.

135 "Procès-verbal du Comité exécutif de l'ACFÉO», Ottawa, 17 janvier 1968, copie dans CRCCF, Fonds ACFO, C2/355/4.
} 
La presse, pour sa part, faisait déjà savoir que l'Ontario s'opposerait aux États généraux. Ainsi, le Magazine Maclean rapportait, en janvier 1968, que «les représentants de l'Ontario s'y opposent carrément tandis que les autres acceptent de poursuivre l'expérience ${ }^{136} »$. Toutefois, la position de l'ACFÉO restait plus nuancée.

Dans la région de Welland, l'opposition aux États généraux s'exprima publiquement. Un des chefs de file de la région, Jacques Dubois, avait fait savoir à Roger Charbonneau qu'au lieu de participer aux prochaines assises, on devrait plutôt favoriser une rencontre des groupes minoritaires. Le 11 février 1968, à Welland, une assemblée réunit quelque 350 personnes. Dans un rapport qu'elle fit de la rencontre, la secrétaire de l'ACFÊO, Solange Plourde-Gagnon, releva les "commentaires un peu sévères» tenus par certains sur «l'anti-démocratie des États généraux concernant la participation des minorités». Un délégué aux dernières assises, Ryan Paquette, affirma par contre que les minorités avaient joué «un grand rôle». Selon Dubois, «les minorités sont arrivées à Montréal plus ou moins bien préparées et c'est la raison pour laquelle nous n'avons pu jouer le rôle de modération ${ }^{137} »$.

Un membre franco-ontarien de la Commission générale, Rodrigue Landriault, un jeune avocat travaillant dans la même étude de droit que Roger-N. Séguin, fit aussi connaître son point de vue:

136 «États généraux: 1,819 paroisses à représenter», dans Magazine Maclean 8(1), janvier 1968.

${ }^{137}$ Solange Plourde-Gagnon à Roger Charbonneau, s.l., 12 février 1968, CRCCF, Fonds ACFO, C2/355/4. 


\section{Gaétan Gervais}

Je n'ai pas d'opinion définitive, à savoir, si nous devons continuer cette participation. Cependant, si nous devons le faire, je crois qu'il faudrait se présenter aux prochaines assises beaucoup mieux organisés que lors des deux premières. Il faudrait être en mesure d'intervenir de façon systématique et efficace sur toutes les questions soulevées afin de faire valoir au regard du public les opinions et désirs des minorités ${ }^{138}$.

Lors de sa réunion le 15 mai 1968, le Comité exécutif de l'ACFÉO prit connaissance de nouvelles oppositions à la participation des Franco-Ontariens aux États généraux. Rodrigue Landriault rapporta que les minorités étaient fort mécontentes «quant à la formule employée pour le vote et la préparation des résolutions et au sujet de l'attitude de certains groupes du Québec ${ }^{139}$ ».

En 1968, d'autres priorités mobilisaient l'attention de l'ACFÉO. En effet, l'Association s'engageait dans de grands changements de fonctionnement et d'orientation. Lors du $\mathrm{XX}^{\mathrm{e}}$ Congrès général, tenu à Ottawa les 20 et 21 mars 1968 , les participants demandèrent qu'on préparât et qu'on soumît au congrès de l'année suivante, des résolutions sur la refonte des cadres de l'ACFÉO. Un comité présidé par Ernest-A. Côté, et comprenant Rodrigue Landriault, Ryan Paquette, Onésime Tremblay, Laurent Isabelle, Jeannine Séguin et quelques autres, tint des réunions de juin 1968 à janvier 1969. En septembre 1968 , le comité soumit un projet qui suscita diverses suggestions. Le comité en tint compte pour préparer une version amendée du projet, texte que le Comité exécutif accepta en décembre 1968. L'ACFÉO avait

${ }^{138}$ Rodrigue Landriault à Roger Charbonneau, Ottawa, 6 mars 1968 , CRCCF, Fonds ACFO, C2/356/2.

139 «Procès-verbal du Comité exécutif de l'ACFÉO», Ottawa, 15 mai 1968, copie dans CRCCF, Fonds ACFO, C2/355/4. 
connu d'autres «restructurations» (en 1950, 1960, 1962, 1963 et 1965), mais jamais d'une telle envergure. Les réformes visaient à rendre l'ACFÉ plus en mesure d'étendre son activité au-delà du domaine de l'éducation.

Le comité de refonte des cadres recommanda un mode de fonctionnement plus démocratique, en accordant aux sociétés affiliées et aux sections locales une plus grande voix dans les organismes de direction (le comité exécutif et le conseil d'administration). On proposa de reconnaître six régions au lieu de vingt-quatre, chacune disposant d'un secrétariat comme celui qu'on avait établi à Toronto en 1965. On décida d'encourager une plus grande participation «selon les techniques d'animation culturelle», ce qui permettrait, avec des «animateurs professionnels», de mieux refléter la pensée des FrancoOntariens ${ }^{140}$. Pour bien couronner cette transformation (quinze affiliées provinciales, des membres particuliers, six conseils régionaux, avec un Bureau de direction et un Comité exécutif), l'ACFÉ changea de nom, devenant en 1969 I'Association canadienne-française de l'Ontario (ACFO). C'est le $\mathrm{XXI}^{\mathrm{e}}$ Congrès général, le 19 mars 1969 , qui sanctionna ces recommandations.

En outre, il existait alors des doutes sur la survie des Etats généraux. Le Conseil de la Vie française, qui suivait de près l'évolution du dossier, avait accepté de réunir les groupes minoritaires «pour discuter entre

\footnotetext{
${ }_{140}$ Roger Charbonneau, "La restructuration des cadres de l'ACFÉO», dans La Vie franco-ontarienne 4(4), février 1969, p. 1-2. Le même numéro de La Vie franco-ontarienne contenait un article d'Yves Breton, «L'animation sociale...? Qu'est-ce donc?», p. 2. Lors de ce congrès de 1969, Gérard Lévesque proposa la création d'un «drapeau aux signes distinctifs pour les Franco-Ontariens», mais cette proposition fut rejetée.
} 
nous des problèmes de la nation ${ }^{141}$ ». En février 1968 , le secrétaire du Conseil, Paul-Émile Gosselin, informait l'ACFÉO que les prochaines assises nationales n'auraient pas lieu, comme prévu, en novembre 1968 , mais seraient reportées au printemps de 1969. Bien plus. À cause de «dissension au sein de la Commission générale», il pourrait ne plus y avoir d'autres assises. Selon Gosselin, on songeait à convoquer «des rencontres régionales hors du Québec comme ils le font dans le Québec ${ }^{142}$ ". Écrivant à Gosselin au début d'avril 1968, Roger Charbonneau terminait sa lettre par ce nota bene: "La vie des États généraux semble chancelante si on en juge par la réunion qui aura lieu en fin de semaine." Gosselin répondait, deux jours plus tard: "Comme vous le notez, les États généraux sont chancelants. Je suis la situation de près et ne manquerai pas de vous tenir au courant ${ }^{143}$."

\section{LA "COMmission de la participation Nationale aUX ÉtATS GÉNÉRAUX"}

À Montréal, la Commission générale voulut intervenir sur deux fronts à la fois. Selon Rosaire Morin, le premier objectif était de «déterminer les pouvoirs nécessaires au plein épanouissement du Québec», alors que l'objectif second était de "définir les droits essentiels aux Canadiens-Français des autres provinces ${ }^{144} \pitchfork$.

\footnotetext{
141 "Procès-verbal du Comité exécutif de l'ACFÉO», Ottawa, 17 janvier 1968, copie dans CRCCF, Fonds ACFO, C2/355/4.

142 P.-E. Gosselin à Roger Charbonneau, Québec, 21 février 1968, CRCCF, Fonds ACFO, C2/356/2.

${ }^{143}$ Roger Charbonneau à P.-E. Gosselin, Ottawa, $1^{\text {er }}$ avril 1968; P.-E. Gosselin à Roger Charbonneau, Québec, 3 avril 1968, CRCCF, Fonds ACFO, C2/356/2.

${ }^{144}$ Cette politique est expliquée dans la lettre de Rosaire Morin, vice-président et directeur général des États généraux, au père [Jean] Patoine, Montréal, 26 février 1968, copie dans CRCCF, Fonds ACFO, C2/356/2.
} 
Les assises de novembre 1967 avaient accompli trois choses: d'abord la reconnaissance du droit à l'autodétermination de la nation canadienne-française, ensuite la demande de plus de pouvoirs pour la province de Québec, enfin la définition des droits des minorités dans les autres provinces canadiennes. Ces droits minoritaires devaient être respectés «en vue de permettre l'épanouissement de la nation canadiennefrançaise ${ }^{145}$ ». Dans sa lettre aux délégués, le 22 mars 1968, le directeur général, Rosaire Morin, rappelait que l'objectif des États généraux était d'exprimer «la volonté de la nation sur le choix du régime politique qui doit la régir ${ }^{146}$ " et que, selon la Commission générale, les assises de novembre 1967 n'avaient ni proposé une «solution totale», ni retenu de "solution globale». Ces tâches reviendraient aux prochaines assises.

Les États généraux, au printemps de 1968, entreprirent une nouvelle série de rencontres régionales, sous la forme d'assemblées convoquées dans 255 villes du Québec. La Commission générale en profita pour renouveler sa demande d'appuis, tant auprès des personnes que des organismes et des sociétés commerciales. Parmi les sociétés souscriptrices, la documentation citait non seulement la société Vachon (les petits gâteaux!), mais encore Bell et IBM ${ }^{147}$. Même si la consultation québécoise n'en fit aucun cas, la Commission générale, elle, n'oubliait pas le problème des groupes minoritaires.

Dans les premiers mois de 1968, les dirigeants des

145 Rosaire Morin aux délégués, le 22 mars 1968, CRCCF, Fonds ACFO, C2/355/3.

146 Rosaire Morin aux délégués, le 22 mars 1968, CRCCF, Fonds ACFO, C2/355/3.

${ }^{147}$ Rosaire Morin aux délégués, avril [sans quantième] 1968, CRCCF, Fonds ACFO, C2/355/3. 
États généraux prirent acte de la résistance grandissante des associations provinciales des provinces anglaises. Surtout, ils se cherchèrent de nouveaux interlocuteurs, plus complaisants. Pour illustrer cette nouvelle politique, on pourrait difficilement trouver un texte plus révélateur que la longue lettre, datée du 26 février 1968, que Rosaire Morin adressa au père Jean Patoine, de l'Association canadienne-française de l'Alberta. Le vice-président et directeur général des États généraux en profitait pour exprimer, "à bâtons rompus et entre deux téléphones», ses «idées personnelles sur la participation, à nos prochaines Assises, des Canadiens-Français des autres provinces ${ }^{148}$ ». L'ACFÉO, elle, ne prit connaissance de cette lettre qu'au début de mai.

Dans sa lettre, Morin admettait à Patoine que «vos délégués» avaient pu se sentir frustrés de ne pouvoir participer à tous les votes aux assises de 1966, ce qui les avait amenés à se considérer comme des citoyens de seconde zone. Pour les intégrer «dans nos délibérations", les dirigeants avaient alors cherché une nouvelle formule. Ainsi, en 1967, "vous avez eu le privilège de voter sur tous les problèmes». Mais comme on comptait les votes «de chacun des grands territoires du Canada français», les délégués hors Québec ne furent pas contents. En votant, ils avaient toujours le sentiment de voter «contre le Québec et à ainsi recevoir la désapprobation des Québécois».

I48 Rosaire Morin (vice-président et directeur général) au père [Jean] Patoine, Montréal, 26 février 1968, copie dans CRCCF, Fonds ACFO, $C 2 / 356 / 2$. Rosaire Morin fit parvenir une copie de cette longue lettre (quatre pages 8,5 x 14) à Jacques-Yvan Morin et à $\mathrm{M}^{\mathrm{gr}}$ Gosselin, mais pas à l'ACFÉO dont la copie, selon une note manuscrite sur le texte, porte la mention "reçu de R. Landriault 8 mai 1968». La lettre, cependant, fut distribuée, en juin 1968, à l'exécutif de l'ACFÉO (il en existe aussi une copie dans les papiers de Robert Barsalou). 
À propos du fonctionnement général des États généraux, Morin jugeait que les méthodes «d'animation culturelle» avaient été efficaces: «il me semble opportun d'accentuer cette mentalité et cette méthode de travail à l'ensemble de la délégation». Après hésitation, il lui semblait maintenant nécessaire de «maintenir la forme unique d'une assemblée générale" parce que la constitution de deux assemblées parallèles «ne pourrait aboutir qu'à des oppositions d'expression et au lieu d'être utile et d'unir, nous deviendrions un motif de dispersion». Morin songeait alors à accorder à chaque région un temps fixe pour s'exprimer, afin de rétablir un «équilibre psychologique», en plus d'alterner les opinions, ce qui changerait le climat de l'assemblée. En plus, il serait «essentiel» de scinder les résolutions pour permettre de voter sur chacun des articles.

Selon Morin, il fallait «modifier substantiellement la participation des délégués des autres provinces au travail des équipes et des ateliers». Et voici que réapparaît l'idée que les minorités devraient traiter de leurs problèmes, non de ceux du Québec. Puisque «la confrontation sur les problèmes québécois est plus néfaste qu'heureuse», Morin voulait éviter la répétition des dernières expériences. Il proposait donc ceci: "Je crois qu'il faudrait plutôt songer à confier, aux représentants des Canadiens-Français d'outrefrontière, des sujets qui leur sont propres, des problèmes qui sont les leurs et des résolutions qui les concernent."

Pour mettre en œuvre cette politique, Morin proposait au père Patoine une "réunion des minorités», dès le 9 mars 1968, si la date lui convenait. À cette réunion, on inviterait "ceux-là qui désirent le plus 
assurer le plein épanouissement des CanadiensFrançais de tout le territoire». Cette définition excluait apparemment les Franco-Ontariens. Selon Morin, il faudrait en particulier étudier la possibilité de tenir des «États régionaux des minorités». Cependant, il hésiterait à convoquer une Assemblée plénière des minorités, où l'Ontario français dominerait comme le Québec a dominé aux assises de 1967. Montrant bien sa méfiance à l'endroit des Franco-Ontariens, Morin poursuivait ainsi son analyse:

Dans le projet d'une assemblée unique, je crois que nous nous trouverions devant un groupe de Franco-Ontariens qui mobiliseraient les décisions, à l'instar de nos dernières délibérations qui étaient d'abord l'expression du Québec. Je ne crois pas que les voix de Vancouver, d'Edmonton ou de Moncton pourraient être reflétées réellement au sein d'une telle assemblée et exprimer les besoins et les ambitions des Canadiens-Français d'outre-frontière. Je crains même que la délégation qui émanerait de l'Ontario ne serait représentative que d'une élite franco-ontarienne, qui dirige au sommet, sans être intégrée dans le peuple canadien-français de l'Ontario. Il se pourrait que cette assemblée serait facilement orientée vers l'autodétermination du Québec et qu'elle pourrait vouloir dicter au Québec la ligne maîtresse de l'avenir des Canadiens-Français du Québec. Croyez-vous réellement pouvoir éviter une telle orientation d'une telle assemblée?

La répercussion prévisible augmente le fossé qui sépare de nombreux Québécois de nos compatriotes des autres provinces. Personnellement, je ne voudrais pas participer a la création d'un mécanisme qui approfondirait les motifs de divisions ${ }^{149}$.

La méfiance de Morin vis-à-vis des Ontariens le poussait à écarter l'ACFÉO au profit d'un mécanisme parallèle contrôlé depuis Montréal. Dans sa longue lettre à Patoine, Morin répétait qu'il cherchait «l'unité

${ }^{149}$ Ibid., CRCCF, Fonds ACFO, C2/356/2. 
de la nation sur les points qui peuvent nous unir, où que nous vivions".

La "rencontre des minorités», elle, pourrait avoir lieu en juin ou en juillet. Il faudrait élaborer des projets d'étude. Cette approche serait plus acceptable aux délégués québécois et le Québec accueillerait favorablement des résolutions émanant ainsi des groupes minoritaires. Les minorités, elles, seraient davantage unies: "Cette conception conserve aux minorités leur participation aux discussions et aux votes de tous les problèmes». Finalement, Morin réitérait ses réserves au sujet de la délégation de l'Ontario: «Enfin, je pense qu'il faudra, particulièrement en Ontario et en Acadie, songer à un mode de représentation différent des normes de sélection actuellement utilisées."

Selon la proposition de Morin, une «rencontre des minorités» se tint à Montréal le 9 mars 1968. Participaient à cette réunion "des minorités», $\mathrm{M}^{\mathrm{g}}$ Paul-Émile Gosselin, le père Jean Patoine, le père Richard Arès, C.E. Couture et Rosaire Morin. ${ }^{\mathrm{gr}}$ Gosselin expliqua le point de vue des minorités mécontentes; elles estimaient que les assises de novembre 1967 n'avaient pas tenu compte de leurs problèmes, qu'on avait en fait tenu les «Etats généraux du Québec». Le père Jean Patoine renchérit, disant que les délégués de l'Ouest étaient devenus très hostiles aux États généraux, même si lui, dans l'optique de la lettre de Morin, approuvait l'idée d'une participation des groupes minoritaires. C.E. Couture affirma que les délégués du Manitoba se sentaient isolés. Selon le père Arès, "ce qui a choqué le plus les délégués des minorités, c'est la division dans leurs rangs, face à l'unité du Québec». À cette rencontre à cinq, on ne convia 
aucun représentant de l'Acadie, ni de l'Ontario, les deux plus grosses communautés minoritaires du pays. L'ACFÉO était évincée.

On décida aussi, ce 9 mars 1968, de créer une Commission, à l'intérieur des États généraux, pour traiter de la question des Canadiens-Français d'outre-frontière (avec le père Patoine à la présidence). C'est d'ailleurs le père Patoine que les dirigeants de Montréal chargèrent de recruter les autres membres de cette Commission (temporairement appelée la Commission des Canadiens-Français d'outrefrontière); celle-ci devait préparer les programmes d'étude et les sessions régionales, en plus d'organiser les délégations des provinces. Si la Commission organisait les délégations provinciales, quel serait donc le rôle de l'ACFÉO? À ce sujet, la Commission nouvellement créée décida de rencontrer les quatre membres ontariens de la Commission générale et l'ACFÉO pour définir les normes de sélection des délégués ${ }^{150}$.

La nouvelle Commission des minorités tint sa première réunion le 21 avril 1968. Elle désigna quatre administrateurs, avec la responsabilité de s'élire entre eux un président, un vice-président, un secrétaire et un trésorier ${ }^{151}$. Cet "exécutif" se réunit à Montréal le 5 mai 1968 et décida de changer le nom de la Commission de Vie française des États généraux, nom que

150 «Compte-rendu [sic] d'une rencontre entre Mr Paul-Émile Gosselin, le Révérend Père Jean Patoine, le Révérend Père Richard Arès, $M$. C.E. Couture et M. Rosaire Morin, samedi, le 9 mars [1968] de 10 h 00 a $14 \mathrm{~h} 00$ ", copies dans CRCCF, Fonds ACFO, C2/355/4 et Fonds Robert-Barsalou, P149/1/4.

${ }^{15 t}$ Il s'agit de Léopold Béliveau (plus tard remplacé par Euclide Daigle, Moncton), Jacques de Courville Nicol (Ottawa), Rhéal Teffaine (Saint-Boniface) et Jean Patoine (Edmonton). 
prit quelque temps la nouvelle Commission, pour l'appeler désormais la Commission de la participation nationale aux États généraux. Elle décida, en plus, de ne pas nommer d'officiers, mais de confier au père Patoine la responsabilité générale du bon fonctionnement de la commission. La Commission de la participation, réunie le $1^{\text {er }}$ juin 1968 , sanctionna les décisions de "l'exécutif ${ }^{152}$ ».

Rodrigue Landriault, membre franco-ontarien de la Commission générale, informa le Comité exécutif de l'ACFÉO, au cours de sa réunion le 15 mai 1968 , de l'existence du nouveau groupe formé à Montréal, précisant que la Commission de la participation nationale préparait une rencontre des groupes minoritaires. Pour sa part, Landriault conseillait de continuer à participer aux États généraux, tout en croyant qu'il fallait, cette fois, mieux se préparer ${ }^{153}$.

\section{LA RENCONTRE DU $1^{\text {ER }}$ JUIN 1968}

En créant une Commission de la participation nationale des États généraux, rouage interne des États généraux, les dirigeants tentaient de contourner les grandes associations provinciales comme l'ACFÉO. La création de la Commission de la participation confirmait aussi l'effacement du Conseil de la Vie française, malgré la présence de $\mathrm{M}^{\mathrm{gr}}$ Paul-Émile Gosselin dans le nouvel organisme. Ainsi, au début de mai 1968 , les journaux apprirent au Conseil de la Vie française que les États généraux entendaient s'occuper

152 «Assemblée de la Commission de la participation nationale aux

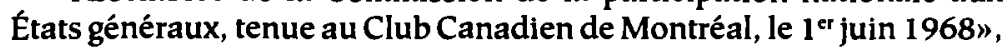
copie dans CRCCF, Fonds ACFO, C2/355/4.

153 «Procès-verbal du Comité exécutif de l'ACFÉO», Ottawa, 15 mai 1968, copie dans CRCCF, Fonds ACFO, C2/355/4. 
eux-mêmes du recrutement des délégués, par l'entremise de la nouvelle Commission. En conséquence, le Conseil de la Vie française renonça au projet de rencontre des minorités; Gosselin en informa Charbonneau, lui disant que, selon les journaux, le comité central «a décidé de s'occuper activement d'organiser la participation des groupes français hors du Québec ${ }^{154}$ ". Dans une addition manuscrite à cette lettre du 6 mai, Gosselin indiqua que les États généraux disposaient de 2500 \$ pour réunir les groupes minoritaires.

La rencontre de la Commission de la participation

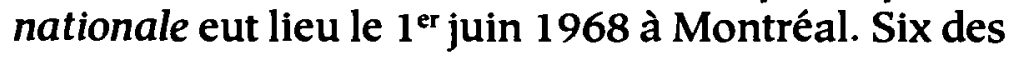
treize membres provenaient de l'Ontario: Jacques de Courville Nicol, Jean-Paul Gélinas, Jean-Louis Duchesneau, Rodrigue Landriault, Ryan Paquette et Lorenzo Cadieux ${ }^{155}$. Toutes les personnes invitées à participer au travail de la commission avaient accepté «avec beaucoup d'intérêt». Au cours de cette

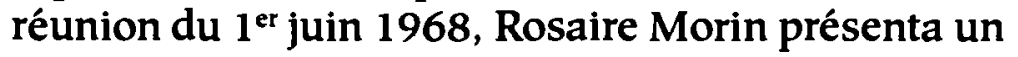
travail «sur les minorités françaises du Canada en relation avec les États généraux», où il traitait de l'historique de leur participation et donnait une projection sur les prochaines assises. Le procès-verbal indique que la discussion fut «longue» et qu'il fut

${ }^{154}$ P.-É. Gosselin à Roger Charbonneau, Québec, 6 mai 1968, CRCCF, Fonds ACFO, C2/356/2.

155 «Assemblée de la Commission de la participation nationale aux États généraux, tenue au Club Canadien de Montréal, le $1^{\text {er }}$ juin 1968", copie dans CRCCF, Fonds ACFO, C2/355/4. Onze membres étaient présents: Rosaire Morin (Montréal), M Paul-Émile Gosselin (Québec), Rhéal Teffaine (Saint-Boniface), Jacques de Courville Nicol (Ottawa), J.P. Gélinas (Ansonville), Jean-Louis Duchesneau (North-Bay), Rodrigue Landriault (Ottawa), Eugène Richard (Moncton), Roger Lalonde (Saint-Victor, Saskatchewan), Jean Cadieux (Moncton) et le père Jean Patoine (Edmonton), et deux étaient absents, Ryan Paquette (Hamilton) et Lorenzo Cadieux (Sudbury). 
décidé que l'auteur reprendrait "ce travail au complet en tenant compte des suggestions et des décisions prises au cours de la discussion. Ce nouveau texte est adjoint au présent procès-verbal ${ }^{156}$ ".

Les journaux eurent connaissance de la rencontre et Le Droit en publia les principales décisions: le changement de nom, la volonté d'organiser la participation aux États généraux des Canadiens français vivant à l'extérieur du Québec. La Commission avait aussi reçu le mandat de tenir les Canadiens au courant des activités des États généraux. Pour atteindre ces objectifs, la Commission devait compter sur les grandes associations provinciales et régionales. La Commission comprenait un exécutif de quatre membres (Jacques de Courville Nicol, Eugène Richard, Rhéal Teffaine et Jean Patoine), ce dernier assurant les liens entre la Commission de la participation et la Commission générale. Selon le rapport paru dans les journaux, on poursuivait toujours le but d' «obtenir pour les prochaines assises une formule meilleure qui ferait ressortir des motifs d'unité, d'entente et de cohésion entre Canadiens français, plutôt que de tenter d'uniformiser des divisions en soulevant des motifs qui créent la dispersion, le choc des idées et la confrontation ${ }^{157}$ \%.

Patoine demanda la coopération de l'ACFÉO: «Personnellement, je suis très favorable à cette participation et je serais très peiné si l'Association canadienne-française d'éducation de l'Ontario devait

${ }^{156}$ En fait, dans les archives de l'ACFÉO, la copie du procès-verbal de «l'Assemblée de la Commission de la participation nationale aux États

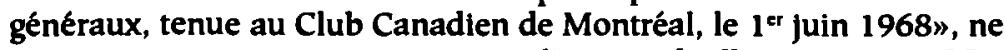
contient pas ce "nouveau texte», ni l'ancien d'ailleurs. Voir CRCCF, Fonds ACFO, C2/355/4.

${ }^{157}$ Article du Droit, repris dans Présence, mal 1968, pp. 27-29. 
décider de s'abstenir", car il y a plus d'avantages que d'inconvénients à participer ${ }^{158}$.

\section{L'ACFÉO RÉCALCITRANTE}

Les grandes associations provinciales continuaient d'hésiter à participer. Le 30 mai 1968, l'ACFÉO communiqua avec les autres associations provinciales pour demander ce qu'elles entendaient faire. Par exemple, Charbonneau écrivit au secrétaire général de la Fédération canadienne-française de ColombieBritannique, Roméo Paquette, pour savoir ce que ferait son association: «Nous avions préconisé une rencontre des minorités afin de s'entendre là-dessus, mais le projet ne s'est pas réalisé ${ }^{159}$.» Charbonneau l'informait que l'ACFEO devait décider le 17 juin 1968 de son éventuelle participation.

Au début de juin, l'ACFÉO commença à recevoir des réponses à sa lettre. Le 6 juin, Euclide Daigle, chef du secrétariat de l'Association acadienne d'éducation, répondit que les organismes acadiens n'avaient pas encore décidé s'ils participeraient, mais qu'ils faisaient partie de ce qu'il appelait, à tort, la «sous-commission de Vie française des États généraux, sous-commission qui regroupe des représentants des minorités et dont le chef de file est le père Jean Patoine, o.m.i.". Le même jour, le 6 juin 1968, le secrétaire général de l'Association culturelle francocanadienne de la Saskatchewan, René Rottiers, écrivait que son association participerait et que l'absentéisme serait «plus néfaste, qu'utile», puisqu'il vaut

\footnotetext{
${ }^{158}$ Jean Patoine à Roger Charbonneau, 4 juin 1968, copie dans CRCCF, Fonds ACFO, C2/356/2.

${ }^{159}$ Roger Charbonneau à Roméo Paquette, Ottawa, 30 mai 1968, copie dans CRCCF, Fonds ACFO, C2/356/2.
} 
mieux proclamer son désaccord; si les minorités devaient s'abstenir, elles donneraient «l'occasion aux groupes séparatistes québécois de proclamer notre désintéressement». Le 11 juin, Roméo Paquette, secrétaire général de la Fédération canadienne-française de la Colombie-Britannique, informait Charbonneau que son association continuerait de participer. Pour l'Association d'éducation des Canadiens-Français du Manitoba, Jacques Molicard répondit que son organisme aussi serait représenté; Molicard informait Charbonneau qu'il y avait eu à Montréal, en avril 1968, une rencontre des minorités avec Rosaire Morin, où on avait décidé de créer une "commission spéciale» pour les minorités ${ }^{160}$. Pour sa part, dès le 11 mai, l'ACFA (Association canadienne-française de l'Alberta) avait déjà discuté de l'opportunité de participer aux assises. On voit donc, d'une part, que les associations provinciales n'étaient pas au courant de la création de la Commission de la participation, et d'autre part, qu'elles entendaient continuer de participer aux États généraux.

L'ACFÉO risquait donc de se retrouver seule dans son opposition aux États généraux. Le 19 juin 1968, lors d'une réunion du Comité exécutif de l'Association, Rodrigue Landriault et Jacques de Courville Nicol («qui siègent respectivement à la commission générale et à la commission de la participation nationale») étaient présents. On savait alors que les prochaines assises ne se tiendraient qu'au printemps de 1969. À ces assises générales, on prévoyait qu'une journée serait réservée aux rencontres par province, qu'une

$\overline{160}$ Euclide Daigle à Roger Charbonneau, 6 juin 1968; René Rottiers à Roger Charbonneau, 6 juin 1968; Roméo Paquette à Roger Charbonneau, 11 juin 1968; Jacques Molicard à Roger Charbonneau, 14 juin 1968, CRCCF, Fonds ACFO, C2/356/2. 


\section{GaÉtan Gervais}

deuxième permettrait de réunir les provinces autres que le Québec, enfín que le troisième jour, on réunirait tout le monde autour des problèmes nationaux. On prévoyait aussi qu'il y aurait des ateliers provinciaux dans quatre domaines (culturel, économique, social, politico-constitutionnel), où les délégués pourraient discuter à partir d'études préparées par des experts qu'on pourrait rémunérer.

Lors de cette rencontre du Comité exécutif, Jacques de Courville Nicol demanda que l'ACFÉO clarifiât trois choses: sa participation aux États généraux, le statut des délégués de l'Ontario et les modalités de leur participation. On indiqua que les autres provinces avaient décidé de participer aux États généraux. Le procès-verbal, ajoutant qu'une «longue discussion» s'ensuivit, nota cinq points:

1 - On dit que les États généraux veulent être une consultation de la nation et sa constitution ne mentionne pourtant qu'un aspect, soit l'aspect constitutionnel. Une consultation de ce genre peut-elle donner des résultats et elle se fera exactement sur quoi et pour quelles raisons.

2 - Dans quelle mesure les buts des Etats généraux peuvent-ils influer sur la restructuration de l'ACFÉO en tenant compte de son désir de sensibiliser la population.

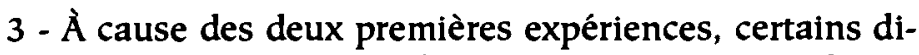
recteurs doutent de l'utilité de participer à cette prochaine réunion des États généraux.

4 - Qui défraiera le coût de participation des délégués de l'Ontario?

5 - Avant de décider de notre participation aux États généraux, il faudrait que ceux-ci nous y invitent par écrit en précisant les buts et les modalités de cette rencontre et à quoi on veut en arriver ${ }^{161}$.

161 "Procès-verbal du Comité exécutif de l'ACFÉO», Ottawa, 19 juin 1968, copie dans CRCCF, Fonds ACFO, C2/355/4. 
Après discussion, on adopta une résolution voulant "Que l'Association ne participe pas aux États généraux, à moins de recevoir une invitation par écrit des États généraux nous donnant des précisions sur les buts et les modalités de la prochaine réunion et qu'on consulte le Conseil d'administration ainsi que d'autres groupements et individus au sujet de la participation des Franco-Ontariens». Le vote: 5 pour, 1 contre, 1 abstention ${ }^{162}$.

L'incertitude s'installait, mais les contacts entre l'ACFÉO et les États généraux furent maintenus. Après un appel téléphonique le 22 juillet 1968 , Roger Charbonneau écrivit à Rosaire Morin, le 26 juillet, pour lui expliquer la composition de la délégation ontarienne. La lettre tentait aussi de répondre aux commentaires de Morin qui avait «souligné que certains de "nos amis" avaient mis en doute la représentativité de l'Ontario aux dernières assises des États généraux ${ }^{163^{\prime}}$. Charbonneau informa Morin que la délégation ontarienne comprendrait 10 directeurs de l'ACFÉO, 82 délégués des sociétés affiliées (à raison de 10 pour les grandes, 7 pour les moyennes, 3 pour les petites), 13 fonctionnaires de l'éducation, 80 délégués nommés par les régions, 40 nommés par des organismes non affiliés. Le total de 225 (au lieu de 210) compensait pour les inévitables désistements de dernière heure qu'il faudrait combler. Charbonneau fit aussi tenir à Morin des copies de la correspondance entre l'ACFÉO et MM. Landriault, de Courville Nicol, Duchesneau et Paquette. La documentation conservée dans les archives de l'ACFÉO ne permet pas de préciser la nature des griefs contre la délégation ontarienne, ni l'identité de ces «amis» insatisfaits $\overline{162 \text { Loc. cit. }}$ ${ }^{163}$ Loc. cit. 
de la composition de cette délégation. Tout au plus trouve-t-on, peu après, une requête de l'APMJOF (Assemblée provinciale des mouvements de jeunes de l'Ontario français), dont le porte-parole, Paul-F. Sylvestre, demandait que la jeunesse formât $20 \%$ de la délégation ontarienne. Le secrétaire général répondit que l'ACFÉO n'avait toujours pas décidé si elle irait ou non aux États généraux ${ }^{164}$.

Le 3 août 1968, la Société nationale des Acadiens et l'Association acadienne d'éducation acceptèrent de participer aux États généraux, comme en 1967. En août, l'assemblée annuelle de l'ACÉLF à Montréal fut l'occasion d'une autre rencontre des dirigeants des États généraux et des groupes minoritaires. Le mécontentement des minorités expliquait la décision de tenir à Ottawa, à la fin de septembre, une rencontre des minorités et des dirigeants des États généraux. Entre-temps, les préparatifs continuaient. À la mi-août 1968, Rosaire Morin écrivit à Roger Charbonneau pour l'informer qu'il enverrait sous peu «un mémoire sur l'orientation des prochaines Assises et sur le mode de participation de nos Canadiens-Français à l'extérieur du Québec ${ }^{165}$ ». À Montréal, le 20 septembre 1968 , lors de sa huitième réunion, le Conseil exécutif des États généraux décida que la question d'une constituante serait abordée dans les documents des États généraux, une question qui touchait la "constitution interne du Québec», donc hors de portée des minorités exclues. On inviterait le gouvernement du Québec à créer cette constituante.

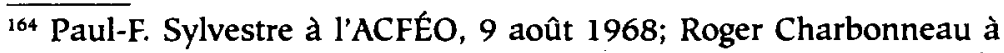
Paul-F. Sylvestre, Ottawa, 14 août 1968, coples dans CRCCF, Fonds ACFO, C2/356/2.

${ }^{165}$ Rosaire Morin à Roger Charbonneau, 14 août 1968, dans CRCCF, Fonds ACFO, C2/356/2. 
Le 18 septembre 1968, le Comité exécutif de l'ACFÉO discuta encore une fois des États généraux. Peu après, Charbonneau écrivit de nouveau à Morin, lui rappelant la conférence téléphonique que lui, Morin, avait eue avec le président général de l'ACFÉO, Roger-N. Séguin, où il avait été question d'un "mémoire" sur les buts des États généraux et d'une réunion des minorités. Charbonneau faisait aussi savoir que l'ACFÉO devait bientôt se réunir pour décider de sa participation. Dans une note manuscrite sur la copie de la lettre, quelqu'un (Charbonneau?) a précisé que Morin avait téléphoné, le 3 octobre, et promis qu'un «mémoire» sur les buts des États généraux parviendrait à l'ACFÉO vers le 8 octobre 1968. Une autre note manuscrite, sur le même document, indiquait, on ne sait pourquoi, que les Acadiens ne voulaient plus de rencontre entre les minorités. Les dirigeants de Montréal rencontreraient séparément les représentants de l'Acadie, de l'Ontario et de l'Ouest ${ }^{166}$.

Le Comité exécutif de l'ACFÉO se réunit le 19 octobre 1968, et le Conseil d'administration au complet se rassembla le lendemain. On apprit alors que l'ACFÉO, malgré sa demande d'information faite en juin, attendait toujours une réponse écrite décrivant les buts et objectifs des prochaines assises des États généraux. L'ACFÉO liait aussi la participation aux modalités de financement du déplacement des délégués. Rodrigue Landriault, qui participait à la rencontre, expliqua les modifications apportées au mode de scrutin aux prochaines assises. Le Conseil d'administration prit alors la résolution suivante, en fait un ultimatum:

166 Roger Charbonneau à Rosaire Morin, Ottawa, $1^{\text {er }}$ octobre 1968 , copie dans CRCCF, Fonds ACFO, C2/356/2. 


\section{Gá́tan Gervass}

a) que la direction des États généraux soit priée de nous faire connaître dans les quinze jours qui suivront la réception de la présente résolution, les buts et les objectifs précis des prochaines assises, les modalités de participation des délégués de l'extérieur du Québec, les droits qu'ils détiendront quant aux votes et tout autre détail que les États généraux jugeront à propos de nous transmettre afin de faciliter la décision.

b) que le comité exécutif prenne connaissance du document mentionné au paragraphe (a) et décide si l'ACFÉO doit organiser la délégation de l'Ontario mais à la condition que les frais de transport et de séjour soient acquittés au préalable par les États généraux ou un autre organisme agissant en son nom.

c) si la décision du comité exécutif est négative, que le Conseil d'administration en soit averti immédiatement et que la nouvelle soit transmise aux États généraux, aux dirigeants francophones des provinces autres que le Québec ainsi qu'aux média d'information ${ }^{167}$.

Il restait à en informer les intéressés.

Le 22 octobre 1968, par conséquent, Roger Charbonneau écrivait aux présidents locaux, aux curés, aux écoles secondaires, aux surintendants, aux professeurs d'école normale, aux conseillers scolaires, pour leur rendre compte de la réunion du Conseil d'administration de l'ACFÉO et pour les informer que l'ACFÉO n'avait pas encore décidé si elle participerait aux États généraux. Le lendemain, le 23 octobre 1968, Roger Charbonneau écrivait à Rosaire Morin, directeur général des États généraux. La lettre lui rappelait l'engagement pris par lui, en juin, auprès du président général de l'ACFÉO (Roger-N. Séguin), puis la lettre du $1^{\text {er }}$ octobre 1968, enfin l'article paru dans Le Devoir du 17 octobre («mais ils n'ont pas

$\overline{167}$ «Procès-verbal du Conseil d'administration de l'ACFÉO», 19 octobre 1968, copie dans CRCCF, Fonds ACFO, C2/355/4. 
voulu en tenir compte étant donné que ce n'est pas un document officiel de votre organisme"). La lettre contenait le texte de la résolution adoptée le 19 octobre par l'ACFÉO' ${ }^{168}$.

Quelques jours plus tard, Rosaire Morin expédiait «Aux Canadiens-Français domiciliés à l'extérieur du Québec» une lettre annonçant que les prochaines assises des États généraux se tiendraient du 6 au 9 mars 1969, à Montréal, «pour concevoir l'avenir de la nation canadienne-française». Dans une section intitulée "Objectif», Morin parlait, encore et toujours, "de cohésion et d'unité», rappelant que le document de base étudiait "la situation des Canadiens-Français, où qu'ils soient domiciliés au Canada»; Morin envoyait en même temps un document de travail intitulé Les Canadiens-Français du Canada. Le deuxième sujet abordé aux prochaines assises serait "la situation économique des Canadiens-Français, principalement au Québec», tandis que le troisième portait sur l'avenir constitutionnel du Québec. Selon Morin, les CanadiensFrançais hors Québec représentaient «17\% de la population canadienne-française", ce qui donnait droit à 430 délégués hors Québec (dont 210 pour l'Ontario). La lettre invitait les intéressés à "communiquer avec les responsables de l'association provinciale désignée ${ }^{169} \%$.

Mieux encore. Après avoir confié à la Commission de la représentation la responsabilité de former les délégations des groupes minoritaires, voici que

$\overline{168}$ Roger Charbonneau à Rosaire Morin, Ottawa, 23 octobre 1968, copie dans CRCCF, Fonds ACFO, C2/356/2.

${ }^{169}$ Rosaire Morin aux Canadiens-Français domiciliés à l'extérieur du Québec, Montréal, 28 octobre 1968, copie dans CRCCF, Fonds ACFO, $\mathrm{C} 2 / 356 / 2$. 
Rosaire Morin, dans une lettre différente, mais aussi datée du 28 octobre (il n'avait pas encore reçu la lettre envoyée par Charbonneau le 23 octobre 1968), demandait à l'ACFÉO d'organiser la délégation de l'Ontario français, l'assurant qu'il y aurait le même financement qu'en $1966^{170}$. La correspondance n'explique pas ce changement de cap du directeur général des États généraux, qui recourait ainsi à l'ACFÉO après avoir tenté de l'évincer quelques mois plus tôt.

La lettre que l'ACFÉO avait envoyée le 23 octobre s'égara et ne parvint à Rosaire Morin que le 11 novembre 1968. Le vice-président répondit le jour même à Charbonneau, lui rappelant la lettre circulaire envoyée fin octobre et l'assurant que "Afin de faciliter la cohésion entre Canadiens-Français des différents territoires, nous élargissons substantiellement les études portant sur l'avenir de la nation». Des «trois principaux documents à l'étude", le premier portait sur l'avenir de «la nation», le second sur le développement économique du Québec et le troisième sur la constitution du Québec («non pas avec la volonté de rechercher des options définitives, mais plutôt dans la pensée de définir les grands principes sur lesquels doit reposer la constitution du Québec»). Les délégués hors Québec pourront participer à tous les ateliers, où ils auront droit de vote "selon les règlements déjà établis l'an dernier».

Mais Morin précisait surtout que «Nous songeons toutefois à inviter particulièrement nos compatriotes des autres provinces à se grouper autour de la définition de leur propre avenir, dans leur propre territoire», ce qui laissait entendre que leurs solutions pourraient être

$\overline{170}$ Rosaire Morin à Roger Charbonneau, Montréal, 29 octobre 1968, CRCCF, Fonds ACFO, C2/356/2. 
différentes des solutions québécoises. Il était aussi question de deux grandes assemblées parallèles, pour les Canadiens-Français hors Québec (où les délégués québécois ne dépasseraient pas $20 \%$ des participants) et pour les Canadiens-Français du Québec, où ceux qui le désirent pourront participer, même de l'extérieur. Au-dessus, il y aurait une "assemblée nationale" regroupant tous les délégués. Cette assemblée nationale, toutefois, n'admettra que les résolutions "recevables", c'est-à-dire celles qui concernent au moins trois des quatre territoires (Québec, Acadie, Ontario, Ouest) car "Nous ne voulons pas donner le spectacle d'une nation divisée et morcelée».

Morin ajoutait qu'ainsi, bien peu de questions pourraient atteindre «l'Assemblée nationale». C'est à l'ACFÉO qu'il revenait d'organiser la délégation ontarienne. Répondant plus directement à la lettre du 23 octobre 1968, Morin ajouta qu'il trouverait "malheureux» d'informer les autres délégations et la presse, si jamais l'ACFÉO ne voulait pas organiser la délégation ontarienne:

Advenant que votre association décide de ne pas organiser votre délégation, ne serait-il pas satisfaisant pour toutes les parties en cause de nous faire connaître tout simplement votre impossibilité de remplir ce rôle. Il va de soi que l'organisation de la délégation ontarienne serait alors bien difficile pour nous, mais nous pourrions travailler dans un climat qui serait plus positif. Je crois personnellement qu'il faudrait éviter les déclarations publiques qui ne peuvent nullement servir les intérêts supérieurs de notre collectivité ${ }^{171}$.

En l'absence de Charbonneau, c'est le secrétaire adjoint, Rémy Beauregard, qui accusa réception de

${ }^{171}$ Rosaire Morin à Roger Charbonneau, Montréal, 11 novembre 1968 , copie dans CRCCF, Fonds ACFO, C2/356/2. 
la lettre de Morin ${ }^{172}$. C'est aussi lui qui convoqua une réunion du Comité exécutif, laquelle eut lieu le 20 novembre 1968. Il se produisit, encore une fois, «une très longue discussion [...] relativement à la participation de l'ACFÉO aux États généraux». Les directeurs étudièrent notamment les documents reçus et la lettre du 11 novembre 1968. De nombreux aspects de la question furent examinés: le manque de ressources de l'ACFÉO pour couvrir le déplacement des délégués, la crainte qu'on se serve des FrancoOntariens "pour faire valoir des points de vue contraires à notre idéologie», le danger qu'une absence n'entraîne une perte de prestige ou ne manifeste un manque de leadership, le désir d'éviter de «noircir son blason alors qu'il vient d'être redoré avec l'obtention d'écoles secondaires françaises», l'obligation de s'expliquer si on décide de s'abstenir, les avantages de se présenter pour faire valoir son point de vue, le désavantage de s'opposer aux États généraux "parce que certains de ses éléments ont des tendances séparatistes», le risque de créer une désunion entre l'Ontario français et les autres minorités, la difficulté d'organiser la délégation, puisque les délégués de 1966 et 1967 étaient très insatisfaits. Le débat tint donc compte d'un grand nombre de facteurs. Puisque les autres grandes associations provinciales avaient décidé de participer, de même que le Conseil de la Vie française, l'ACFÉO ne devrait-elle pas faire un effort, afin d'éviter que ne se présente, pour représenter l'Ontario à la place de l'ACFÉO, "d'autres Franco-Ontariens, qui ne seraient pas représentatifs ${ }^{173}$ »? Ce qui fit basculer la balance, en fin de

172 Rémy Beauregard à Rosaire Morin, Ottawa, 12 novembre 1968, copie dans CRCCF, Fonds ACFO, C2/356/2.

${ }^{173}$ «Procès-verbal du Comité exécutif de l'ACFÉO», 20 novembre 1968 , 
compte, ce fut sans doute la lettre du 11 novembre 1968. Morin ne répondait pas aux questions posées par l'ACFÉO dès juin 1968: quels étaient les «buts et objectifs» des assises et quelles seraient les modalités des votes.

Le procès-verbal du Comité exécutif motiva sa décision en quatre points: (1) on n'a pas bien défini les buts et les objectifs des États généraux, (2) on y parle de nation sans la définir, (3) deux des trois sujets à l'étude seront l'avenir économique et la constitution du Québec ( «comme par le passé nos opinions sur ces sujets seront mal reçues puisque nous ne sommes pas des Québécois") et, surtout, (4) une phrase en particulier avait provoqué les directeurs. Dans sa lettre, Morin écrivait: «Nous pensons que nos compatriotes des autres provinces seront plus heureux de rechercher des solutions à leurs problèmes que de s'appliquer à régler ceux du Québec.» À quoi le procès-verbal ajoutait: «Les directeurs estiment qu'il n'est pas nécessaire d'aller aux États généraux pour rechercher les solutions à nos problèmes.» Puis ils adoptèrent ( 5 pour, 2 abstentions) la résolution suivante:

QUE l'ACFÉO se désiste de toute participation aux États généraux de mars 1969 et qu'elle indique publiquement ses raisons de non-participation et que le président, le vice-président et le trésorier rédige[nt] un communiqué à cet effet qui sera expédié aux média d'information, aux États généraux, aux associations des autres provinces ainsi qu'aux membres du conseil d'administration ${ }^{174}$.

Non seulement l'ACFÉO refusa-t-elle de participer, mais elle entendait le faire savoir partout, à l'encontre de la demande expresse de Rosaire Morin.

copie dans CRCCF, Fonds ACFO, C2/355/4.

${ }^{174}$ Ibid., CRCCF, Fonds ACFO, C2/355/4. 
Le président général de l'ACFÉO, Roger-N. Séguin, avait pris le pouls de son Comité exécutif, le 20 novembre 1968. Celui-ci lui demanda de signer lui-même, à titre de président général de l'Association, la lettre informant les États généraux que l'ACFÉO ne participerait pas aux prochaines assises. Le lettre précise: «Les directeurs ont noté que les États généraux se donnent pour objectifs l'avenir de la nation et l'unité qui doit y exister, mais cela en des termes très vagues.» La lettre rappelait d'une part que Morin parlait de la constitution et du développement économique du Québec, et d'autre part qu'il ajoutait que les délégués des minorités «seront plus heureux de rechercher des solutions à leurs problèmes que de s'appliquer à régler ceux du Québec». Et Séguin d'expliquer: «Les directeurs ont eu beaucoup de difficulté à concilier ces deux affirmations.» Les directeurs, en outre, jugeaient que leur devoir leur commandait d'informer les Franco-Ontariens et la presse de leur décision ${ }^{175}$.

Et de fait, le jour même, le secrétaire adjoint de l'ACFÉO, Rémy Beauregard, informait les membres du Conseil d'administration de la décision du Comité exécutif. L'ACFÉO diffusa un communiqué de presse qui annonçait "sa décision de ne pas participer aux prochaines délibérations des États généraux». Après avoir examiné les explications fournies par les dirigeants des États généraux, le Comité exécutif se disait «incapable de voir le bien-fondé de sa participation à la formation de la délégation francoontarienne pour les prochaines assises». On précisait ainsi:

$\overline{175}$ Roger-N. Séguin, président général de l'ACFÉO, à Rosaire Morin, Ottawa, 27 novembre 1968, copie dans CRCCF, Fonds ACFO, C2/356/4. 
Il est vrai qu'on y mentionne l'avenir de la nation, qu'on y parle d'unir au lieu de diviser, mais cela en des termes vagues. Par contre, il y est clairement question du développement économique et de la constitution du Québec. On ajoute même que les francophones des autres provinces seront plus heureux de rechercher des solutions à leur problèmes que de s'appliquer à régler ceux du Québec.

Dans cette optique, qui prévalait déjà lors des assises de 1967 et de 1968 [sic, c'est-à-dire 1966 et 1967] auxquelles assistait une forte délégation franco-ontarienne, l'ACFÉO ne croit pas qu'il y ait nécessité de s'y joindre en 1969.

L'ACFÉO se dissocie donc de l'organisation de la délégation franco-ontarienne et elle ne participera pas en groupe aux prochaines assises des États généraux ${ }^{176}$.

Les ponts étaient donc définitivement coupés.

Avec une extrême parcimonie de mots, Morin, généralement loquace, répondit sèchement en cinq petits paragraphes d'une phrase chacun: «Les membres du bureau exécutif me prient de répondre à votre lettre du 27 novembre. - Ils regrettent de constater votre impossibilité d'organiser la délégation FrancoOntarienne [sic]./Ils s'étonnent davantage des termes du communiqué remis aux journaux./ Ils formulent l'espoir que vous appuierez les cadres qui travailleront à l'organisation de la délégation francoontarienne./ Veuillez agréer, cher monsieur Séguin, l'assurance de mes sentiments les meilleurs ${ }^{177}$.»

La décision de l'ACFÉO fut applaudie dans certains milieux. En éditorial, par exemple, le poste de radio CIRC (Ottawa) approuva la décision, disant que les États généraux n'avaient plus leur raison

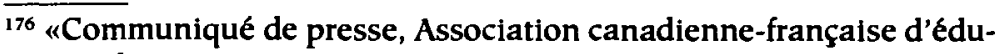
cation d'Ontario", Ottawa 27 novembre 1968, copie dans CRCCF, Fonds ACFO, C2/356/2.

177 Rosaire Morin à Roger-N. Séguin, Montréal, 29 novembre 1968 , copie dans CRCCF, Fonds ACFO, C2/356/2. 


\section{GaEtan Gervals}

d'être puisqu'il y avait maintenant le Parti québécois: «À cause de documents de travail nettement orientés, à cause d'un simulacre de démocratie, à cause d'un dialogue à sens unique, on n'a jamais réussi à prendre le pouls de la nation: c'est le pouls des organisateurs qu'on a pris, avec les résultats qu'on connaît ${ }^{178}$." Par contre, d'autres ne partageaient pas l'avis de l'ACFÉO, comme Florent Lalonde, qui écrivit à Charbonneau que «le mouvement séparatiste semble perdre de son envergure». À quoi Roger Charbonneau répliquait: «j'aimerais que nous puissions en dire autant des dirigeants des États généraux». Dans la région du sud de l'Ontario, toutefois, il semble que les gens étaient plutôt satisfaits de la décision de l'ACFÉO de ne plus participer aux États généraux ${ }^{179}$.

L'ACFÉO n'était pas seule à s'inquiéter de la pente sur laquelle glissaient les États généraux. Les documents distribués aux délégués en octobre ne firent qu'accroître les inquiétudes, même chez ceux qui continuaient de participer. Ainsi, le lendemain même de la déclaration de l'ACFÉO, Adrien Pouliot écrivait au juge André Déchène (de l'Alberta), lui transmettant une lettre qu'il avait envoyée à $\mathrm{M}^{\mathrm{gr}}$ Paul-Émile Gosselin. Selon Pouliot, les documents préparés par les Etats généraux le décevaient: «C'est vraiment décourageant, mais le fait est patent qu'il y a dans les cellules de cet organisme [les États généraux] un esprit absolument réfractaire à l'unité canadienne», une attitude qui lui semblait d'autant plus

\footnotetext{
178 «Éditorial CJRC», 5 décembre 1968, [transcription], copie dans CRCCF, Fonds ACFO, C2/356/2.

${ }^{179}$ Florent Lalonde à Roger Charbonneau, 15 décembre 1968; Roger Charbonneau à Florent Lalonde, 23 décembre 1968; Roger Charbonneau à Jacques Dubois, 23 décembre 1968, copies dans CRCCF, Fonds ACFO, C2/356/2.
} 
néfaste que Pierre-E. Trudeau s'apprêtait à favoriser les groupes français au Canada. Pouliot craignait, même s'il espérait se tromper, «que l'on fomente inconsciemment ou peut-être même à dessein! des germes d'un séparatisme de mauvais aloi ${ }^{180}$ ".

L'ACFÉO ne revint pas sur sa décision, ni à l'invitation de Rosaire Morin, ni à la demande de Florent Lalonde. Le Comité exécutif, en janvier 1969, confirma sa décision. Selon Charbonneau, qui répondait à Lalonde: «les directeurs ont décidé de maintenir le statu quo. Les commentaires que nous recevons des autres provinces portent à croire que la décision de l'ACFÉO était sage ${ }^{181}$."

L'absence de l'ACFÉO ne changea pas grand-chose aux États généraux qui poursuivirent leur irrésistible marche vers l'assemblée "constituante». Rosaire Morin donna, le 27 février 1969, une conférence de presse pour expliquer le déroulement des assises. Comme toujours, Morin rappela que le tout devait se dérouler "sous le thème de l'unité»: "Nous avons réussi la première prise de conscience de notre nation canadienne-française et nous croyons avoir trouvé le mécanisme qui permettra à notre société de s'affirmer ${ }^{182}$.» Sinon, il pourrait y avoir une autre convocation des États généraux.

\footnotetext{
${ }^{180}$ Adrien Pouliot à André M. Déchène, Québec, '28 novembre 1968 , copie dans CRCCF, Fonds ACFO, C2/356/2.

181 Roger Charbonneau à Florent Lalonde, Ottawa, 30 janvier 1969, copie dans CRCCF, Fonds ACFO, C2/356/2.

${ }^{182}$ François Barbeau, «Place à une "assemblée constituante" - Les prochaines assises des Etats généraux pourraient être les dernières", dans Le Devoir, 28 février 1969, p. 3.
} 
UNE DÉLÉGATION RACCOURCIE

Ne pouvant plus compter sur l'ACFÉO, les dirigeants des Etats généraux tentèrent de constituer une délégation ontarienne autour des quelques personnes qui siégeaient dans les commissions, notamment à la Commission de la participation nationale. Devant le désistement de l'ACFÉO, il revint au directeur général, aidé de quelques délégués francoontariens, de tenter d'organiser la délégation ontarienne.

Dès la fin d'octobre 1968, Rosaire Morin avait envoyé des versions préliminaires de chapitres. Aux délégués de l'Ontario, on envoya une section traitant de l'Ontario; les délégués devaient réagir au contenu des documents, par écrit ou par téléphone, avant le 10 novembre 1968. Ce document contenait des sections sur l'histoire, la démographie, l'enseignement, la situation culturelle, économique et religieuse.

Le 17 janvier 1969, Rosaire Morin écrivait une lettre «À chaque délégué de l'Ontario» (ceux qui avaient participé aux assises de 1967), au nom de la Commission générale, pour les inviter aux prochaines assises, les inscriptions obligatoires se faisant le mercredi soir, 5 mars. La lettre précisait: «En Ontario, un comité élu par les Franco-Ontariens comprend MM. Jean-Louis Duchesneau, Jean-Paul Gélinas, Rodrigue Landriault, Ryan Paquette, Séraphin Marion, R.P. Lorenzo Cadieux, Jacques de Courville Nicol et Gaston Gélinas. Ce comité dirige la délégation de l'Ontario". À côté de cette affirmation, en marge, la copie de la lettre survivant dans les archives de l'ACFÉO porte un gros point d'interrogation. Les États généraux invitaient «tous les membres qui ont participé aux Assises de 1967» à retourner leur for- 
mulaire personnel avant le $\mathbf{3 0}$ janvier. La lettre continuait: "À cette date, les différentes associations seront invitées à désigner des délégués pour les postes à pourvoir.»

Il n'y avait pas de droits d'inscription et la Commission générale rembourserait le prix d'un billet de train «à ceux qui pourront difficilement se permettre un tel déboursé». Quant au logement, il dépendait de la générosité des Montréalais: «Elle [la Commission générale] offre un logement gratuit, chez un délégué montréalais, aux 400 premiers délégués de l'extérieur qui se prévaudront de ce geste hospitalier. Elle a obtenu un prix de $\$ 5.00$ par jour, par chambre simple, de l'hôtel Queen's.»

Morin souhaitait encore la participation franco-ontarienne et terminait sa lettre par un plaidoyer:

Notre invitation se veut pressante. La nation canadiennefrançais a besoin de chacun de nous. Ces Etats généraux auxquels vous participez constituent un événement unique dans notre histoire. C'est le premier rassemblement qui s'opère au-delà des partis politiques, dans le but précis de parvenir à une conscience claire des lignes de force qui entraînent la nation canadienne-française vers son avenir. Cet événement est l'un des plus importants de notre milieu et de notre époque. Vous pouvez en être les artisans; n'hésitez pas à le devenir ${ }^{183}$.

Ce plaidoyer résume assez bien les intentions de Morin. Dans une autre lettre du 23 janvier 1969, il s'adressait à l'ACFÉO pour l'inviter à retourner son formulaire d'inscription aux États généraux. La lettre, avec sa formule non remplie, se trouve toujours dans

${ }^{183}$ Rosaire Morin à chaque délégué de l'Ontario, Montréal, 17 janvier 1969, copie dans CRCCF, Fonds ACFO, C2/356/2. 
les archives ${ }^{184}$. De même, Rosaire Morin fit parvenir à Roger Charbonneau, le 15 février 1969, sa «lettre de créance" pour qu'il participât aux États généraux. Ce document aussi se trouve toujours dans les archives de l'ACFO, n'ayant évidemment jamais servi.

Ces efforts pour organiser la délégation ontarienne furent apparemment plutôt difficiles, pour deux raisons. La première, c'est le peu d'aide qu'on put obtenir de la Commission générale des États généraux, l'autre étant le refus de l'ACFÉO de participer. D'ailleurs, les deux organismes furent blâmés par la poignée de délégués qui prirent le chemin de Montréal. Aussi, on manqua de fonds, ce qui obligea les délégués à payer eux-mêmes les frais de déplacement à Montréal. Une semaine avant les assises, il n'y avait encore que le quart des délégués ontariens (donc une cinquantaine) d'inscrits. Selon Le Droit, les "organisateurs de la délégation ontarienne" étaient Rodrigue Landriault et Jacques de Courville Nicol (d'Ottawa); Jean-Louis Duchesneau (de North-Bay); Jean-Paul Gélinas (d'Ansonville); Marc-Yvain Giroux (de Welland); Aurélien Bouchard ("du poste CJBC à Toronto») 185 . Alors que 210 places étaient réservées à l'Ontario, seulement 38 délégués se présentèrent, dont 17 d'Ottawa; sur les 38 délégués de 1969, 18 avaient participé aux assises de 1967.

Dans un éditorial intitulé "Sous le thème de l'unité», Marcel Gingras écrivait dans Le Droit, à la veille des États généraux, qu'il était rassuré par les propos de Rosaire Morin. Gingras se croyait autorisé

\footnotetext{
${ }_{184}$ Rosaire Morin à l'Association canadienne-française d'éducation d'Ontario, 23 janvier 1969, CRCCF, Fonds ACFO, C2/356/2.

185 «À Montréal, du 5 au 9 mars - Les minorités tenteront de définir le mode de leur participation aux prochaines assises des Etats généraux», dans Le Droit, 28 février 1969, p. 5.
} 
à respirer, sur la foi des propos de François-Albert Angers, qui avait distingué entre le droit de choisir et le choix arrêté. Les Québécois et «leurs frères des autres provinces" n'aspiraient qu'à cette unité. Néanmoins, Gingras retenait «une certaine appréhension lorsqu'on sait qu'aux assises, les minoritaires seront confinés à l'étude de leurs propres problèmes, dans une commission dite "des minorités". N'est-ce pas au départ faire d'eux une caste à part, même si on leur adjoindra quelques Québécois», alors que dans les autres commissions, ce sera le contraire: un maximum de $20 \%$ des membres pouvaient provenir des groupes minoritaires ${ }^{186}$.

\section{LA RENCONTRE PRÉLIMINAIRE DES MINORITÉS FRANÇAISES (5 MARS 1969)}

Comme aux assises précédentes, les minorités tentèrent de se concerter. Une semaine avant les assises de Montréal, Le Droit résumait une rencontre du 27 février, tenue à l'Union du Canada et convoquée par Rodrigue Landriault, "pour compléter la délégation de I'Est». Au cours de cette réunion, il fut décidé de convoquer toutes les délégations des groupes minoritaires, au début des assises, pour décider si elles devaient participer de façon active ou se contenter d'observer. Puisque les délégués des minorités ne connaissaient que trop bien la nature des problèmes dans leur région, ils préféraient débattre de l'avenir de l'ensemble du Canada français. Les délégués ontariens réunis à Ottawa entendaient proposer que les délégués minoritaires se regroupassent pour discuter des changements à apporter à la constitution

186 Éditorial de Marcel Gingras, «Sous le thème de l'unité», dans Le Droit, 5 mars 1969, p. 6. 
canadienne. Si la décision était d'observer seulement, alors les délégués se présenteraient plutôt aux ateliers des délégués québécois. Au cours de cette réunion du 27 février, on discuta aussi de l'opportunité de tenir une réunion des États généraux des Canadiens français de l'extérieur du Québec ${ }^{187}$.

Malgré tout, et plutôt naïvement, la délégation ontarienne semblait croire que les États généraux de 1969 seraient, par leur contenu, différents de ceux de 1967. Les faits, bientôt, contrarièrent ces espoirs.

La rencontre des minorités eut lieu, au salon Duluth de l'hôtel Reine-Élisabeth, le mercredi soir 5 mars 1969. Rosaire Morin rencontra certains représentants des minorités (Ontario, Alberta, Colombie-Britannique), les exhortant à ne pas causer de division, et les invita

[...] à ne pas prendre de position ou adopter de résolution qui pourraient s'opposer aux aspirations des délégués du Québec, car elles pourraient provoquer un affrontement et créer une division profonde et stérile de la nation canadienne-française.

M. Morin a demandé aux délégués minoritaires d'accepter sans opposition ouverte les réclamations de la délégation québécoise, quelles qu'elles soient.

Pour cette raison, il a refusé de permettre aux minorités de participer en bloc aux études de l'avenir politique et constitutionnel du Canada français.

La délégation ontarienne avait demandé de participer à cette étude, qui forme le but principal de l'organisme.

Il a toutefois été entendu, après compromis, que les minorités pourraient "réclamer pleinement leurs droits" par des amendements à la Constitution canadienne dans le

187 «`̀ Montréal, du 5 au 9 mars - Les minorités tenteront de définir le mode de leur participation aux prochaines assises des États généraux", dans Le Droit, 28 février 1969, p. 5. 
cadre des travaux qui leur ont été assignés à l'ordre du jour, soit l'étude des divers aspects et problèmes de leur situation minoritaire, à la condition que ces demandes ne s'opposent pas aux demandes que formulera la délégation du Québec ${ }^{188}$.

Ce paternalisme et cette condescendance ne pouvaient mieux proclamer l'inégalité fondamentale des délégués. Jacques de Courville Nicol déclara que les minorités ne pouvaient accepter cet «engrenage» conduisant à la proposition d'une constituante et de rédaction d'une constitution du Québec, alors qu'on écartait les minorités de la discussion ${ }^{189}$. Lors de cette rencontre préliminaire des minorités, les groupes présents décidèrent que les minorités participeraient aux États généraux non en observateurs, mais en membres actifs. On discuta aussi de la possibilité de prochains Etats généraux des minorités.

Qu'allaient devenir les propositions des minorités? Les États généraux avaient mandaté une «commission de révision des résolutions", habilitée à rejeter les propositions «qui s'opposent aux désirs de la majorité» et afin d'assurer la "cohésion et l'unité».

La veille des États généraux, dans Le Devoir, Vincent Prince s'interrogea sur les assises. Les dirigeants disaient bien qu'ils ne voulaient pas adopter une option constitutionnelle particulière, mais cela, c'était discuter dans le vide, sans référence à aucun cadre constitutionnel particulier. «Si l'on en juge par les sessions antérieures, ce pourrait bien n'être qu'une façon d'éviter d'appeler les choses vraiment par leur nom.» Selon Prince, "Les États généraux, que cela plaise ou non, ont été, dès le départ, envahis par les

$\overline{188}$ Jules Labelle, «Affrontement possible entre les délégués québécois et les minorités», dans Le Droit, 6 mars 1969, p. 1.

${ }^{189}$ Loc. cit. 
champions de l'indépendance ou les promoteurs de la thèse des États associés». Ainsi, ils "n'ont jamais été représentatifs». Il y a eu noyautage des groupes extrêmes dès le début ${ }^{190}$. Cet éditorial de Prince causa quelques remous qui poussèrent Claude Ryan, dans un nouvel éditorial, le 4 mars, à reprendre le sujet. Selon Ryan, les résolutions adoptées en 1967 contenaient déjà une option politique.

\section{LE DÉROULEMENT DES ÉTATS GÉNERAUX} DU 5 AU 9 MARS 1969

Les dernières assises des Etats généraux se déroulèrent à l'hôtel Reine-Élisabeth de Montréal, du $5 \mathrm{au}$ 9 mars 1969. Selon le rapport officiel, 1866 personnes participèrent, dont 777 "délégués territoriaux» du Québec, plus 265 délégués d'associations, 180 observateurs, 103 journalistes, 254 invités, 162 auxiliaires et, bien entendu, les 125 délégués des autres provinces $^{191}$. On avait réservé 430 places pour les minorités, il n'en vint que 125; l'Ontario français disposait de 210 places, il en occupa 38. Il appert donc que le boycottage des Etats généraux par les minorités avait été plutôt efficace ${ }^{192}$.

190 Éditorial de Vincent Prince, "Dernière session des Etats généraux?", dans Le Devoir, 4 mars 1969, p. 4.

${ }^{191}$ Voir: Les États généraux. Assises nationales tenues a l'hôtel Reine Elisabeth du 5 au 9 mars 1969 ([Montréal, Action nationale, s.d.], pp. 616-619. Ces actes furent aussi publiés dans la revue de L'Action nationale 58(9-10), $646 \mathrm{p}$.

192 Dans les actes, aux pages 616-619, on trouvera dans le détail la répartition des sièges. Les minorités avalent droit à 430 sièges, dont 210 pour l'Ontario (il en vint 38), 124 pour l'Acadie (qui en délégua 24) et 93 pour l'Ouest ( 63 participèrent). En fait, les minorités n'envoyèrent que 125 délégués (sur les 430 sièges disponibles), ces 125 «minoritaires» représentant 6,9\% des 1866 participants. La voix des groupes minoritaires, forcément, fut encore plus faible qu'avant. 
René Lévesque, le chef du nouveau Parti québécois, envoya un message de bons vœux aux délégués, leur souhaitant de "poursuivre et d'accentuer cette action catalysante qui fait de vous tous une importante étape vivante de notre évolution nationale». Jean Lesage, chef du Parti libéral du Québec, assura les délégués que leurs efforts constituaient «un apport à l'évolution de la nation canadienne-française", tandis que Jean-Jacques Bertrand, premier ministre, reconnaissait l'effort des États généraux vers une définition collective ${ }^{193}$.

À la séance d'ouverture des assises, c'est encore, comme en 1967, Jacques-Yvan Morin qui prononça le discours de circonstance sur «L'avenir du Canada français", tandis que Rosaire Morin fit une conférence sur les «Perspectives d'avenir». Ce dernier répéta qu'en ce moment, les États généraux ne pouvaient pas encore choisir une option constitutionnelle globale. En 1969, il n'y eut pas de guerre des drapeaux, parce qu'on avait adopté un "protocole des drapeaux» qui reconnaissait au fleurdelisé québécois la place d'honneur, le drapeau canadien occupant une position inférieure, sur un mât plus bas.

En après-midi, le 6 mars 1969, les délégués se répartirent en douze groupes, quatre pour l'atelier politique sur la constitution du Québec, cinq pour l'atelier économique sur le développement économique du Québec et trois pour l' «atelier des minorités françaises» (la démographie, l'enseignement en français et le rayonnement culturel). Ces douze groupes devaient préparer des "avant-projets de résolution" qui seraient ensuite acheminés vers les «douze groupes de révision». Les "résolutions révisées" seraient alors

193 «Les voux des politiciens», dans Le Devoir, 7 mars 1969, p. 9. 
soumises aux trois "ateliers de travail», qui en feraient aussi une révision, «selon des techniques de travail inspirées de l'animation sociale». Par la suite, les projets révisés de résolutions parviendraient à l'Assemblée nationale, nom qu'on donnait désormais à «l'assemblée générale ${ }^{194}$ ».

Pendant que les délégués québécois discutaient de l'avenir constitutionnel du Canada français et d'économie, les délégués minoritaires, répartis en trois groupes, s'occupaient de questions bien plus banales. L'atelier de démographie se demandait s'il fallait faire un recensement des "Canadiens français en dehors du Québec", qui devrait s'en occuper, au frais de qui; le groupe discuta des avantages d'établir des «Maisons du Québec» dans les différentes provinces, il s'interrogea sur l'adoption au Québec d'une «loi du retour» pour encourager les minoritaires à «rentrer au Québec» (18 oui, 7 non et 10 abstentions), sur l'anglicisation, sur l'immigration. Le deuxième atelier, sur l'enseignement du français, traita de l'usage du français, des écoles, de la langue, de l'éducation selon la constitution (la majorité veut un rôle prépondérant du gouvernement fédéral), des bourses, des échanges, etc. Enfin, le troisième atelier, sur le rayonnement culturel parla de solidarité, des relations entre les groupes, des relations avec le Québec, des «Maisons du Québec», des divers instruments de rayonnement, des moyens de communication ${ }^{195}$. En un mot, des sujets plutôt ternes à côté de «'avenir du Canada français».

\footnotetext{
${ }^{194}$ Les États généraux. Assises nationales tenues à l'hôtel Reine Elisabeth du 5 au 9 mars 1969, p. 51.

${ }^{195}$ Pour le texte des questions et le détail des réponses, voir Les Etats généraux. Assises nationales tenues d l'hôtel Reine Élisabeth du 5 au 9 mars 1969, pp. 116-130.
} 
Des «avant-projets de résolutions" émergèrent de l'atelier des minorités, demandant la prise d'un recensement de la population et des effectifs scolaires, tâche qui devait relever d'un organisme "reconnu par la nation canadienne-française». On recommandait aussi la création de "Maisons du Québec» et l'adoption de politiques sur les migrations. Dans le domaine scolaire, on proposa diverses solutions, $y$ compris celle qui permettrait au gouvernement fédéral d'intervenir (après un amendement constitutionnel) là où la minorité est lésée. À l'atelier du rayonnement culturel, on fit des recommandations touchant les communications, la création d'un organisme coordonnateur des minorités, l'aide du gouvernement du Québec, les médias, l'animation, l'aide aux centres culturels ${ }^{196}$. Ces résolutions, passées au crible des "groupes de révision», puis des «ateliers de travail», furent présentées, sans changement de fond, mais dans une forme plus cohérente ${ }^{197}$.

Dès le 6 mars, le journaliste du Droit, Jules Labelle, évoquait le danger d'affrontement, que rien ne semblait capable d'éviter. Sous le titre «Dialogue interdit», l'éditorialiste du Droit, Marcel Gingras, écrivait que "pour un grand nombre de délégués du Québec, les participants des autres provinces ne sont que tolérés». Citant Albert Regimbal, Gingras disait que les minorités demandaient au moins qu'on les écoutât. À l'émission télévisée "Aujourd'hui», le jeudi 6 mars 1969, on avait entendu certains délégués

196 Pour le texte des avant-projets de résolution, voir Les États généraux. Assises nationales tenues à l'hôtel Reine Élisabeth du 5 au 9 mars 1969, pp. 158-161.

${ }^{197}$ Pour le texte des projets de résolution, voir Les États généraux. Assises nationales tenues d̀ l'hôtel Reine Élisabeth du 5 au 9 mars 1969, pp. 186-189 (groupe de révision) et pp. 205-209 (ateliers de travail). 
dire que les minorités étaient "finies», "perdues", «mortes», enfin qu'elles étaient irrémédiablement vouées à «l'assimilation». Le Droit y trouva une autre preuve de ce «refus de dialogue». L'émission permit même à un savant délégué de citer la phrase de Berryer: "Quand la maison brûle, on ne s'occupe pas des écuries". Malgré tout, l'éditorialiste espérait un dialogue ${ }^{198}$.

Le débat sur les résolutions commença le samedi matin, le 8 mars 1969, lors de la discussion, par "l'Assemblée nationale», des "projets de résolutions émanant de l'atelier des minorités françaises». Selon les procédures adoptées plus tôt, les résolutions devaient être adoptées "en bloc» et aussi "discutées en bloc", même si on votait ensuite sur chaque résolution. Les résolutions portaient sur la nécessité d'un recensement des minorités, sur la création de Maisons du Québec, sur les mouvements migratoires, sur l'enseignement du français, sur la compétence constitutionnelle en éducation, sur les relations entre Canadiens-Français, sur les droits des CanadiensFrançais, sur la vie économique des "CanadiensFrançais hors du Québec», sur l'aide du gouvernement du Québec, sur les communications, sur la compétence constitutionnelle en radiodiffusion. Chaque résolution, composée d'un à sept paragraphes, était reçue ou rejetée en bloc.

Le tout premier intervenant fut Étienne Saint-Aubin,

198 Éditorial de Marcel Gingras, «Dialogue interdit», dans Le Droit, 8 mars 1969, p. 6 . On se rappelait peut-être qu'en 1967 , lors de la Conférence de demain, à Toronto, le premier ministre provincial du Québec, Daniel Johnson, déclarait: "Notre devoir, en venant ici, était d'inciter les autres provinces à accentuer la dualité canadienne. Les Québécois, qui rejettent sans scrupule le sort d'un million des leurs vivant hors des frontières québécoises, sont des démagogues.» 
qui s'opposa à la résolution demandant que le gouvernement du Québec oriente l'immigration vers les "centres viables", terme pour désigner les régions où les concentrations de population française permettaient de maintenir, même à l'extérieur du Québec, des foyers de langue et de culture françaises. Selon ce délégué ontarien, «le Québec devrait faciliter le retour des Francophones vers le territoire national, le Québec, afin de se renforcer comme État [...] Ça vient fatiguant [sic] de se croire des missionnaires qui vont changer quelque chose qui est inchangeable dans presque toutes les provinces, sauf disons le Nouveau-Brunswick et peut-être l'Ontario».

Au cours du débat, d'autres Franco-Ontariens prirent la parole (la délégation ontarienne ne comptait que deux femmes, Évelyne Lachapelle et Madeleine Roy). Albert Regimbal (écrit "Régimbald» dans les actes) appuya fortement la résolution, qui demandait aussi la création des Maisons du Québec (un projet qu'on discutait déjà à Ottawa en 1961, lors de la rencontre des sociétés Saint-Jean-Baptiste de l'Ontario et du Québec). De son côté, Jacques de Courville Nicol (écrit «Nichol») parla en faveur de la résolution. Paul Morissette appuya aussi l'ensemble de la résolution, mais il n'était pas d'accord avec la partie touchant l'immigration: "Je suis moi-même de Sudbury. Je ne crois plus à la viabilité des centres francophones à l'extérieur du Québec. Je suis moi-même francophone minoritaire et j'affirme ici qu'il faut songer d'abord au Québec." Marcel Corriveau déclara qu'il "ne faut pas se leurrer. Un Canada bilingue, c'est utopique, ça n'a jamais existé et ça n'existera jamais, malgré ce que Trudeau peut en dire. Il faut bien comprendre que, sauf l'Acadie et le Nord de l'Ontario, les Canadiens-Français vont 
s'assimiler de plus en plus.» Selon lui, il fallait done sauver le Québec, non les minorités sans avenir. Donald Obonsawin (écrit "Vanswan»!) expliqua le sens de la résolution qui ne préconisait pas le détournement des immigrants québécois vers d'autres régions, mais leur direction vers les «centres viables» dans le cas d'immigrants qui se destinent de toute manière vers les autres provinces. Paul Therrien affirma qu'un vote négatif favoriserait l'assimilation. Outre ces sept Franco-Ontariens, trente-neuf (39) autres délégués participèrent aux discussions ${ }^{199}$.

L'ensemble des résolutions de l'atelier des minorités françaises fut adopté. Mais il faut cependant préciser que lors de l'adoption de ces résolutions, seulement vingt-sept (27) délégués ontariens participèrent au vote (moins d'une soixantaine de l'Ouest, treize de l'Acadie, mais 500 du Québec). Le vote québécois, toutefois, se divisa fortement lors des résolutions touchant la compétence fédérale en matière de radiodiffusion et de télévision, ce qui équivalait, compte tenu des procédures, à un rejet de la proposition.

Le samedi après-midi, «l'Assemblée nationale» discuta des résolutions émanant de l'atelier économique. Au cours de ces discussions, seulement deux Franco-Ontariens ont pris la parole. Bernard Benoît nota la très grande présence du gouvernement du Québec qui, selon lui, a «failli à sa tâche et manqué le bateau». Il relevait deux grandes réussites (le mouvement coopératif et Hydro-Québec), mais ne voyait pas d'autre solution qu'un certain interventionnisme

$\overline{199}$ "Débats de l'Assemblée nationale», dans Les États généraux. Assises nationales tenues d̀ l'hôtel Reine Élisabeth du 5 au 9 mars 1969, pp. 213-249. 
de l'État. Bernard Lafontaine demanda la parole pour une question de principe: puisque de nombreux délégués québécois avaient, le matin même, débattu des résolutions émanant des minorités, il voulait à son tour se prononcer sur les résolutions touchant le Québec ${ }^{200}$. Sur presque tous les votes, 27 délégués ontariens participèrent, généralement avec 18 ou 19 abstentions, et 9 ou 8 oui (aucun vote négatif). La consigne d'abstention semblait donc être suivie.

Le dimanche matin, «l'Assemblée nationale» étudiait les résolutions de l'atelier constitutionnel. La première résolution discutée demandait que le Québec, «à l'exemple de la majorité des peuples souverains», se dotât d'une constitution dans laquelle se trouveraient une affirmation du droit du Québec à l'autodétermination, une charte des droits, l'adoption de symboles officiels d'un État, la définition des frontières «respectant l'intégrité existante et à englober les prolongements politiques et naturels» (une sorte de "divisionnisme» avant la lettre!), une clause disant qu'on ne pouvait toucher à l'intégrité territoriale sans un référendum. Cette constitution devait contenir des dispositions «affirmant la souveraineté du Québec sur son sol, son sous-sol, son espace aérien, ses eaux territoriales et son sol sousmarin et des droits égaux à ceux des autres États quant à toute forme d'utilisation de l'espace atmosphérique et extra-atmosphérique». Sur cette résolution, les Ontariens votèrent 9 en faveur, 1 contre et 16 s'abstinrent (pour le Québec: 598 pour, 12 contre et 10 abstentions, ce qui donne un appui québécois à

200 «Débats de l'Assemblée nationale sur les projets de résolutions émanant de l'atelier économique», dans Les États généraux. Assises nationales tenues d̀ l'hôtel Reine Elisabeth du 5 au 9 mars 1969, pp. 256-157 (B. Benoît) et pp. 279-280 (B. Lafontaine). 
96,45\%). D'autres résolutions portaient sur la charte des droits, où les Ontariens votèrent exactement dans les mêmes proportions (10 oui, 16 abstentions, aucun non).

Les résolutions de l'atelier politique définissaient les pouvoirs du Québec dans une constitution à venir. La résolution la plus controversée, sans doute, fut celle qui demandait la convocation d'une constituante. Diverses résolutions définissaient les modalités de l'élection et du fonctionnement de la Constituante.

Au cours de la discussion qui précéda le vote sur ces résolutions de l'atelier politique, quelques Franco-Ontariens prirent la parole. Jacques Vallée appuya les résolutions, qui conduiraient à un «régime politique plus démocratique, plus efficace», grâce à son régime présidentiel, sa représentation proportionnelle, son droit d'initiative. Jacques de Courville Nicol, parlant à titre de membre de la Commission de la participation, dit que le délégués ontariens, malgré de nombreux obstacles (mauvaise presse, retrait de l'ACFÉO, manque de fonds) sont "venus ici au Québec, parce que nous avions confiance en tous les Québécois, en tous les CanadiensFrançais. Nous sommes venus ici à titre d'amitié. Nous sommes venus ici objectivement pour rechercher l'entente et l'unité.» De Courville Nicol rappelait que les minorités avaient accepté, le 16 novembre 1968, de se rassembler dans un même atelier, pour éviter les affrontements. Or les ateliers des minorités avaient exclu la question constitutionnelle, de sorte que les minorités n'avaient jamais eu l'occasion de se prononcer sur la question fondamentale qui avait donné naissance aux États généraux, c'est-à-dire «l'avenir du Canada français». De Courville Nicol concluait que les minorités n'ayant pu se prononcer, 
et par souci d'éviter les affrontements, il conseillait aux minorités de s'abstenir de voter sur les résolutions d'un «atelier complètement québécois».

Gérard Lévesque commença ainsi son intervention: «Messieurs les délégués du Canada français (lequel n'a jamais été limité au Québec), j'espère que vous allez respecter mon droit de parole, même si je parle contre certains articles." Selon Lévesque, le Québec pouvait décider par lui-même, mais les minorités avaient aussi droit à leurs propres aspirations. D'ailleurs, demandait-il, faut-il confondre le Québec avec les «délégués québécois», est-on passé des États généraux du Canada français aux États généraux du Québec français? Si c'est le cas, il faudrait alors des États généraux des minorités ${ }^{201}$.

Sur la question même de la constituante (vote numéro 27, dans les actes), les délégués québécois appuyèrent à $94,8 \%$ ( 569 oui, 0 non et 20 abstentions), tandis que les Ontariens votèrent: 8 pour, 0 contre, 18 abstentions. Une résolution complémentaire portait sur les modalités de la Constituante.

La séance de clôture eut lieu à midi, le dimanche 9 mars 1969. Rosaire Morin fit un premier discours, puis Jacques-Yvan Morin prononça le discours de clôture. Ce dernier parla des travaux des États généraux et de la naissance "d'un nouvel homme». Dans une phrase finale truffée de toutes les ambiguïtés, il terminait: «Debout, donc, Québécois et CanadiensFrançais! Non seulement nous sommes, mais nous

201 «Débats de l'Assemblée nationale sur les projets de résolutions émanant de l'atelier politique», dans Les États généraux. Assises nationales tenues d̀ l'hôtel Reine Élisabeth du 5 au 9 mars 1969, pp. 312-313 (Jacques Vallée), pp. 316-31 7 (Jacques de Courville Nicol), pp. 328-329 (Gérard Lévesque). 
sommes libres, nous sommes responsables de nousmêmes et de nos frères ${ }^{202}$."

\section{BILAN DES ASSISES DE 1969}

Dès le samedi, les journaux firent état de la position des minorités. Car loin de nuancer les «résolutions séparatistes» de 1967, les assises de 1969 les avaient amplifiées. La politique d'abstention aurait eu un double objectif: d'abord protester contre le refus des États généraux de permettre aux minorités de participer aux discussions sur l'avenir constitutionnel des Canadiens-Français, ensuite laisser les Québécois se prononcer seuls sur leur constitution provinciale. C'est ce qu'expliquèrent aux journalistes les deux principaux porte-parole de la délégation franco-ontarienne, l'avocat Rodrigue Landriault et Jacques de Courville Nicol. Selon Landriault:

Le sujet à l'étude était la constitution du Québec, un des territoires du Canada français. Notre délégation n'a pas été appelée à se prononcer sur son avenir constitutionnel, en dépit de nos demandes en ce sens [...] Nous sommes venus ici à titre individuel. Personnellement je reconnais au Québec le droit de s'autodéterminer. Mais il ne peut prendre cette décision au nom du Canada français, qui déborde les frontières du Québec ${ }^{203}$.

L'ultime geste des États généraux, son couronnement en quelque sort, fut de demander la convocation d'une constituante. L'idée avait couru depuis le début des États généraux. Dans la brochure Un peuple

${ }^{202}$ Discours de clôture de Jacques-Yvan Morin, dans Les États généraux. Assises nationales tenues à l'hôtel Reine Élisabeth du 5 au 9 mars 1969, p. 360.

${ }^{203}$ Pour le compte rendu des rencontres et les citations, voir Jules Labelle, «Aux États généraux du Canada français - Politique d'abstention des minorités hors du Québec», dans Le Droit, 10 mars 1969, p. 1 . 
parle, en 1966, il y avait une section (intitulée «... et après?»), où les dirigeants des États généraux s'inquiétaient du «silence du peuple», un silence dont il y avait plusieurs exemples. "La Commission Laurendeau-Dunton en est un exemple [du silence du peuple], de même que la création du Comité de la Constitution par le Parlement du Québec. Pour sa part, le gouvernement actuel du Québec n'a-t-il pas parlé souvent de l'éventuelle convocation d'une Constituante pour le peuple québécois ${ }^{204}$." Ainsi, dès le début, l'idée d'une constituante pour le peuple québécois était explicite. Ce dernier acte des États généraux s'inscrivait dans la parfaite continuité des premiers moments.

Cette constituante mettait le Québec sur le droit chemin de l'indépendance. De la chrysalide des États généraux sortirait le papillon de l'indépendance. C'est une route que les minorités ne pouvaient percevoir autrement que comme une nouvelle preuve de la rupture qui divisait désormais les néonationalistes québécois et les minorités. Dans son éditorial du 10 mars, Marcel Gingras trouvait l'idée d'une constituante dépassée: "La noblesse de l'intention s'impose à l'attention, mais nous nous permettons de douter de la pureté des résultats [...] Nous n'affirmons rien, nous posons tout simplement la question en songeant aux millions de dollars que devront verser les contribuables du Québec pour faire vivre la Constituante pendant 12 mois, sans compter ceux qu'ils verseront, l'heure venue du référendum ${ }^{205}$.»

${ }^{204}$ Un peuple parle [Montréal], États généraux du Canada français, [1966], non paginé [14 pages]. Un exemplaire de cette brochure se trouve au CRCCF, Fonds ACFO, C2/355/3.

${ }^{205}$ Éditorial de Marcel Gingras, "Vers une Constituante?», dans Le Droit, 10 mars 1969, p. 6. 


\section{Gáttan Gervais}

Quelques jours après les assises, l'éditorial du Droit mettait en cause la représentativité des États généraux: «On $y$ attendait 2,400 participants, 1,383 seulement s'y sont présentés, dont 122 de l'extérieur du Québec, - donc, non-séparatistes à priori, - de ces 1,383 participants, moins de 800 se donnaient la peine de voter lorsqu'on le leur demandait ${ }^{206}$." Le journal critiquait aussi leur méthode de travail, avec les "groupes de révision» et les «comités d'amplification"

Lancés en 1966 pour faire «l'unité et la cohésion» de toute la «nation canadienne-française», les États généraux avaient plutôt démontré "que la nation canadienne-française telle qu'on la concevait dans le passé, n'exist[ait] plus», et qu'on se trouvait désormais devant une "nation du Québec" tout à fait distincte des groupes canadiens-français minoritaires des autres provinces, dont d'aucuns affirment qu'ils sont irrécupérables et voués à la disparition dans la majorité anglophone ${ }^{207}$ ».

Le lendemain des assises de 1969, Vincent Prince intitula son éditorial, dans Le Devoir, «Les États généraux ont continué de faire le jeu des souverainistes». Revenant sur la question de la représentativité, Prince écrivait qu'on aurait souhaité que les délégués représentassent une plus grande gamme d'opinions, mais que, en pratique, les États généraux

n'ont intéressé, en très forte partie, que ceux qui ne croient plus au fédéralisme ou à la dimension canadienne. - Ils sont devenus le lieu de ralliement de la minorité qui veut

${ }^{206}$ Editorial de Marcel Gingras, «Propos à bâtons rompus sur les États généraux», dans Le Droit, 12 mars 1969, p. 6.

${ }^{207}$ Jules Labelle, "Aux États généraux du Canada français - Politique d'abstention des minorités hors du Québec", dans Le Droit, 10 mars 1969 , p. 1. 
réaliser l'é[q]uation Etat-Nation. Dans l'ensemble, ils se sont placés derrière les thèses du Parti québécois que dirige M. René Lévesque.

Pour ce parti, cet appui pourrait être fort précieux [...] la bourgeoisie moyenne y était assez largement représentée.

Cette bourgeoisie moyenne peut constituer une très bonne caution pour l'idée d'indépendance [...].

[...] ils auraient pu se transformer en parti politique, mais, en réalité la chose était inutile puisqu'il existait déjà un tel parti convenant à leurs aspirations et que, en ce faisant, ils auraient réduit le prestige qui peut rester attaché à des décisions prises par un groupe censément représentatif de toute la nation canadienne-française ${ }^{208}$.

Prince terminait en disant que la faute n'était pas à ceux qui avaient noyauté les États généraux, mais aux absents.

Plusieurs délégués des minorités accusèrent les États généraux d'avoir pipé les dés. Les allégeances souverainistes des dirigeants (Jacques-Yvan Morin, Rosaire Morin, surtout Michel Pelletier) ont favorisé une évolution vers le séparatisme, au détriment de l'idée de la «nation canadienne-française», comme le montraient déjà leurs déclarations publiques et les documents de base rédigés à l'intention des délégués. Leur dirigisme a assuré le triomphe d'une option politique particulière. En quittant les États généraux, la délégation du Manitoba, par son président Rhéal Teffaine, déclarait: «Nous avions été invités à participer aux assises des États généraux du Canada français, mais nous constatons qu'il s'agit des États généraux du Québec.» La démarche des Êtats généraux fut aussi dénoncée par la délégation de l'Alberta puisqu'on limitait le Canada français «au seul territoire du Québec».

${ }^{208}$ Éditorial de Vincent Prince, "Les états généraux ont continué de faire le jeu des souverainistes», dans Le Devoir, 10 mars 1969, p. 4. 
Les délégations de la Saskatchewan et de la Colombie-Britannique abondèrent dans le même sens.

Le secrétaire général de l'Association de la jeunesse franco-ontarienne, Gérard Lévesque, à la fin des États généraux, demanda que le Québec n'utilisât pas contre sa minorité anglaise des tactiques semblables à celles du Règlement XVII. Il voulait bien laisser aux Québécois le soin de déterminer leur avenir, mais on ne devait plus parler des États généraux du Canada français, mais du Québec, ajoutant qu'il «faudra peut-être tenir pour ces Canadiens français hors-Québec leurs propres États généraux». Lévesque critiqua le projet de faire du français la seule langue officielle au Québec, à l'encontre de la charte des droits adoptée par ces mêmes Québécois. Ce projet d'unilinguisme arrivait d'autant plus mal que les provinces anglaises montraient enfin une ouverture pour faire du français une langue officielle au Canada. Il s'inquiétait du «mur de Berlin» qu'on voulait ériger autour du Québec. Il précisa qu'un Québec fort ne voulait pas nécessairement dire un Québec souverain: «Le Canada français existe d'un océan à l'autre, et son existence passera d'une survivance à un épanouissement dans la mesure où nous aurons un Québec fort dans un Canada uni ${ }^{209}$."

Dans un autre éditorial sur la question des États généraux, le 12 mars 1969, Marcel Gingras s'en prenait à toute la machine des États généraux: «Manifestation séparatiste savamment préparée et préparée de longue main, elle a plus ou moins échoué». Pour commencer, Gingras rendait hommage à l'objectivité de Jacques-Yvan Morin qui, malgré ses convictions

209 "Les francophones des autres provinces ne se sentent plus concernés», dans Le Droit, 10 mars 1969, p. 3. 
personnelles, plaça durant trois ans les États généraux sous le signe de la recherche, du dialogue et de la réflexion. Mais tous les séparatistes ne furent pas «aussi civilisés» que lui. À la fin des assises, le directeur adjoint des États généraux, Michel Pelletier, ancien président de l'Association des étudiants de l'Université de Montréal, déclara que «L'avenir du Québec ne concerne que le Québec, que le peuple du Québec». Cette affirmation était au moins discutable, puisque les Anglo-Québécois, qui sont bien des «Québécois», n'avaient pu participer aux États généraux. Gingras ne blâmait aucunement les séparatistes qui ont participé aux États généraux, mais les fédéralistes absents ${ }^{210}$.

\section{Conclusion}

Que reste-t-il des Etats généraux du Canada français, après trente ans?

Il suffit d'examiner les biographies des principaux acteurs politiques de la période, de lire les ouvrages historiques traitant des années soixante, de dépouiller les bibliographies des périodiques et journaux de l'époque, pour constater le peu de place que les Etats généraux occupèrent, ou occupent aujourd'hui, dans le discours public. En dehors des quelques jours que durèrent les assises de novembre 1966, novembre 1967 et mars 1969, il n'est jamais question des États généraux, sauf dans des journaux nationalistes comme Le Devoir.

L'idéologie du nationalisme canadien-français, basée sur le respect des droits religieux et linguistiques

${ }^{210}$ Éditorial de Marcel Gingras, «Propos a bâtons rompus sur les États généraux», dans Le Droit, 12 mars 1969, p. 6. 
d'un bout à l'autre du pays, a soutenu de nombreux combats scolaires, politiques et sociaux pendant un siècle. Cette politique se trouva à l'origine des luttes durables menées par le nationalisme canadienfrançais pour l'indépendance du Canada (notamment dans ses symboles comme le drapeau, l'hymne), pour la reconnaissance de ses deux "peuples fondateurs» (le Canada français et le Canada anglais), pour le respect du bilinguisme (monnaie bilingue, timbres bilingues, chèques bilingues, affichage), pour une participation canadienne-française plus équitable à la fonction publique fédérale. Dans ces courants de revendications s'élaborèrent, depuis Mercier au siècle dernier, mais surtout depuis Duplessis, des revendications autonomistes en faveur des provinces. L'État français que Groulx et d'autres ont réclamé depuis les années 1920 était un État provincial, mais, de plus en plus, l'idée d'un État souverain remplaçait celle de «l'autonomie provinciale».

À l'origine de la mésentente entre les Québécois et les minorités, il y a l'opposition de deux visions du monde. L'ancienne, à laquelle se rattachaient les Franco-Ontariens, souscrivait aux vieux idéaux du Canada français et résistait devant la nouvelle, tournée vers l'érection d'un État québécois absolu et maître de toutes les sphères d'activité.

Attachés à leur longue expérience canadiennefrançaise, les groupes minoritaires comme l'Ontario français tenaient pour une évidence que les États généraux intéressaient la "nation canadiennefrançaise». Aux Franco-Ontariens, les documents et la correspondance parlaient sans cesse d'unité, de Canada français, de démocratie, des intérêts supé- 
rieurs de la collectivité, de la recherche des «dénominateurs communs». Les Franco-Ontariens eurent done le sentiment d'avoir été trompés quand ils apprirent que l'unité était celle du Québec, que la démocratie passait par l'unanimité du vote québécois, que les "dénominateurs communs" ne s'appliquaient qu'au Québec. Pour les Franco-Ontariens qui participèrent, aucun de ces mots (unité, nation, démocratie, intérêts supérieurs) ne semblait correspondre à ce qu'eux entendaient par ces termes.

Un groupe social définit son identité d'abord par son discours, puis par les représentations qu'il a de lui-même. Au temps du Canada français, un discours cohérent, basé sur le nationalisme catholique, et des représentations claires, identifiaient les Canadiens-Français. Les États généraux ont permis de montrer que, dans la mouvance nationaliste, un "discours» et des "représentations» strictement québécoises définissaient désormais leur identité. En fait, depuis trente ans, nous assistons à des discours et à des représentations différentes, de part et d'autre de la frontière québécoise. Ainsi, il existe désormais un discours québécois sur les minorités (avec sa nouvelle théologie qui oppose "l'homme canadienfrançais», ancien, et l'homme nouveau, «l'homo quebecensis»). D'autre part, il s'élabore aussi un discours des minorités sur le Québec. Leur existence étant menacée, certains Franco-Ontariens, encore aujourd'hui, cherchent des amarres en port sûr, allant jusqu'à reprendre à leur compte le discours québécois sur l'Ontario français.

L'Ontario français a été bien représenté en 1966 et en 1967, grâce à l'encadrement de l'ACFÉO. Mais cette association subissait elle aussi d'importantes 
transformations à la même époque, elle suivait des dossiers encore plus importants, notamment la création des écoles secondaires françaises. En 1968, avant de finir par demander à l'ACFÉO d'organiser de nouveau la délégation ontarienne, les dirigeants des États généraux avaient mis en cause la représentativité de la délégation ontarienne. Les votes à $98 \%$ dans la délégation québécoise ne laissent pas penser que cette délégation-là était plus représentative que la délégation ontarienne.

Aux États généraux, on tenta de museler les minorités, on les empêcha de se prononcer sur les dossiers constitutionnels, on leur attribua une place de second rang, on les traita avec condescendance et paternalisme. Alors que les minorités prétendaient prendre place à la grande table, on leur assigna d'étroits strapontins le long des murs. Ainsi, leur dignité commandait aux minorités de se retirer. C'est la décision que l'ACFÉO finit par adopter après deux années d'hésitations. Car les minorités françaises finirent par reconnaître que leur rôle de figurant servait de caution morale à des machinations politiques orientées vers la séparation du Québec.

La décision de l'ACFÉO ne provoqua pas la rupture entre les néonationalistes et les minorités. De même, les États généraux n'ont ni causé ni précipité la fin du Canada français, ils en apportèrent seulement une preuve éloquente.

* L'auteur remercie ses collègues de la Société Charlevoix, et aussi André Girouard, participant aux États généraux de 1967. Leurs commentaires ont permis d'améliorer le texte initial. L'auteur veut aussi remercier les archivistes du CRCCF, notamment madame Bernadette Legault-Routhier, qui ont grandement facilité le dépouillement des archives de l'ACFO. 